\title{
Measuring behavioral disruption in children who have been in motor vehicle accidents
}

Kimberly Mullen James
West Virginia University

Follow this and additional works at: https://researchrepository.wvu.edu/etd

\section{Recommended Citation}

James, Kimberly Mullen, "Measuring behavioral disruption in children who have been in motor vehicle accidents" (1999). Graduate Theses, Dissertations, and Problem Reports. 1046.

https://researchrepository.wvu.edu/etd/1046

This Dissertation is protected by copyright and/or related rights. It has been brought to you by the The Research Repository @ WVU with permission from the rights-holder(s). You are free to use this Dissertation in any way that is permitted by the copyright and related rights legislation that applies to your use. For other uses you must obtain permission from the rights-holder(s) directly, unless additional rights are indicated by a Creative Commons license in the record and/ or on the work itself. This Dissertation has been accepted for inclusion in WVU Graduate Theses, Dissertations, and Problem Reports collection by an authorized administrator of The Research Repository @ WVU.

For more information, please contact researchrepository@mail.wvu.edu. 
Measuring Behavioral Disruption in Children Who Have Been in Motor Vehicle Accidents

Kimberly Mullen James, M.A.

Dissertation Submitted to the Eberly College of Arts and Sciences

at West Virginia University

in partial fulfillment of the requirements for the degree of

Doctor of Philosophy

in

Psychology

\author{
Joseph R. Scotti, Ph.D., Chair \\ Jody Kashden, Ph.D. \\ Kevin T. Larkin, Ph.D. \\ Daniel W. McNeil, Ph.D \\ JoNell Strough, Ph.D.
}

\title{
Morgantown, West Virginia
}

1999

Keywords: Clinical Stroop, Motor Vehicle Accidents, Trauma, Children Copyright 1999 Kimberly Mullen James 
Measuring Behavioral Disruption in Children Who Have Been in Motor Vehicle Accidents Kimberly Mullen James

\begin{abstract}
This study examined the overt behavioral response of children following recent exposure to a motor vehicle accident (MVA). Forty-five children completed a clinical Stroop task. Children were divided, based on prior psychometric assessment, into three groups: (a) survivors of a recent MVA, and experiencing behavioral distress; (b) survivors of a recent MVA, and not experiencing behavioral distress; and (c) those who have not experienced an MVA. Differential color-naming and error response to four types of Stroop stimuli was assessed: (a) MVA-related words, (b) school-stress related words, (c) neutral household words, and (d) colored Xs. Analysis of participant characteristics indicated no significant differences between the groups on child variables such as gender, race, reading level, grade in school, or age; or parent variables such as education, employment or marital status. Additionally, there were no differences between the two MVA groups in parent report of the severity of the MVA. Results revealed that the distressed MVA survivors exhibited longer color-naming times for MVA-related words, compared to comparison word and participant groups. However, this Stroop Effect was only obtained for the children reading at or above a fourth-grade level. Children reading below the fourth-grade level took longer to color-name than high readers, irrespective of word type and participant group. Additionally, there appeared to be a fatigue effect for all participants, evidenced by an overall increase in color-naming time over trials. The Stroop effect was only apparent after fatigue was statistically controlled. No differences were obtained in the number of errors across word types and participant groups. Finally, psychometric data were not correlated with Stroop performance on the
\end{abstract}


MVA-related words. These results suggest that the clinical Stroop color-naming (but not error) task may identify distressed MVA survivors who are reading at or above the fourth grade reading level. For children reading below the fourth-grade level the reading response may be challenging enough to block the Stroop effect. The lack of correlation between verbal report of distress and color-naming performance on the MVA-words also signifies the importance of direct assessment approaches such as the clinical Stroop task to the assessment of post-accident distress. 


\section{Acknowledegments}

I would like to express my appreciation to the members of my dissertation committee, Drs. Jody Kashden, Kevin T. Larkin, Daniel W. McNeil, Joseph R. Scotti, and JoNell Strough, who each gave valuable time, assistance, and support during the planning and execution of this study. I am especially indebted to my advisor and committee chair, Dr. Joseph R. Scotti, who inspired my interest in trauma and objective assessment methods, and who has been a true mentor for all areas of my academic and professional development. Special thanks also go to Dr. Kevin T. Larkin, who made available his psychophysiology laboratory and equipment for conducting the study, and to Dr. Daniel W. McNeil, who generously provided the Stroop program utilized in the study. Recognitions would not be complete without offering my gratitude to my husband John V. James, Jr. for his enduring love and support during the implementation of this project and for his guidance in statistical matters. Finally, I would like to thank my parents, Constance and John Mullen, who, from the beginning, encouraged me to pursue my highest goals.

Funding for this research was provided in part from a grant to Joseph R. Scotti, Ph.D., Prinicipal Investigator, from the National Institutes of Health (NIH)/National Institute of Mental Health (NIMH), Grant \# 1-RO3-MH55533-01, which is gratefully acknowledged. The views expressed here do not necessarily represent those of NIH or NIMH. 
Table of Contents

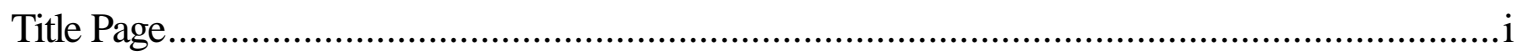

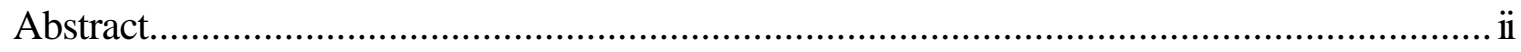

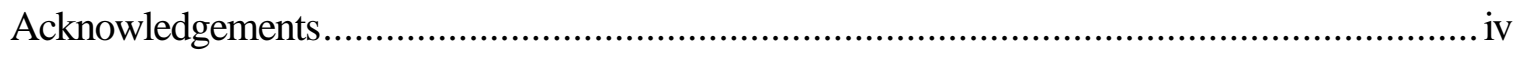

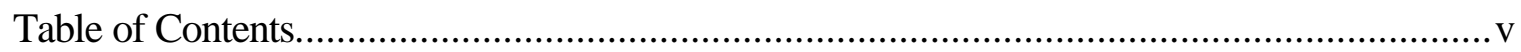





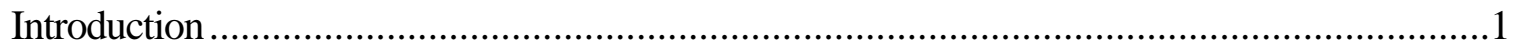

Child Post-Trauma Behavioral Pathology .............................................................

Post-Traumatic Stress Disorder........................................................... 2

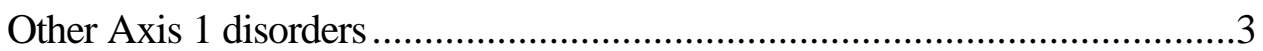

Definition of Traumatic Accident .....................................................................4

Overview of Research on Behavioral Responses to MVAs .....................................5

Adult MVA studies .............................................................................

Child MVA studies ....................................................................... 7

Examining the Overt Responses to Stimuli that Symbolize or

Resemble Traumatic MVAs ............................................................

The Stroop Task as a Paradigm for Measuring Overt Behavior .............................. 9

The Stroop color-word task .......................................................... 11

The clinical Stroop task ............................................................. 12

A Demonstration of Overt Behavioral Disruption1 ............................................2 
Selective Attention to Threat Cues........................................................................... 13

The Stroop Task with Trauma Survivors ............................................................. 16

The Clinical Stroop Task and Children................................................................19

Limitation of an Information Processing Interpretation........................................21

Stimulus Equivalence Relations .....................................................................22

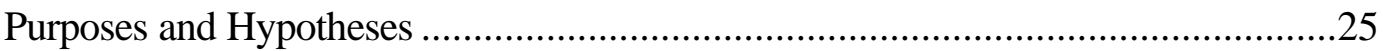

Extension of empirical research to child survivors of MVAs........................25

Developmental considerations...............................................................26

Examination of differential Stroop performance .........................................27

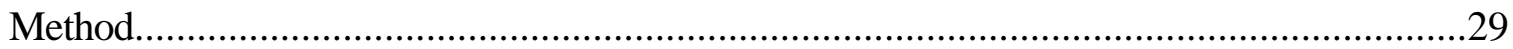



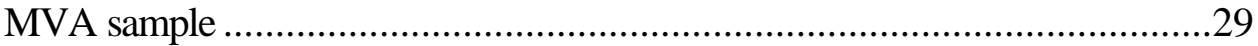

Comparison (Non-MVA) sample ............................................................29

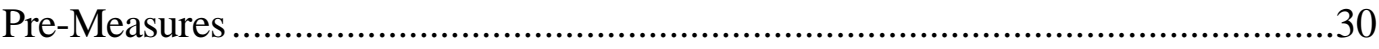

Demographics questionnaire .......................................................... 30

Accident Characteristics Identification Scale-Child and Parent Version...........31

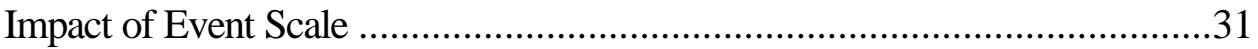

Child Behavior Checklist ........................................................................32

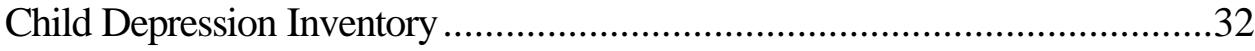

Children's Manifest Anxiety Scale-Revised ..............................................32

Anxiety Disorders Interview Schedule for Children and Parents....................33 
Clinical Stroop Task Measures

Wechsler Individual Achievement Test-Reading Subtest

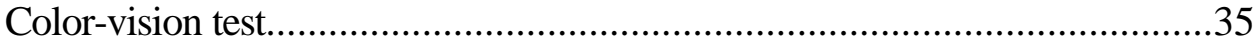

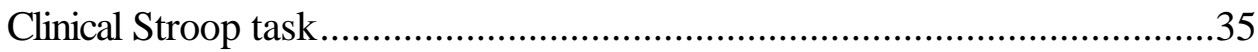

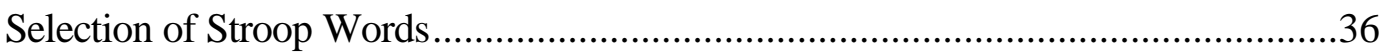

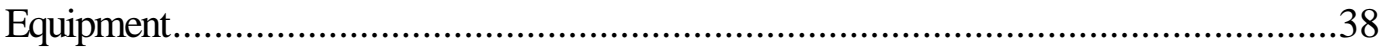



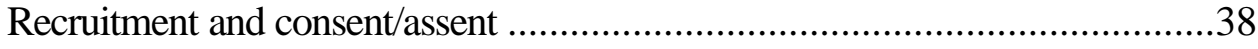



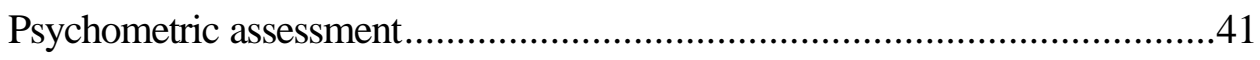





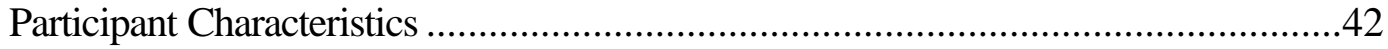

General demographic variables ......................................................42

Psychometric scales ...................................................................42

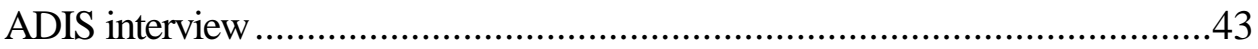

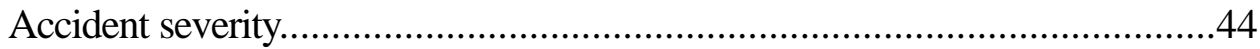

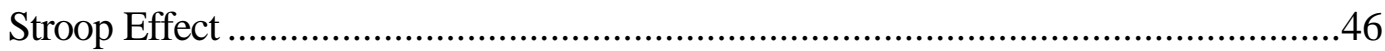

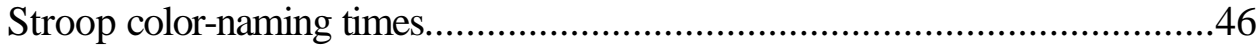

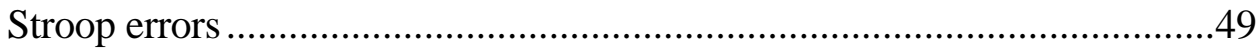

Association Between Stroop Effect and Psychometrics .......................................51 
Correlation Among Psychometric Measures.......................................................51

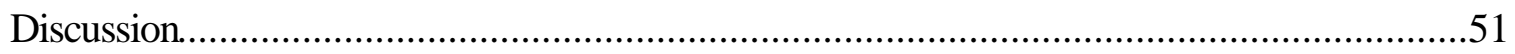

Summary of Major Hypotheses and Results...................................................51

The Stroop effect hypotheses .........................................................51

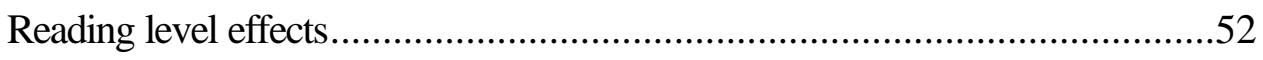

Results of primary analyses...........................................................

Conditioned Emotional Response Paradigm ......................................................53

The Absence of Clinical Stroop Effect for low Readers ........................................55

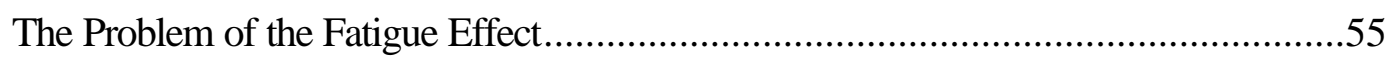

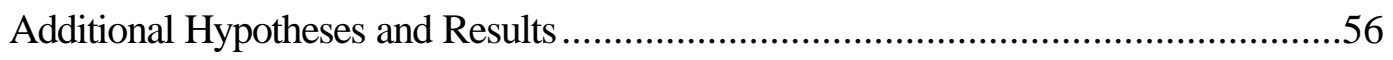

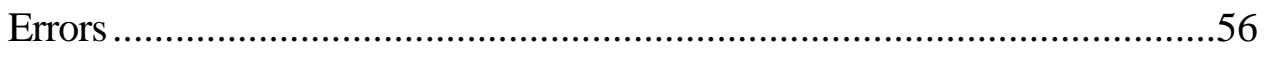

MVA-word color-naming times and psychometrics................................57

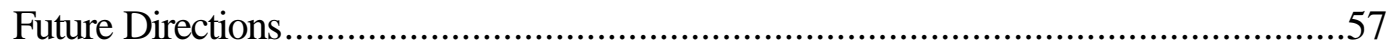

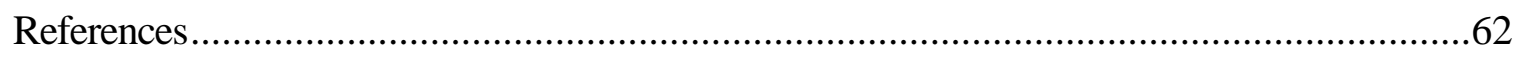

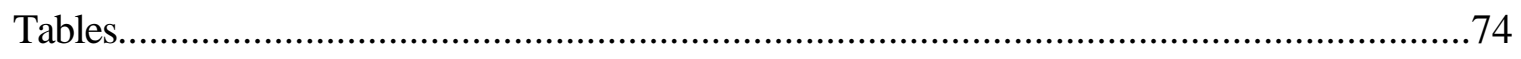

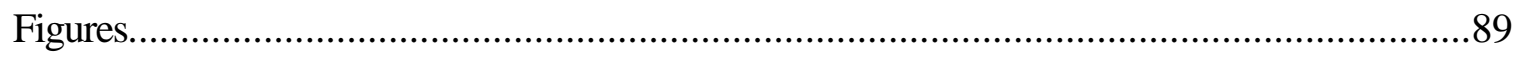

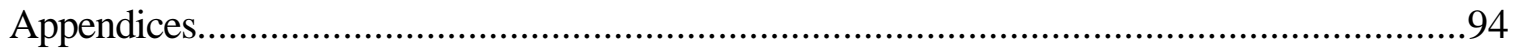




List of Tables

Table 1. DSM-IV Diagnostic Criteria for Post-traumatic Stress Disorder ...........................74





Table 4. Mean Scores on Psychometric Measures by Group.............................................79

Table 5. Percentage of Children Exceeding Clinical Cut-off (T-score $\geq 60)$.........................80

Table 6. ADIS Diagnoses and Number of Cases by Group ............................................ 81

Table 7. Mean Scores on ACCIDENTS and Accident Demographic

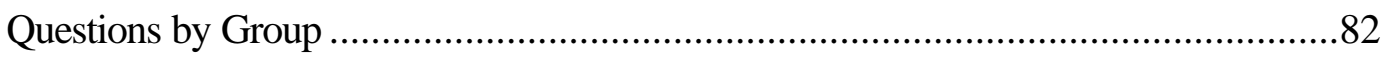

Table 8. Mean Raw Color-Naming Times in Seconds by Group and Word Type..................83

Table 9. Mean Color-Naming Times in Seconds Corrected for Individual Speed



Table 10. Mean Corrected Color-Naming Times in Seconds Adjusted for

Covariates by Group, Word Type and Reading Level.......................................85

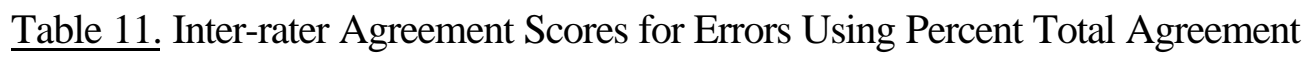

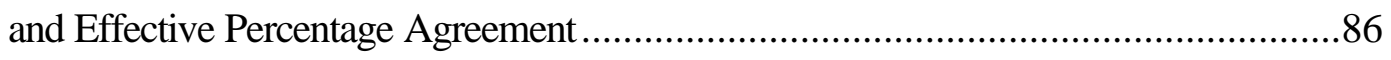

Table 12. Mean Number of Errors by Group and Word Type.........................................87

Table 13. Correlations Among Psychometric Measures.....................................................8 


\section{List of Figures}



Figure 2. Mean color-naming times by Group and Word Type for high readers.....................90

Figure 3. Mean color-naming times (adjusted for covariates) by Group



Figure 4. Mean color-naming times (adjusted for covariates) by Group and



Figure 5. Mean number of errors by Reading Level and Word Type.................................93 


\section{Measuring Behavioral Disruption in Children Who Have Been in Motor Vehicle Accidents}

Within the past decade, the psychological literature has reflected a growing interest by researchers in the responses of children to traumatic experiences, such as physical or sexual abuse, natural disasters, crime, and war. Prior to this decade, studies of children reactions to such events were either limited to case-reports, or overlooked completely. However, the psychological and psychiatric literatures have begun to empirically document that the distress experienced by children following exposure to traumatic events is similar to that of adults (Hopkins \& King, 1994; Vogel \& Vernberg, 1993). It is now generally accepted that adults and children exposed to traumatic events are likely to experience a wide range of clinical and subclinical behavioral problems (Vogel \& Vernberg, 1993).

One class of childhood traumatic experiences that remains relatively unexplored is events of human error, or accidents. Rice et al. (1989, as cited in Scotti, Beach, Northrup, Rode, \& Forsyth, 1995) note that within the general population, the yearly incidence of accidental injury exceeds the figure of 50 million persons per year, with motor vehicle accidents (MVAs) comprising the largest portion of those injuries. Thus, the likelihood of child exposure to traumatic accidents is high. Pediatric data indicate that accidental injury poses Ahe most serious threat@o the physical health of children with respect to frequency of occurrence (Methany, 1988, p. 108); however, the behavioral ramifications of child involvement in traumatic accidents remain poorly understood.

\section{Child Post-Trauma Behavioral Pathology}

A range of clinical and subclinical behavioral excesses and deficits have been documented in 
children who have experienced traumatic events. Vogel and Vernberg (1993), in a review of the documented behaviors exhibited by children who have experienced trauma, report that trauma-related responses include: behavioral regression (e.g., enuretic behavior in children previously toilet-trained), sleep disturbances, specific trauma-related phobias, separation difficulties, re-enactment of the traumatic event during play, social withdrawal, depressed affect, and other behaviors associated with stress response syndromes (e.g., intrusions of memories related to the event, hypervigilant detecting behavior). Clusters of symptoms meeting criteria for post-traumatic stress disorder and other Axis I disorders, as specified by the Diagnostic and Statistical Manual (DSM), Third Edition, Revised (DSM-III-R; American Psychiatric Association [APA], 1987), have also been observed, but with less frequency than the occurrence of isolated symptoms or subclinical levels of Axis I disorders (Vogel \& Vernberg, 1993).

$\underline{\text { Post-Traumatic Stress Disorder. Although it has long been acknowledged that individuals may }}$ experience a particular constellation of behaviors following a traumatic event (e.g., Glass, 1954), it was not until 1980, in the third edition of the DSM (APA, 1980), that a frequently observed cluster of behaviors was codified as post-traumatic stress disorder (PTSD). This development stemmed largely from the exposure of clinicians to the behavioral excesses and deficits being reported by Vietnam War veterans and adult victims of violent crime (Vogel \& Vernberg, 1993). The behaviors associated with the diagnosis of PTSD were also being noted by clinicians working with children (e.g., Eth \& Pynoos, 1985). Thus, in 1987, the DSM-III-R included some PTSD behaviors that were specific to children, and it was officially recognized that children may indeed exhibit the behaviors that have comprised this disorder. For example, the fourth edition of the DSM (APA, 1994) notes that re-experiencing the 
event, one of the hallmark symptoms of PTSD, may, for children, take the form of repetitive play in which aspects of the trauma are expressed, or nightmares with a general threat content unrelated to the traumatic event (e.g., monsters). For a complete list of the current DSM-IV criteria for a diagnosis of PTSD, refer to Table 1.

Other Axis I disorders. As noted above, children exposed to traumatic events may subsequently exhibit general stress-related behaviors (e.g., behavioral regression, tearfulness, re-enactment of the event in play), behaviors consistent with a diagnosis of PTSD (e.g., Schwarz \& Kowalski, 1991; Terr, 1983), or a subset of the behaviors required for a diagnosis of PTSD (e.g., Taylor \& Koch, 1995). Additionally, other DSM-III-R and DSM-IV Axis I disorders have been diagnosed in children who have experienced trauma, including: specific phobia (e.g., Himle, Crystal, Curtis, \& Fluent, 1991; Taylor \& Koch, 1995), generalized anxiety disorder (Hubbard, Realmuto, Northwood, \& Masten, 1995), and depressive disorder (e.g., Kinzie, Sack, Angell, Manson, \& Rath, 1986; Mghir, Freed, Raskin, \& Katon, 1995). Further, studies of comorbidity of psychiatric diagnoses in children who have experienced trauma have suggested that depression (Goenjian, Pynoos, Steinberg, \& Najarian, 1995; Mghir et al., 1995) and generalized anxiety disorder (Hubbard et al., 1995) may co-occur with PTSD. Thus, it is evident that a wide range of pathological behaviors--from mild or moderate levels of subclinical fear, anxiety, and behavioral regression, to diagnosable clinical disorders--may be observed in children who have been exposed to traumatic events. However, as noted earlier, a review of the literature demonstrates that the bulk of the research examining the behavioral responses to trauma in children has focused on events such as natural disaster, abuse, and criminal victimization. Very little research has investigated whether similar behaviors may be observed following a distinct class of 
traumatic event, the occurrence of a traumatic accident, in particular, MVAs.

\section{$\underline{\text { Definition of Traumatic Accident }}$}

Scotti et al. (1995) have defined traumatic accidents as Anintentional harm incurred to self, others, or property due to unforeseen human error or technological failure." This definition implies several distinctions between traumatic accidents and other classes of trauma. First, an accident is the result of human error, either by act of omission or commission. This is contrasted with such events as earthquakes, floods, or tornadoes, that result from natural forces that cannot be attributed to or prevented by human behavior. Relatedly, because accidents are characterized by error, there is a lack of intent to harm. Thus, crime, abuse, terrorism, and warfare cannot be considered accidents. Third, accidents are distinct from many other types of trauma in that they are singular events, with a fairly distinct onset and termination. Finally, depending on the number of victims, an accident may or may not also be considered a disaster--a discrete, public event that is the result of human error, cruelty, or natural forces, and involving individuals from more than one family (Scotti et al., 1995).

The above definition of accidents includes such traumatic events as structural collapses (e.g., the collapse of a parking garage), transportation accidents (e.g., MVAs, train or plane crashes), environmental toxin release (e.g., chemical spills or explosions), fire (e.g., wildfires inadvertently started by humans) and mechanical malfunction (e.g., injury resulting from human supervised equipment malfunction). Of these, MVAs may be the most frequently experienced type of traumatic accidental event (e.g., Helzer, Robins, \& McEvoy, 1987; Norris, 1992). In her epidemiological study, Norris (1992) noted that including all types of trauma, MVAs represent the "single most significant event" (p. 416), with respect to frequency and severity. 
Despite the substantial potential for experiencing a traumatic MVA, research investigating the behavioral sequelae is lacking. Further, as will become evident in the next section, of the research investigating traumatic accidents, nearly all has studied an adult population, with empirical study of the responses of children to MVAs remaining strikingly absent.

An Overview of the Research on Behavioral Responses to Motor Vehicle Accidents

Adult MVA studies. Researchers have begun to demonstrate that significant levels of behavioral distress may be found in adult victims of MVAs (e.g., Blanchard, Hickling, Taylor, Loos, \& Gerardi, 1994a; Blanchard et al., 1995; Bryant \& Harvey, 1995, 1996; Mayou, Bryant, \& Duthie, 1993; Taylor \& Koch, 1995). In a study investigating the acute reactions to MVAs, Bryant and Harvey (1996) assessed the incidence of initial post-traumatic responses following an MVA in 114 persons hospitalized for their injuries. Participants were assessed for post-traumatic symptoms (e.g., intrusions, avoidance, and anxiety) with the Impact of Event Scale (IES; Horowitz, Wilner, \& Alvarez, 1979) and the StateTrait Anxiety Inventory (STAI; Spielberger, Gorsuch, \& Lushene, 1970) within two weeks of their motor vehicle accident. Results indicated that one-third of the participants reported extreme IES scores that were comparable to those reported by survivors of other well-studied traumatic events (e.g., Australian bushfires, shootings). Additionally, one third of the participants reported clinical levels of state anxiety. These results indicate that persons may experience major symptoms of distress within the two weeks following an MVA.

Other research has suggested that such PTSD-related behaviors may continue past the acute phase (up to one month after the traumatic event, as specified by DSM-IV). Blanchard et al. (1994a) investigated psychological morbidity following MVAs. These authors assessed 50 MVA victims, and 40 
age and gender matched, non-MVA controls for psychological morbidity within one to four months of their accidents. Results indicated that $46 \%$ of the MVA group met DSM-III-R criteria for PTSD, $20 \%$ demonstrated "sub-syndromal" PTSD (some, but not all of the criteria met), and 2\% met criteria for driving-related specific phobia. Additionally, 48\% of the MVA-PTSD group also met criteria for major depression. The authors note that their sample may reflect a referral bias, as many participants were referred from health professionals following a request for medical attention related to the accident (referral sources were asked to refer all people who had recently experienced an MVA, not just those with psychological distress; however, whether this occurred can not be confirmed). Thus, overestimation of the rate of psychological morbidity following an MVA for the general population may have occurred.

Mayou et al. (1993) investigated 188 MVA survivors requiring hospitalization or with whiplash injuries. Forty-one percent reported anxiety or depression, $18 \%$ described symptoms consistent with sub-clinical PTSD, 13\% reported specific travel phobia consistent with DSMIII-R criteria, and $11 \%$ met DSM-III-R criteria for PTSD.

In a study designed to assess the duration of PTSD symptoms, Blanchard et al. (1995) performed a follow-up of 98 survivors of recent motor vehicle accidents who had sought medical attention. Participants were assessed every month for six months after their MVA. Month-by-month changes in PTSD symptoms were determined. Results indicated that MVA-related PTSD declined from $41 \%$ to $21 \%$ over the six-month assessment period. Incidence of sub-clinical PTSD declined from $26 \%$ to $22 \%$. Further, symptoms of avoidance and numbing declined significantly more than hyperarousal symptoms. 
Bryant and Harvey (1995) assessed for PTSD symptomology in 56 MVA victims, 12 months post-accident, using the IES. Results indicated that significant levels of intrusive and avoidant symptomology were reported by $20 \%$ of the sample, indicating that PTSD behaviors may become chronic in duration.

To summarize, investigations of the behavioral responses of adults following a traumatic MVA suggest that persons may exhibit PTSD, subclinical PTSD, or depression-related behaviors. Symptoms of behavioral distress may become apparent within two weeks of the trauma (Bryant \& Harvey, 1996), and may maintain at 6 (Blanchard et al., 1995) and 12 (Bryant \& Harvey, 1995) months.

Child MVA studies. To date, no large-scale, empirical studies of the behavioral consequences for children exposed to traumatic motor vehicle accidents have been published. However, two descriptive accounts (Milgram, Toubuana, Klingman, Raviv, \& Goldstein, 1988; Tuckman, 1973) of the acute and chronic stress reactions of children involved in bus-train collisions are available. In general, these papers suggested that the reactions of the children included difficulty concentrating, traumaspecific fear, increased frequency of crying, depressed behavior, irritability, regressive behavior, reexperiencing the trauma, somatic complaints, and sleep disturbance (e.g., insomnia, nightmares). These behaviors are consistent with behaviors noted in children who have experienced other types of traumatic accidents (e.g., the sinking of a ferry with child passengers; Yule \& Williams, 1990).

Additionally, a case report of PTSD in a three-year-old female, following an MVA, has been provided by Jones and Peterson (1993). These authors describe a behavioral presentation of nightmares, aggression, and trauma-specific fears one month after an MVA. There were no physical injuries to the child, and her father (the driver) received only minimal injury; however, their automobile 
was destroyed by impact with a truck. Home-based treatment, using age-appropriate exposure via play-therapy, and distraction techniques reportedly remediated all symptoms within three weeks.

These three descriptive accounts illustrate a serious deficit in empirical attempts to understand the behavioral ramifications of the exposure of children to MVAs. Clearly, there exists a great need for the systematic study, using a large sample of participants, of the types of behaviors that children may exhibit following exposure to this relatively frequent type of accident.

Examining the Overt Responses to Stimuli that Symbolize or Resemble Traumatic MVAs

Many clinicians and researchers have adopted the "triple response system" as an organizational guide for clinical and experimental pursuits (e.g., Cone, 1978; Evans, 1986; Lang, 1968). According to this view, three response systems must be examined during behavioral assessment: (a) the subjective, verbal report of either private or potentially observable behavior (e.g., a client's report of the amount of cognitive distress experienced in a particular environment); (b) overt, observable behavior (e.g., the extent to which an object or situation is motorically avoided or confronted); and (c) physiological behavior (e.g., change in heart-rate, skin conductance, or blood-pressure).

A body of research (e.g., Bernstein, 1973; Hodgson \& Rachman, 1974) has demonstrated that the three behavioral systems may be poorly correlated with each other. For example, Bernstein (1973) demonstrated that participants in a direct avoidance test could be persuaded through social pressure to physically approach a feared object, while reporting experiencing intense anxiety. Although such dysynchrony has been proposed to result from the confounding of response content with assessment method (Cone, 1979), the utility of a comprehensive system of assessment that targets multiple responses is still acknowledged (Cone, 1979). Additionally, the tripartite approach to behavioral 
assessment allows the clinician to tailor interventions to the individual response patterns of their clients (Drobes \& Lang, 1995).

Thus, in studying the effects of a traumatic MVA, one can conceptualize three response systems that may be assessed: verbal report, observable overt behavior, and physiological behavior. By far, the majority of previous research, of all types of trauma, has relied on the use of behavioral self-report for data (Baum, Solomon, \& Ursano, 1993). However, some investigation of the physiological response to trauma has been made (e.g., Blanchard, Kolb, Gerardi, Ryan, \& Pallmeyer, 1986; Malloy, Fairbank, \& Keane, 1983), with these studies generally indicating that exposure to cues reminiscent of the traumatic event is associated with elevated heart-rate, blood pressure, and/or skin conductance.

Extending this paradigm to victims of automobile accidents, Blanchard and his colleagues (1994b; see also Blanchard, Steffek, Jaccard, \& Nicholson, 1991) have applied psycho-physiological assessment to adult victims of recent MVAs. Heart-rate, systolic and diastolic blood-pressure, forehead EMG, and electrodermal activity were measured during three conditions: a mental arithmetic stressor, exposure to stimuli reminiscent of the participant own MVA, and a standard videotape of an MVA. Participants were previously subdivided into full-PTSD, subclinical-PTSD, and no-PTSD groups. Results indicated that for this particular sample, the heart rate response to the idiosyncratic videotape reliably discriminated the full PTSD participants from the other two groups.

The Stroop Task as a Paradigm for Measuring Overt Behavior

A body of research has also investigated the third response system--overt behavior--with respect to trauma. A frequently utilized method of studying this system in persons with full or subsyndromal PTSD (as well as with other anxiety disorders) has been to examine differential response 
or response times to a task, when stimuli related to the individualf source of fear are presented concurrent with or as part of the task. For example, one type of dichotic listening task (Treisman \& Geffen, 1967) requires that a participant verbally repeat aloud (shadow) information that is being presented in a designated ear, via earphones, while not responding to alternate information concurrently being presented in the other, Annattended, @ar. Target stimuli (i.e., words related to the individualf source of fear) are superimposed on the task, usually presented in the unattended ear. For example, in one study with combat veterans exhibiting PTSD (Scotti, 1992), target words included (a) combatrelated threat words, (b) positive words, (c) negative/noncombat-related words, (d) neutral words, (e) ambiguous words, and (f) rape-related words, all presented in the unattended ear. Differential shadowing errors and physiological response during the presentation of the target words to the unattended ear were measured. The results generally supported previous research that has used this type of task with a clinical population. Specifically, the combat veterans diagnosed with PTSD evidenced differential responding to combat words (increased shadowing errors and physiological response), as compared to the control words. Further, for the combat veterans diagnosed with PTSD, differential responding to the PTSD words was significantly greater than for the two non-PTSD control groups.

The dichotic listening task is one that measures overt behavior. That is, error during shadowing--a common outcome of the clinical application of this task--may be considered an overt behavioral response that occurs in the presence of threatening stimuli. Another commonly used task that measures differential overt behavioral response to stimuli is the clinical Stroop task. 
The Stroop color-word task. The clinical Stroop task has been adapted from the Stroop ColorWord Task, created by J. Ridley Stroop (1935). The Stroop task was originally designed to assess the effect on color-naming behavior of simultaneously presented, conflicting types of word stimuli. Specifically, participants were asked to name, as quickly and accurately as possible, the printed color of 100 presentations of five written color names on a card, where the color of the print and word were different. This performance was compared with the speed of naming the printed color of 100 presentations of the same five colors from a card of colored-squares.

Results indicated that it took an average of 47 seconds longer to color-name when the printed colors were different from the written color words, than to name the colored squares. Stroop (1935) and later researchers (e.g., Fraisse, 1969; Posner, 1978) have suggested that these results indicate that the associations formed between the word stimuli and a reading response are more robust than the those formed between the color stimuli and a naming response. That is, people have greater learning histories for reading words than naming colors. Thus, the word stimulus was hypothesized to Anterfere@ with the naming of the color stimulus.

Since its inception, the Stroop task has been used to investigate several proposed cognitive processes. For example, in addition to theories of attention, the paradigm has been used to examine theories of semantic memory, bilingual memory organization, reading, processing speed, and automaticity (Dunbar \& MacLeod, 1984). Additionally, researchers within clinical psychology have begun to utilize a modified version of the task to assess differential color-naming rates when stimuli include words that are specific to participants $=$ linical concerns. 
The clinical Stroop task. In the clinical Stroop task paradigm (e.g., Mathews \& MacLeod, 1985), participants are presented with groups of neutral and personally relevant fear words and are asked to name aloud the color of each word as quickly as possible, while making no response with respect to semantic content. Response latencies for the different word groups are then compared. Some studies have included general threat words (e.g., Foa, Feske, Murdock, Kozak, \& McCarthy, 1991) or positive words (e.g., McNally, Kaspi, Riemann, \& Zeitlin, 1990) as additional controls. The results of studies using the Stroop task have generally found significantly longer response latencies for words that are related to individual sources of clinical concern (e.g., combat-related words for the veteran; contamination-related words for the participants with obsessive compulsive disorder) than for control words.

\section{$\underline{\text { A Demonstration of Overt Behavioral Disruption }}$}

This "Stroop effect," the finding that varying response latencies exist across different types of stimuli, in the clinical literature, is relevant to the earlier discussion of the need for multi-modal assessment. Responding on the clinical Stroop task may be considered a sample of overt behavior in the presence of varying stimuli. That is, variations in Stroop response times, across groups of stimuli can provide the clinician or researcher with observable instances of differential overt responses to those stimuli.

When performance on the Stroop task is significantly impaired during the presentation of words that are congruent with the psychopathology under examination (i.e., the participant exhibits significantly longer response time, compared to during the presentation of other types of words) it may be said that behavioral disruption of the task behavior has occurred. This type of disruption is frequently thought to 
be the result of competing detecting behavior for stimuli related to the individuals source of fear, a behavior often referred to as "hypervigilance," and a common diagnostic feature of anxiety disorders, particularly PTSD. Generally, cognitive processes and structures have been evoked to explain the development of hypervigilant detecting behavior.

\section{Selective Attention to Threat Cues}

Many of the clinical anxiety researchers employing the Stroop paradigm have adopted some variant of the selective attention theories to account for the clinical Stroop effect (e.g., Cassiday, McNally, \& Zeitlin,1992; Foa et al., 1991; Foa, Ilai, McCarthy, Shoyer, \& Murdock, 1993; Kaspi, McNally, \& Amir,1995; Mathews \& MacLeod, 1985; McNally et al., 1987). Generally, it is hypothesized that delays in color-naming--referred to as Stroop interferenceBoccur when the semantic meaning of a word automatically (and involuntarily) Attracts@he participant a attention despite effort to attend to the word's color. Thus, it is suggested that persons with anxiety disorders have an involuntary attentional bias for attending to threat-related stimuli (Anypervigilant behavior, @as defined by DSM-IV, might be another name for Attentional bias@hat does not require the use of the construct Attention@ Stroop interference (i.e., the overt, behavioral response to threatening stimuli) is thought to result from failure to attend to the task at hand (color-naming) due to selective attention and processing of the meanings of the words.

Foa and colleagues (e.g., Foa \& Kozak, 1986; Kozak, Foa, \& Steketee, 1988) have attempted to explain selective attention in terms of a semantic Afear-network@mechanism, adapted from Lang (1979) bioinformational conceptualization of fear. According to this theory, fear is represented in memory as a propositional network containing information about: (a) the features of feared stimuli 
(responsible for cuing the rest of the network); (b) the repertoire of verbal, physiological, and overt behavioral responses; and (c) interpretive information about the meaning of the stimulus and response components of the network (Foa \& Kozak, 1986). Such a network is thought to facilitate cognitive, motor, and psychophysiological responding in the presence of threatening stimuli. Thus, Foa and Kozak (1986) suggest that this information structure may be thought of as a Aprogram@or escape or avoidance behavior. When stimuli in the environment match information contained within the fear network, the network is activated (Foa \& Kozak, 1986). Activation, in turn, results in some type of escape or avoidance response.

According to this model, all humans have fear networks represented in memory. However, persons with and without anxiety disorders are hypothesized to vary in terms of the dimensions and workings of their networks. Specifically, persons with anxiety disorders, relative to those without, have networks that contain excessive response elements. That is, information to the effect of "my anxiety will persist unless escape or avoidance occurs." Second, in persons with anxiety disorders, fear stimuli and responses are associated with interpretative information that is unrealistic in terms of potential outcome of the situation (e.g., going crazy, cardiac arrest, death). Third, threat stimuli have a relatively higher negative valence for individuals with anxiety disorders (Foa \& Kozak, 1986).

Additionally, Foa, Steketee, and Rothbaum (1989) have distinguished the fear networks of individuals with PTSD, compared to other anxiety disorders, as: (a) being greater in general size, (b) having more intense response elements that produce psychophysiological arousal, and (c) being more readily accessible. With respect to the latter point, Lang, Levin, Miller, and Kozak (1983) have suggested that anxiety disordered, compared to non-anxiety disordered individuals, require less 
Amatching@etween fear structures and elements in the environment for the network to be activated; and that ambiguous threat stimuli (e.g., words acting as descriptions of threatening events) may be capable of leading to activation. These authors suggest that this Aase of accessibility@phenomenon might result because of the increased likelihood that other elements in the network might already be activated, thus increasing the likelihood of generalized responding. Litz and Keane (1989) note that the high basal level of arousal often documented in persons with PTSD may facilitate perception of and responding to ambiguous threat stimuli. Thus, such individuals may be primed to perceive and attend to fear-relevant stimuli (including ambiguous stimuli, such as general threat words).

The proposed characteristics of the fear networks of anxiety-disordered individuals discussed above may explain why the Stroop effect occurs upon exposure to personally-relevant, threat-related stimuli in persons with PTSD. This model would predict that a higher basal level of arousal (perhaps resulting from the concurrent activation of other elements in the network), often observed in persons with PTSD, may facilitate stimulus generalization, such that ambiguous stimuli (e.g., words) become capable of network activation. Additionally, once perceived as threatening, such stimuli would have a higher negative valence for the anxiety-disordered individual than for the typical person. The network has an escape/avoidance function, and examination and interpretation of stimuli (for threat detection) subsequently occurs as stimuli are encountered. It is then, perhaps, time spent in this interpretation component, that results in the longer response latencies noted during the Stroop task.

A second way of explaining selective attention to threat cues has been put forth by Williams, Mathews, and MacLeod (1996). It is beyond the scope of this paper to provide a detailed account of this model; in brief, however, these authors draw on Cohen, Dunbar, and McClelland ₹(1990) 
Axonnectionist@model of Stroop interference (for a detailed description of the connectionist model, see Cohen et al.,1990; Williams et al.,1996), and describe a network of activating input, intermediate, and response modules that are connected by processing pathways. Stroop interference is thought to occur because of increased resting activation levels for input modules, or stronger connections in the word pathways between modules for threatening information, relative to other types of word stimuli.

Although these information processing models of the Stroop effect (e.g. Foa \& Kozak, 1986;

Kozak et al.,1988; Williams et al., 1996) may have intuitive appeal, it will later be proposed that a more parsimonious explanation of how stimuli--including words--become conditioned stimuli for fear-related behavior may be utilized. In the next section, the application of the clinical Stroop task with trauma survivors will be discussed.

The Stroop Task with Trauma Survivors

The Stroop effect has been well-documented with adults diagnosed with PTSD. McNally et al. (1990) administered a clinical Stroop task to 15 Vietnam combat veterans with and 15 without PTSD, as specified by DSM-III-R criteria. Five white cards were constructed, with each containing five words inclusive of a particular category of word, printed 100 times, in five different colors. Word categories included: (a) words related to Vietnam (e.g., Airefight,@Aodybag@ (b) positive words (e.g., Aove,@ Ahappy@ (c) words related to obsessive-compulsive disorder (OCD; e.g., Ayerms, @Aurine@ and (d) neutral words (e.g., Anput,@Aconcrete@matched to the PTSD words in terms of frequency of usage in American English. Participants were instructed to name the colors of the words, reading left to right, without attending to content, as quickly and accurately as possible. Cards were presented in the following order: control, neutral, positive, OCD, and PTSD (PTSD was presented last as pilot data had 
suggested that when PTSD-related words are presented first, the behavioral disruption with which they are associated maintains during the other word categories). The dependent variable was the time taken to color-name all the items on a single card.

Results indicated that veterans with PTSD had significantly longer response times to name the colors of PTSD-related words than any other category of words. Additionally, participants with PTSD did not demonstrate significantly longer response times for positive words, which the authors interpreted to mean that it was the specific trauma-related words, and not general emotionality, which was associated with the effect.

Foa et al. (1991) modified the Stroop paradigm for administration via a personal computer. These authors utilized a computer program that allowed precise measurement of color-naming latencies in response to single words presented one at a time on a color monitor. Rape victims with and without PTSD and persons who had not experienced trauma named the color of words in the following categories: (a) rape-related words (e.g., Asssault@) (b) general threat (e.g., Acancer@) (c) neutral (e.g., Araisin@, and (d) nonwords (e.g., Anarvos@ The ten words in each category were presented three times each, for a total of 120 trials. Results indicated that the participants previously diagnosed with PTSD had significantly longer response latencies for the rape-related words than did the non-PTSD rape victims and non-rape control subject, suggesting that the behavioral disruption was related to a diagnosis of PTSD, and not merely the experience of rape.

Cassiday et al. (1992) also employed a computerized Stroop paradigm with rape victims with and without PTSD, and non-trauma participants. Participants were instructed to color-name the following categories of words: (a) high-threat rape words (e.g., Aape@() (b) moderate-threat rape 
words (e.g., Arrime@) (c) positive words (e.g., Alove@) and (e) neutral words (e.g., Aypical@) Results revealed that, compared to rape-victims without PTSD and non-trauma control participants, rape victims with PTSD had significantly longer response latencies for high-threat words than for moderatethreat, positive, and neutral words.

Kaspi et al. (1995) presented Vietnam veterans with and without PTSD with neutral, positive, negative, and combat words. Words appeared on a computer monitor in either a blocked or random fashion. Random presentation was included in the paradigm to determine whether the blocking of words (the standard procedure) may inflate Stroop effects by producing inter-item semantic priming, or resulting in increases in participant rumination about the meaning of threat stimuli. Results suggested that both groups exhibited longer response latencies for combat stimuli than for neutral, positive, or other negative words, but this effect was only statistically significant for the PTSD group. Additionally, positive words were not associated with longer response latencies than neutral words across both groups, suggesting, as other studies have, that it is not the emotional valence of the stimuli, but rather association with the traumatic event that produced the behavioral disruption. Finally, there were no significant differences across participant groups on Stroop performance with a blocked or random word presentation.

Vrana, Roodman, and Beckham (1995) investigated Stroop color-naming of trauma-related words in 42 male Vietnam combat veterans with PTSD, and 15 without. Word stimuli were chosen to be either very specific to the Vietnam experience (e.g., Apoint, @Ahopper@ general--typically known by both war and non-war personnel--but still Vietnam-related (e.g., Akill,@Abodybags@ general stress not related specifically to Vietnam (e.g., Afear,@Aleath@) or neutral (e.g., Avash, @Abus@ Results of this 
study suggested that, for all subjects, each of the three anxiety word-groups slowed color-naming, relative to the neutral word-groups. However, the effect was more pronounced with the veterans with PTSD. Interestingly, the general Vietnam-related stimuli were associated with greater Stroop response time than the specific Vietnam-related stimuli. This may have occurred because the general words were more related to death than the specific words, an effect shown by Scotti (1992) with a dichotic listening task.

\section{The Clinical Stroop Task and Children}

Although children have frequently been administered the original Stroop paradigm as a means of investigating variables related to reading skill acquisition (e.g., Horn \& Manis, 1987; Schadler \& Thissen, 1981; Stanovich, Cunningham, \& West, 1981), there has been strikingly little use of the Stroop task with children for clinical research. Instead nearly all clinical Stroop tasks have been administered to an adult population.

An exception is the work of Martin, Horder, and Jones (1992). These researchers administered a modified Aspider@Stroop task to 48 spider-phobic or non-phobic children. These researchers found that, like similar studies with adults, color-naming took statistically significantly longer for the spiderphobic children than for the non-phobic children.

Additionally, Green and McKenna (1993) studied possible developmental aspects of an Aating@Stroop effect, as produced by 120 noneating disordered children and adolescents (aged 9, 11, and 14 years). Stroop stimuli consisted of food-related, body-shape-related, and neutral words. These authors found that there were significant performance decrements (i.e., reductions in color-naming time) for the food and shape-related words with the 14-year-old girls. Further, here was a color-naming 
decrement with the food-related words for the 11-year-old girls, but not the shape-words. Results were interpreted in terms of cultural pressures on females to diet to obtain an ideal body-shape, and the developmental stages these pressures may begin to exact influence. Although participants were not clinically disordered, the modified Stroop task employed in this study could conceivably be used with a clinical sample of eating-disordered children, and thus may be considered a clinical use of the Stroop task.

More recently, Kindt, Brosschot, and Everaerd (1997) used a clinical Stroop task to assess differential color-naming times for health concern-related words (with and without a threatening valence) with high and low anxious children (ages 8 and 9) prior to receiving an inoculation. They found that participant groups did not differ in color-naming times for health concern-related words (e.g., Anjection, @fainting@ and were slower to name these words than concern-unrelated words (e.g., Akidnap,@killer). There was no main effect for word valence. Interestingly, when the study was repeated with the inoculation component removed, participants still exhibited longer times in the presence of health concern-related words, compared to health concern-unrelated words. Additionally, there was a main effect for valence, with all participants exhibiting longer times for all threatening words, irrespective of health concern-relatedness.

In general, the longer response times for responding to threatening stimuli in clinical Stroop studies have been interpreted as support for the theory of the existence of an information processing structure in memory. Differential response times on the Stroop task are thought to be a measure of differential attention, which in turn is taken as evidence for an informational network. 


\section{Limitation of an Information Processing Interpretation}

Despite these data, an information processing-based theory of fear responding is limited in a number of ways. First, such a theory is an example of what Donahoe and Palmer (1994) call an Anferred-process approach@o understanding environment-behavior functional relations. In such an approach, functional relations between observed environmental and behavioral events are identified, and then used to infer sub-behavioral (i.e., unobservable) processes hypothesized to underlie the functional relations. Unfortunately, inferred environment-behavior relations have no empirical support independent of the behavioral observations, and thus should not be used as an explanation of the observations. To do so is to engage in circular reasoning. That is, circularity is encountered when we respond to the question AWhy does overt behavioral response change in the presence of threatening stimuli?@vith ABecause a fear-network has been activated;@and the subsequent question AHow do you know a fear network has been activated?@vith ABecause longer response latencies occur in the presence of threatening stimuli.@

Donahoe and Palmer (1994) suggest that the inferred-process approach occurs when empirically-based behavioral observations result in hypotheses about intervening processes and structures that would be consistent with such observations. Further, often such inferences are followed by more empirical study of the phenomenon at hand, usually utilizing a similar methodology, and consequently resulting in similar results. These consistent findings are then frequently viewed as support for the inferred-process theory. However, such similarity in findings is merely an example of reliability, not validity.

Information processing theory and research is clearly the result of an inferred-process approach. 
For example, Foa and Kozak (1986) note that their fear network model has roots in a bioinfomational conceptualization of fear (Lang, 1977, 1979) and their own clinical observations. Following the development of their model, empirical findings have been used to support the theory. For example, the presence of psychophysiological response during the presentation of threatening stimuli has been taken as support for the validity of a fear-network model (e.g., Litz \& Keane, 1989; McNally et al., 1987). Similarly, the sensitivity to threat stimuli noted in the above described studies has also been viewed as support for the theory. However, these studies utilized methodologies similar to those that resulted in the initial observation and subsequent theory (e.g., the presentation of personally-relevant threat stimuli under experimental conditions). Additionally, there is no direct evidence of the proposed internal structures. Instead, the processes and structures put forth by the network model are merely constructs. Thus, the conclusion that validity has been demonstrated is tenuous, at best.

Additionally, according to information processing theory, physiological response occurring after the network has been activated, is a precursor of exhibition of overt motor behavior encoded in the network (Foa \& Kozak, 1986). However, at least one study (Scotti, 1992) has countered this hypothesis by demonstrating that physiological response may follow behavioral response (i.e., behavioral disruption).

With these limitations in mind, it seems important that a more parsimonious explanation of overt, behavioral responses following threat-related stimuli be provided. Further, such explanation should be one that is grounded by empirical observation.

\section{Stimulus Equivalence Relations}

As an alternative, an explanation for the Clinical Stroop effect in anxious individuals may be put 
forth that does not rely on hypotheses about unobservable and inferred structures, networks, and processes. Instead, the mechanism of Stroop interference may be that of stimulus equivalence (see Scotti, 1992, for a discussion of the application of stimulus equivalence to the differential responding on a dichotic listening task). This behavior analytic term refers to the event when physically dissimilar stimuli (e.g., the spoken word ACAR, @ picture of a car, and the printed letters AC-A-R@come to, through learned contextual discriminations, set the occasion for a common response (e.g., physiological arousal). The different stimuli are said to be members of an equivalence class (Donahoe \& Palmer, 1994). Importantly, when stimulus equivalence has occurred, at least one of the stimulus-response relations in the equivalence class has not been directly taught. For example, a child with developmental disabilities is taught, through discrimination training, to respond to the spoken word Aoilet@by pointing to an actual toilet; and is also taught to respond to the spoken word Aoilet@y pointing to a picture of a toilet. Stimulus equivalence has occurred if the child, without additional instruction, then points to the actual toilet following presentation of a picture of a toilet.

In our current discussion of the Stroop effect observed in clinically-anxious individuals, the printed threat words have come to be members of the same stimulus class as the physical objects or events they symbolize. For example, for a recent survivor of an MVA, the physical object car may become, through respondent conditioning, a stimulus that results in physiological arousal and orienting (e.g., observing all on-coming cars to attempt to identify whether one is losing control and about to smash into your car). Because of prior learning history that has equated the physical object car, with the spoken word ACAR, @he written word AC-A-R, @and a picture of a car, the latter stimuli (spoken ACAR, @vritten word AC-A-R, @and picture of a car) may also develop stimulus control over 
physiological arousal, even though they were not directly associated with the original learning trial (i.e., the car crash). Thus, words presented in a Stroop task are likely to occasion a response that has similar features to the response at the original learning trial (i.e., physiological reactivity, orienting behavior).

To summarize, the concept of stimulus equivalence has been presented to explain the event when different stimuli come to set the occasion, via histories of contextual discrimination, for a class of similar responses. For the present purposes, this term is useful in explaining how certain stimuli not associated with a traumatic event, for example printed words, may come to be discriminative stimuli for responses similar to those evoked at the time of the original learning event. Yet to be discussed, however, is how printed words with stimulus control over responses which are similar to the responses evoked at the time of the original traumatic event are then related to impaired Stroop color-naming performance. That is, how is it that on-going Stroop task behavior is disrupted following the presentation of words that are in an equivalence class with trauma stimuli?

An explanation has been put forth by Scotti (1992) that is based on the laboratory observations of Estes and Skinner. Estes and Skinner (1941, as cited by Scotti, 1992), utilizing what they called a conditioned emotional response (CER) paradigm, found that the random presentation of a tone that had previously been paired with shock was associated with a decreased rate of operant behavior (i.e., reinforced lever pressing). It was assumed that the tone (a conditioned stimulus) disrupted the operant behavior because of its prior pairing with the shock (an unconditioned stimulus). Scotti (1992) showed this same pattern of disruption with veterans engaging in a dichotic listening task. To generalize these findings to the issue at hand, the Stroop color-naming task may be considered an operant behavior. Children have a history of being reinforced for naming colors and following the direction of adults, thus, 
the color-naming response can be considered an operant. As observed by Estes and Skinner (1941, cited in Scotti, 1992), and in studies using the clinical Stroop task, the presentation of printed MVArelated words that are associated, through stimulus equivalence, with a prior aversive unconditioned stimulus (the car crashing into a tree) is likely to disrupt operant behavior. Although the printed words were not directly associated with the aversive conditioning event (i.e., the printed words were not part of the crash), through stimulus equivalence they have come to be in an equivalence class with other stimuli actually associated with the event, and to evoke a common response (Scotti, 1992). It is possible that the behavioral disruption frequently observed in Clinical Stroop studies may have occurred because conditioned responses (e.g., physiological responses) to the conditioned stimuli (MVA-words) disrupted the operant task (color-naming). That is, color-naming performance decreases when some other behavior, for example, physiological reactivity, co-occurs.

Notably, basic research conducted with humans has begun to empirically demonstrate instances of stimulus equivalence (e.g., Barnes \& Keenan, 1993; Catania, Horne, \& Lowe 1989), thus eliminating the need to infer that unobservable cognitive processes are responsible for differential response to stimuli. Instead the finding may be understood in terms of basic behavior analytic findings, discovered using methodologies grounded in direct observation.

\section{Purposes and Hypotheses}

Extension of empirical research to child survivors of MVAs. As previously discussed, empirical study of the behavioral ramifications of the relatively common childhood event--experiencing a traumatic MVA--has been severely neglected. Not a single controlled, large-sample study of the effects of MVAs on children has been published. Further, of the few descriptive studies investigating this area, all have 
relied on self- or parent-report methods to obtain data on private and overt behavioral sequelae. Because such data are retrospective, and often subjective, they are difficult to verify objectively. Thus, clinic-based measures of overt, anxiety-associated behavior become very important for accurate diagnostic and treatment outcome purposes. Although the Stroop paradigm has been used to assess overt differential behavior in the presence of trauma-related stimuli with adults, no investigations have yet utilized a child population. Thus, the overriding goal of this study was to provide an experimental investigation of the use of the clinical Stroop task as a measure of overt behavioral disruption in child survivors of MVAs.

Developmental considerations. The feasibility of an application of the Stroop paradigm to a child MVA population was investigated. Developmental considerations of the application of a Stroop paradigm to a child population was considered in two ways. First, it was assessed in terms of whether Stroop-related stimuli can be identified that will be developmentally appropriate for a child population. As the children in this study spanned a large range of ages (7-13 years), Stroop words needed to be identified that had likely been established in each child flearning history. That is, the words needed to be readable and Adentified with@by children across the age-range of the study, to the extent that they were capable of producing differential Stroop response times.

Second, the study explored the possibility of overall differences in performance with respect to participants Feading ability. Studies of the development of reading behaviors have frequently utilized a Stroop paradigm to identify age differences in reading skill. For example, studies have found that the Stroop effect is generally not observed until around the end of the first grade. During second and third grade, the Stroop effect usually rises to its highest level, and then gradually declines until approximately 
age 60 (Horn \& Manis, 1987). This pattern is thought to coincide with the acquisition of reading skill. Before the first grade, children typically do not engage in reading behavior, thus it would not be expected that they would evidence the Stroop effect. However, as reading skill develops--typically by the end of first grade, and on into the second and third grades--it would be expected that interference would occur (e.g., as words are likely to be highly salient stimuli for primitive reading responses, such as sounding-out syllables). As the children reading skill becomes more proficient, however, it seems logical that less effort and time would be required during the reading response (some have suggested that at this point reading has become Automatic @or over-learned--that is--it takes place without the child purposefully attending to the letters, syllables, and sounds; see Laberge \& Samuels, 1974). As less effort is needed to read, it is likely that the ability to engage in a simultaneous task (i.e., color-naming) would be facilitated.

Thus, the present study investigated whether developmental differences in reading skill between children are associated with differential performance on a clinical Stroop task. Specifically, it hypothesized that, across all participants, Alow readers@defined by children reading at the first- through third-grade level, will generally exhibit greater overall color-naming response times for all word stimuli relative to the more experienced readers, or Aigh readers, @lefined by those children reading at the fourth-grade level or higher.

Examination of differential Stroop performance. Second, this study examined differential behavioral response to four types of Stroop stimuli in three groups of children: (a) survivors of MVAs who are currently exhibiting post-traumatic symptoms, (b) survivors of MVAs who are not exhibiting trauma-related responses, and a comparison group of non-MVA participants. Each participant was 
presented with MVA-related experimental words, school-stress control words, and neutral control words. School-stress words were included to represent a Ageneral@ype of stress to control for the possibility that stressful words in general are associated with longer color-naming times. Additionally, colored XXXXs were also presented as a measure of pure color-naming speed to examine whether any overall differences in color-naming between the groups exist.

It was first predicted that the MVA-Distressed group would exhibit a differential Stroop effect for word type, taking significantly longer to color-name MVA words than the comparison stimuli (i.e., school stress and neutral words, XXXXs). Second, it was predicted that the MVA-Distressed group would evidence a greater Stroop effect for the MVA words than the Non-MVA, and MVANondistressed groups.

Additionally, differences in rate of task errors was investigated. Similar to above, it was predicted that the MVA-Distressed group would exhibit a differential error effect for word type, making more errors while color-naming MVA words than comparison words, and that this effect would be more pronounced for the Distressed-MVA group than the Non-MVA, and MVA-Nondistressed group.

A final purpose of this study was to investigate whether the level of behavioral disruption associated with the MVA words was significantly related to structured interview and other psychometric data. Specifically, it was assessed whether or not color-naming times for the MVA-words (i.e., levels of overt disruption on the Stroop task) and psychometric report of clinically significant levels of behavioral distress are correlated. As discussed above, previous research has demonstrated that the different response systems may not be correlated with each other (e.g., Bernstein, 1973; Hodgson \& Rachman, 
1974). Thus, no predictions were made as to whether the results of these two response-methods would be correlated in the present study.

\section{Method}

\section{$\underline{\text { Participants }}$}

MVA sample. Thirty children between the ages of 7 and 13 years who had experienced an MVA within the last 13 months were recruited from local hospitals, and from community-based cable television advertisement and flyers. These children were later subdivided into two groups: (a) children currently experiencing clinically-significant MVA-related distress, and (b) children not experiencing clinically-significant MVA-related distress, as indicated by the children₹ responses to the Impact of Event Scale (IES; Horowitz et al., 1979). Additionally, these groups were also later sub-divided into High and Low Reader groups. High readers were defined as those children reading at the fourth gradelevel or above, according to the Wechsler Individual Achievement Test (WIAT; Psychological Corporation, 1992). Low readers were defined as those children reading at the second or third gradelevel. Children were to be excluded from participation if: (a) they sustained significant head trauma such that they were not able to respond adequately to the research protocol (e.g., as evidenced by a Glasgow Coma Scale below 15; Teasdale \& Jennett, 1974); (b) they were visually-impaired or color blind (and so were unable to complete the Stroop task); or (c) read at a level below that typical of a seven-year-old child, as evidenced by a score below 14 on the WIAT reading screener. None of the children who agreed to participate in the study were excluded based on these criteria.

Comparison (Non-MVA) sample. A comparison sample of 15 children who had never experienced an MVA was recruited from local elementary schools, and from community-based cable 
television advertisement and flyers. This group represented a community comparison sample--no $\underline{a}$ priori means were taken to identify whether participants in this sample did or did not evidence clinicallysignificant levels of psychopathology. These children were later divided into High and Low Reader groups. High readers were defined as those children reading at the fourth grade-level or above, according to the Wechsler Individual Achievement Test (WIAT; Psychological Corporation, 1992). Low readers were defined as those children reading at the second or third grade-level. Visually impaired or color-blind children, and children reading below that typical of a seven-year old child were to be excluded from participation in the study. None of the children who agreed to participate in the study met these exclusionary criteria. One child, however, was disqualified during the Stroop task (prior to exposure to the experimental stimuli) because he found the task too difficult to complete.

\section{$\underline{\text { Pre-Measures }}$}

As part of an on-going, grant-funded project (J. R. Scotti), all participants had completed an extensive psychometric assessment, developed by Rode (1997). Part of this assessment, the IES was used to divide the MVA participants into two groups: MVA-Nondistressed (MVA-ND), and MVADistressed (MVA-D). The remaining measures were used only to describe the participant sample. The measures described in the following sections comprised the psychometric assessment.

Demographics questionnaire. A brief parent-completed questionnaire was developed to assess relevant background information on each child and his or her family. Questions covered areas such as age, gender, history of significant medical or mental health experience, previous exposure to trauma, family income, and family composition. Questions regarding the motor vehicle accident were included on the demographic measure provided to the MVA sample. 
Accident Characteristics Identification Scale - Child and Parent Versions. The Accident Characteristics Identification Scale (ACCIDENTS; Scotti et al., 1992) is a nine-item, Likert-type measure. The measure includes questions relating to the severity and impact of the MVA, and has discriminated between non-accident, mild, and heavy accident exposure groups with adults (Scotti et al., 1992). Parents completed the ACCIDENTS. Children completed a version modified by Rode (1997) for children (ACCIDENTS-C). Parents of children from the Non-MVA sample were asked to provide answers to the first two questions from this scale assessing number of previous MVAs experienced, and level of fear of riding in an automobile.

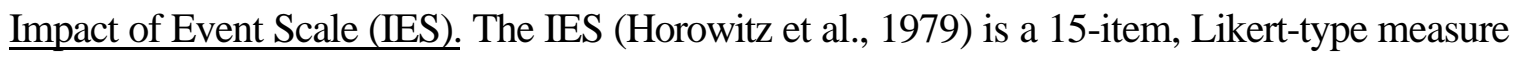
designed to assess emotional distress following exposure to a nominated traumatic event. Two factors of distress are measured: intrusion of thoughts about the nominated event, and avoidance of thoughts and stimuli associated with the event. This measure has been widely used in the assessment of PTSD among adult trauma victims, particularly combat veterans. The measure has been demonstrated to have discriminate and construct validity with combat veterans (Schwarzwald, Solomon, Wiesenberg, \& Mikulincer, 1987). Additionally, the IES has been used to assess traumatic responding among adult survivors of MVAs (Scotti et al., 1992). The IES has been used successfully with children, aged 8-16, exposed to a passenger ship disaster (Yule \& Udwin, 1991; Yule \& Williams, 1990), and with children exposed to violence (Malmquist, 1986). Scores obtained in these child studies were similar to those reported with adult populations; however, normative data with children are not yet available on this measure. Therefore, in our study both MVA and Non-MVA participants were asked to complete the measure with respect to motor vehicle accidents or routine motor vehicle exposure, respectively. 
Child Behavior Checklist-Parent Form (CBCL). The CBCL (Achenbach, 1991) is a 138-item parent-completed questionnaire designed to identify parents $\mp$ eport of their child ₹ behavior across a range of domains (including internalizing and externalizing behaviors), and social competency. The scale assumes at least a fifth-grade educational level, and takes approximately 20 minutes to complete. The CBCL has demonstrated high test-retest and inter-interviewer reliability; and high content, construct, and criterion validity (Achenbach, 1991). For the present study, the Total $\underline{T}$-score, and $\underline{T}$-scores for the Internalizing and Externalizing subscales of the Behavior Scale were used for analyses.

Child Depression Inventory (CDI). The CDI (Kovacs, 1985) is a 27-item, self-report measure. For each item, the child chooses which of three statements best describes him or her over the past two weeks. Items are worded to be readable and understandable for children aged 8 to 17 years. Cognitive, behavioral, and emotional symptoms commonly associated with a diagnosis of depression are assessed. Curry and Craighead (1993) report that the CDI is the most frequently used measure of child depression for psychological research. Psychometric data on the CDI indicate that it may not clearly differentiate depressed and nondepressed children, but it does appear to discriminate between overall emotionally distressed and normal children (Kazdin, 1987). Tests of internal consistency and split-half reliability have demonstrated adequate results (Curry \& Craighead, 1993).

Children Manifest Anxiety Scale-Revised (RCMAS). The RCMAS, or AWhat I Think and Feel@Reynolds \& Richmond, 1978) is a 37-item, child-completed, dichotomous choice measure designed to assess three aspects of child anxiety: physiological arousal, worry, and difficulty with concentration. The measure includes a lie scale to identify answers targeting social desirability. The measure is widely used for clinical and research purposes, and has been demonstrated to have adequate 
construct, content (Reynolds \& Richmond, 1978), and concurrent (Reynolds, 1980) validity. Discriminant validity has been less clearly evidenced, the measure may more accurately discriminate between children with and without emotional distress than specifically discriminating between anxious and nonanxious children. The measure is written at a third-grade reading level, and was normed on a sample of children in grades 1 through 12. Two scores are obtained from the RCMAS, an Anxiety score and a Lie score.

Anxiety Disorders Interview Schedule for Children and Parents (ADIS-C and ADIS-P). The ADIS-C and ADIS-P (Silverman \& Nelles, 1988) are structured interviews targeting 6 to 18 year-old children, individually completed by both child and parent. Although the interview focuses on identifying symptoms of anxiety disorders, the measure also provides a broad screening for other Axis I symptoms and diagnoses. The interview has demonstrated adequate inter-rater and test-retest reliability (Silverman \& Nelles, 1988). The DSM-III-R version of the ADIS was used, as only this version of the ADIS was available at the onset of this study.

$\underline{\text { Clinical Stroop Task Measures }}$

Following psychometric assessment, the MVA sample and the non-MVA control group were administered the following measures.

The Wechsler Individual Achievement Test-Reading Subtest. The Wechsler Individual Achievement Test (WIAT; Psychological Corporation, 1992) is a standardized, individually administered battery used to assess the scholastic achievement of children who are in Grades K through 12, and ages 5:0 (5 years, 0 months) to 19:11 (19 years, 11 months). The battery contains eight subtests designed to encompass the range of curriculum objectives found in school instructional 
programs. Three of the WIAT subtestsBBasic Reading, Mathematics Reasoning, and Spelling--may be used as brief (10-15 minutes for all three subtests) screening instruments for general achievement, or to answer specific referral questions (e.g., AOn what level is this child reading?@and are also published separately as the WIAT Screener (Psychological Corporation, 1992).

Of present interest for this study is the Basic Reading Subtest. This test contains a series of pictures and printed words for assessing decoding and word-reading ability. Norm tables (derived from a sample of 4,252 children, with equal numbers of females and males, and a diverse range of ages and race) may be used to derive standard scores, percentile rank, age and grade equivalents, normal distribution equivalents, and stanine.

Tests of reliability for the WIAT subtests have been favorable (Psychological Corporation, 1992). Split-half reliability coefficients for the subtest and composite standards scores were obtained at each age-level for a measure of test-score consistency. Results for the Basic Reading subtest indicated an average reliability coefficient, across all ages, of $\underline{r}=.92$. Additionally, the stability of scores on the WIAT was assessed in a separate study of 367 children (the sample was drawn from grades 1, 3, 5, 8, and 11) who were tested twice. The stability coefficients of the Reading Subtest, averaged for all five, grades was .94 (Psychological Corporation, 1992). Additionally, scores from the Basic Reading Subtest of the WIAT have been highly correlated with scores from reading scales of several other achievement tests, including the Wide Range Achievement Test-Revised (Jastak \& Wilkinson, 1984), $\underline{\mathrm{r}}=.86$; and the Woodcock-Johnson Psycho-educational Battery-Revised (Woodcock \& Johnson, 1989), $\underline{\mathrm{r}}=.79$. 
Color-vision test. The Pseudo-isochromatic Plates for Testing Color Perception-Revised (American Optical Company, 1940) were used to screen for color-blindness (defective red-green vision). This series of plates has been demonstrated to be an effective screener of red-green color-vision defect, the most common color-vision defect (Hardy, Rand, \& Rittler, 1946). This screening test was used to ensure participants could accurately recognize the different colors on the Stroop screens.

Clinical Stroop task. In the present study, six stimulus screens, including an MVA stimuli screen (e.g., Arash@ a School-stress stimuli screen (e.g., Aest@) three different household-neutral stimuli screens (e.g., Aven@) and colored Xs, were presented on a standard, color computer monitor. Additionally, a practice screen, consisting of neutral word stimuli (e.g., Aboat@was presented first. The order of the stimuli was set as follows: Practice, Neutral 1, School, Neutral 2, MVA, Neutral 3. This order, with the School-stress words preceding the MVA-words, was chosen because previous research (McNally et al., 1990) has demonstrated that carryover effects may occur after the presentation of trauma words (i.e., color-naming times remaining longer for all word types following presentation of trauma words). All word stimuli groups were statistically similar in terms of frequency of occurrence in children s school reading texts, length, and number of syllables (see below for a description of how this was determined).

For all Stroop screens, there were five words (or groups of Xs) and five colors (i.e., red, blue, green, white, and yellow), each appearing 10 times, for a total of 50 stimulus words per screen. No color or word appeared adjacent to itself, either vertically or horizontally. This presentation was created using a modified version of the Stroop program described by McNeil et al. (1995). 
$\underline{\text { Selection of Stroop Words }}$

In order to verify that the words selected for the clinical Stroop task were reliable and valid examples of their respective categories, the following procedures were conducted.

A list of 15 words for each word category type (MVA, School-stress, and Neutral) was generated by the primary investigator, a child clinical doctoral candidate with experience working with children with school-related anxiety, a licensed clinical psychologist with experience working with trauma-related anxiety, and three additional clinical graduate students. For inclusion in this list, each word was one that: (a) has been demonstrated to be included in at least four of eight common academic reading textbooks series, and (b) appears in the textbooks appropriate for the second-grade child (Harris \& Jacobson, 1982).

Each of the 45 words generated, regardless of category, were randomly presented on an individual sheet of paper. Fifty undergraduate students unfamiliar with the experimental question were asked to: (a) assign each word to an MVA-related, School-related, Neutral, or Unassignable category; and (b) rate the distress produced by each word (using a 5-point scale, $0=$ Anot at all distressing, $@$ $=$ Arery much distressing@ The ten words selected for the MVA and School-Stressor categories were reliably assigned (70\% or greater) to the MVA and School-Stress categories, and were those that had the highest mean distress scores. The 15 words selected for each of the neutral categories were reliably assigned (70\% or greater) to the neutral category, and had mean distress score ratings between 0 and 1 . The 15 neutral words were randomly assigned to three neutral groups of five words each. Analysis of variance (ANOVA) conducted on Word Group distress ratings indicated that there was a main effect for Word Group, $\underline{\mathrm{F}}(4,1172)=68.0, \underline{\mathrm{p}}<.01$. Follow-up planned comparisons 
using Fisher Least Significant Difference (LSD) test indicated that: (a) the MVA and School-stress word groups were not statistically different from each other in terms of ratings of distress, (b) the three Neutral word groups were not statistically different from each other in terms of word ratings of distress, and (c) the MVA and School word groups had significantly higher distress ratings than each of the Neutral word groups.

The final five word groups were then assessed as to differences in their frequency of usage and occurrence in the English language for children. This provided evidence that any Stroop effect would not be due to the participant being more or less familiar with the words in a word category. A word vocabulary and frequency text called Basic Reading Vocabularies (Harris \& Jacobson, 1982), written to encompass vocabulary typically taught to children in grade school, was used for this purpose. For this book, eight elementary and secondary-school reading series were identified. Each series contained books at the preprimer and primer levels, a first-grade reader, two readers at the second and third grade levels, and one or more readers at each level from fourth through eighth grade. There was a total of 118 books analyzed, with about 5,600,000 running words of text. Basic Reading Vocabularies provides the reader with the lowest grade level at which the word appeared in at least four of the eight series, and the total frequency with which it appeared across the 118 books.

The Harris and Jacobson (1982) frequency counts were used to determine whether the words in the five Stroop stimuli word groups were statistically similar with respect to frequency in children₹ English language. These frequency ratings were used because this count represents the words found in childrens reading material. Other frequency texts have analyzed vocabulary found in adult reading material (e.g., Francis \& Kucera, 1982), therefore limiting their generalizability to a child population. 
The frequency of each word in each group was identified. The data were then subjected to statistical analysis with a Kruskal-Wallis ANOVA (as these data violate assumptions of normality, a nonparametric test is prudent) to identify whether each word group was significantly different from the other, with respect to frequency. Results indicated that the word groups were not different from one another, $\chi 5(4, \mathrm{~N}=25)=.53, \mathrm{p}>.05$. An identical process indicated that the five word groups were not statistically different in terms of word length, $\chi 5(4, \mathrm{~N}=25)=1.82, \mathrm{p}>.05$; and syllables, $\chi 5$ $(4, \mathrm{~N}=25)=.17, \mathrm{p}>.05$. Thus, the final five groups were statistically similar with respect to frequency of occurrence in children English language, length, and syllables (for the final list of Stroop words refer to Table 2).

$\underline{\text { Equipment }}$

The Stroop color-naming task was presented on an IBM-compatible personal computer (486) with a color monitor $(27.0 \mathrm{~cm} \times 19.5 \mathrm{~cm})$. The computer program for the Stroop task, described by McNeil et al. (1995), allowed performance on the task to be timed via the experimenter pressing a key on the computer keypad to start and stop the timer. A digital stopwatch was used for timing 15second rest periods between screens.

\section{$\underline{\text { Procedures }}$}


Scotti) investigating the effects of MVAs on children, using a multi-method assessment protocol (psychometric, psychophysiological, and overt behavior assessments). In brief, participants completed: (a) an extensive psychometric assessment designed to identify self and parent-report of functioning, and risk factors and mediators for post-accident distress; (b) physiological assessment to measure 
differential reactivity to MVA-related, audiotaped vignettes; and (c) overt behavior assessment, using the clinical Stroop task discussed in the present study. Participants were recruited for participation in all parts of the project. However, only some of the psychometric data--those described above--were used in the data analysis for the present study, and none of the psychophysiological data were included.

Interested parents, responding to recruitment letters, community-based flyers, or advertisement on a local television bulletin board, contacted the experimenters by telephone or mail. During this initial telephone call (or in a subsequent telephone call, in the case of those families who had mailed us a recruitment response form indicating interest and a telephone number where they could be reached) the purpose of the study, and the extent of participation (including risks and benefits) were briefly described. Appointments were made with all families who agreed to participate, and occurred at the Psychology Department at West Virginia University. At the appointment, purposes and conditions of the assessment were again explained, as well as limits of confidentiality, particularly as they pertain to child abuse. Parents or guardians were asked to sign consent, and children were asked to sign assent for participation (see Appendices A and B for copies of the consent and assent forms). Parents or guardians were provided with an opportunity to review assessment materials prior to signing consent.

The clinical Stroop task. After consent and assent were obtained, the psychophysiological assessment component of the overarching study occurred (taking approximately 35 minutes), followed by a brief (approximately 5 minutes) break for the participant while the experimenter prepared the Stroop task. The principal investigator of the over-arching grant-funded project (J. R. Scotti), the author of the present study, or one of two trained graduate-level research assistants served as experimenters for the Stroop task. As psychometric assessment had not yet been conducted, experimenters were blind 
as to whether or not the MVA participants were distressed. Psychophysiological monitoring continued during the Stroop assessment; however, the results of those data are not included in the present analyses.

The Stroop procedure was conducted in a dimly lit, small assessment room, devoid of typical distracting stimuli (e.g., pictures on walls, knick-knacs). Participants sat at a computer monitor, where they were tested. The experimenter sat in a chair to the right of the participant, also facing the computer. Standardized instructions (see Appendix C) were provided to the participant to name the color of the words displayed on the computer monitor as quickly as possible. The participant was instructed to color-name from top to bottom each column of words, beginning with the left-most column (for examples of how the Neutral and MVA Stroop screens appeared refer to Appendices D and E).

The experimenter controlled the timing of each screen and its presentation. As a participant began and finished naming the colors on a screen, the experimenter pressed the space-bar on the computer keypad, starting and stopping an internal timer. Between screen presentations, participants were given a 15-second rest period, which was timed with a stopwatch. Completion of the task took approximately 10 minutes.

After completion of the Stroop assessment, the participants were disconnected from the psychophysiological monitoring equipment, and were again provided a short break and the opportunity to use the bathroom or get a drink of water. They then participated in the psychometric component of the study (typically their parent or guardian began participating in the parent part of the psychometric assessment while the child participated in the psychophysiological and Stroop assessments). 
Psychometric assessment. As part of the psychometric component of the overarching study, all participants and a parent/guardian were administered the ADIS-C, and ADIS-P by a trained graduate student. Additionally, several parent/guardian and child-completed questionnaires were administered, including: (a) Child Behavior Checklist-Parent Forms, (b) Child Depression Inventory, (c) Children₹ Manifest Anxiety Scale-Revised, and (d) Impact of Event Scale. Accident severity was assessed by the ACCIDENTS (Scotti et al., 1992), with the children completing a version modified to be developmentally appropriate (Rode, 1997).

Also during this component, the WIAT Basic Reading subtest (Wechsler, 1992) was administered to determine the child reading level. Provided that the child was reading at or above the level of a typical child who is seven years, zero months in age (the cut-off score being a raw score of 14), the child \& Stroop data were included in the Stroop study participant sample. Finally, the colorvision screener was administered. No participants were excluded because of reading level or colorvision deficiencies.

Results

\section{$\underline{\text { Participant Groups }}$}

The IES, a measure of symptoms related to the accident, was used to divide the MVA participants into distressed and nondistressed subgroups. This measure was chosen because it assesses responses to a traumatic event in terms of intrusive re-experiencing and avoidance of trauma-related stimuli--hallmark features of PTSD. High scores on the IES are indicative of symptoms of post-trauma distress. Because norms and clinical cut-offs are not standardized for the IES, frequencies for each IES total score for the MVA participants were obtained. The sample was then split at the median (score of 
8), with any total score at or above the median resulting in assignment to the MVA-Distressed group (MVA-D); below the median meant assignment to the MVA-Nondistressed group (MVA-ND).

\section{$\underline{\text { Participant Characteristics }}$}

A total of 46 families consented to participate in the study. One 7-year old male child in the Non-MVA group was disqualified during the Stroop task (prior to exposure to the experimental stimuli) because he found the task too difficult to complete. The data from this participant were not included in any subsequent analyses. Thus, the final sample included 45 participants, with 15 participants in each of the three groups. Visual inspection indicated that the two MVA groups were similar in terms of sources for recruitment (approximately half of the participants were recruited from hospital records and half from community/school advertisements). The Non-MVA group was only recruited from community/school advertisements.

General demographic variables. Table 3 provides a comparison among the three participant groups on demographic variables. Chi-square analyses failed to reveal any group differences in the children gender; race; percent reading above or below the fourth-grade reading level, yearly family income, parent participating in the assessment; or education, employment, and marital status of participating parent. Analysis of variance (ANOVA) did not reveal any differences among the participant groups in terms of the child ₹ mean age, grade in school, or reading grade level.

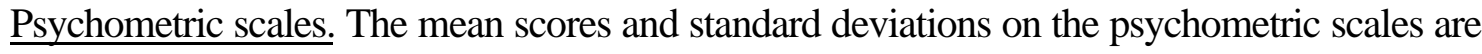
presented in Table 4 for each group. ANOVA revealed that significant group effects were obtained for all scales: CBCL total scale, $\underline{\mathrm{F}}(2,42)=7.85, \underline{\mathrm{p}}<.01 ; \mathrm{CBCL}$ externalizing scale, $\underline{\mathrm{F}}(2,42)=6.23$, $\mathrm{p}<.01 ; \mathrm{CBCL}$ internalizing scale, $\underline{\mathrm{F}}(2,42)=9.57, \underline{\mathrm{p}}<.01 ; \mathrm{CDI}, \underline{\mathrm{F}}(2,42)=6.59, \underline{\mathrm{p}}<.01 ;$ IES 
total score, $\underline{\mathrm{F}}(2,42)=38.89, \underline{\mathrm{p}}<.01$; IES avoidance scale, $\underline{\mathrm{F}}(2,42)=36.16, \underline{\mathrm{p}}<.01$; IES intrusion scale, $\underline{\mathrm{F}}(2,42)=25.08, \underline{\mathrm{p}}<.01$; and RCMAS total anxiety scale, $\underline{\mathrm{F}}(2,42)=10.65, \mathrm{p}<.01$.

Post hoc comparisons using Fisher₹LSD test indicated that the MVA-D group scored significantly higher than the Non-MVA group on every scale except the CDI. Further, the MVA-D group scored significantly higher than the MVA-ND group on all of the scales. Finally, the Non-MVA and MVA-ND means did not differ, except on the CDI and RCMAS, with the Non-MVA group scoring higher in both cases.

Table 5 presents, for each participant group, the percent of children whose scores met or exceeded the clinical cut-off (T-score \$ 60) for the CBCL total, CBCL internalizing scale, CBCL externalizing scale, CDI, and RCMAS scales (these being the scales with established clinical cut-offs). Chi-square analyses revealed that the three groups did not differ in the percentage of children scoring in the clinically significant range on any of the measures except for on the CBCL internalizing scale, $\chi 5(2$, $\underline{\mathrm{N}}=45)=11.25, \underline{\mathrm{p}}<.05$, with the MVA-D group containing the greatest percentage of children exceeding the clinical cut-off. When the Non-MVA and MVA-ND groups were collapsed, they significantly differed from the MVA-D group in percentage of children scoring in the clinically significant range on the CBCL internalizing scale, $\chi 5(1, \underline{N}=45)=10.6, \underline{p}<.01$. Similarly, when the MVA-ND and MVA-D groups were collapsed, they significantly differed from the Non-MVA group in percentage of children scoring in the clinically significant range on this measure, $\chi 5(1, \underline{N}=45)=4.68, \underline{p}<.05$.


total of 90 interviews (45 child interviews, 45 parent interviews). All interviews were scored by either the present author, the principal investigator of the over-arching study, or one of the trained research 
assistants noted above. Twenty percent $(n=18)$ of the tapes were scored by a second rater (another of the trained experimenters) for inter-rater agreement, with six tapes (three child and three parent) from each participant group randomly selected. Percent Total Agreement (for agreement in the scoring of clinical diagnoses, correct or error) was obtained for each participant, revealing that the mean Percentage Total Agreement scores were 100\% for the Non-MVA and MVA-ND groups, and 90\% for the MVA-D group.

Table 5 presents, for each participant group, the percent of children whose ADIS scores (for both parent and child version) met criteria for a clinical diagnosis of a DSM-IV Axis I disorder. Chisquare analyses revealed that the three groups did not differ in the percentage of children meeting criteria for a DSM-IV clinical diagnosis on this measure. Table 6 lists the ADIS diagnoses (for both parent and child version) obtained, and the number of cases in each participant group. Some participants received more than one diagnoses. It should be noted that the ADIS interviews did not permit identifying whether the diagnosis developed after the MVA, so some diagnoses may have been present prior to the accident, or unrelated to it. The exception, however, was the diagnosis of PTSD, which requires identification of the traumatic event. Thus, all respondents endorsing symptoms of PTSD on the ADIS interview necessarily indicated a precipitating traumatic event. Three of the 5 PTSD cases in the MVA-D group were reported to be related to the MVA being assessed. In contrast, none of the PTSD diagnoses in the MVA-ND group were reported to be related to the MVA event.

Accident severity. The ACCIDENTS, parent and child versions, were given to both MVA groups to assess for reported group differences in the severity of the MVAs. Additionally, parents in the Non-MVA group were asked to complete the first two questions of the ACCIDENTS questionnaire 
(AHow many MVAs has your child experienced?@and AHow much does your child currently fear riding in a car?@ thus yielding a total score for the Non-MVA group on the ACCIDENTS parent version. Table 7 presents mean scores and standard deviations for the ACCIDENTS total scores on both parent and child versions, and the parent report of the child s level of fear of riding in a car (question 2 on ACCIDENTS, parent version), number of accidents (question 1 on ACCIDENTS, parent version), and time in months between accident and assessment. ANOVA revealed that there were significant group differences in ACCIDENTS total score on both the child, $\underline{\mathrm{F}}(1,29)=4.72, \underline{\mathrm{p}}<.05$, and parent $\underline{F}(2,42)=43.67, \underline{p}<.01$, completed versions. The MVA-D group had higher total scores on the ACCIDENTS, child version, than the MVA-ND group, indicating a perception of greater accident severity and impact by the distressed children. Additionally, post hoc comparisons using LSD analyses indicated that, as would be expected, the Non-MVA group had significantly lower ACCIDENTS scores than both MVA groups on the parent version of the ACCIDENTS. The two MVA groups did not differ from one another on the ACCIDENTS, parent version, indicating that, as reported by parents, the MVAs experienced by these two groups were comparable in severity and impact.

ANOVA revealed that childrens mean rating of current fear while riding in a car for the two MVA groups differed significantly, $\underline{\mathrm{F}}(1,28)=5.16, \underline{\mathrm{p}}<.05$, with the MVA-D group reporting more fear. Parent report of this item also demonstrated group differences, $\underline{F}(2,42)=7.56, \underline{p}<.01$, with parents of the MVA-D children reporting more fear of riding in a car by their children than the parents of the Non-MVA and MVA-ND children. Additionally, there were no differences between the NonMVA and MVA-ND groups in the parent report of childrens fear. Finally, ANOVA did not reveal differences in the total number of accidents experienced, or the time between accident and assessment 
between the two MVA groups.

\section{$\underline{\text { Stroop Effect }}$}

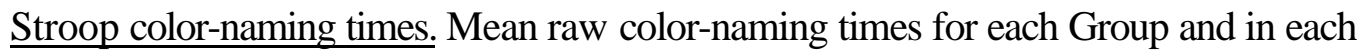

Word Type are presented in Table 8. ANOVA revealed no Group differences in time to name colored $\mathrm{XXXX}$ (i.e., overall color-naming time). In order to control for individual differences in overall colornaming speed, Stroop effect times used in subsequent analyses were obtained by subtracting the time to name colored XXXX f from the time to name each Word Type. Table 9 presents these corrected mean Stroop effect color-naming times for each Group and Word Type.

A 3 x 2 x 5 (Group x Reading Level x Word Type) repeated measures ANOVA (with the Huynh-Feldt correction for repeated measures) was conducted with Group and Reading Level as between-subject variables, and Word Type as a within-subject variable (note that Reading Level was examined in terms of Aow@and Ahigh@eaders--those reading below or at and above the fourth grade level--not absolute reading grade level). A significant main effect was found for Reading Level, $\underline{\mathrm{F}}(1,38)$ $=11.1, \mathrm{p}<.01$, and for Word Type, $\underline{\mathrm{F}}(4,152)=9.74,, \mathrm{p}<.001$. A significant interaction effect was also obtained for Word Type $x$ Reading Level, $\underline{F}(4,152)=3.62, \underline{p}<.01$. None of the analyses by Group were significant. Figures 1 and 2 depict the mean Stroop effect times by Group and Word Type for low and high readers, respectively. Upon visually examining the data, it became apparent that participants in both groups appeared to be experiencing an overall increase in color-naming time across the word types, and that low readers generally took twice as long to color-name as the high readers. This word effect was interpreted as a fatigue effect that needed to be controlled for to render subsequent analyses meaningful (although, it was apparent that the children in the MVA-D group who 
were high readers were taking longer to read MVA words than comparison words). To accomplish this, the above analysis was repeated using the color-naming times on the first and last sets of neutral words (the first and last sets of words that the participants were exposed to) as covariates (the difference score between the first and last set of neutral words was attempted, but did not result in a significant covariate, and was subsequently not used).

A 3 x 2 x 3 (Group x Reading Level x Word Type) repeated measures analysis of covariance (ANCOVA) was conducted using Group and Reading Level as between-subject variables, Word Type (School, Neutral 2, MVA) as a within-subject variable, Neutral 1 and 3 color-naming times as covariates, and the Huynh-Feldt correction for repeated measures. This analysis revealed a significant main effect for Word Type, $\underline{\mathrm{F}}(2,72)=5.48, \underline{\mathrm{p}}<.01$, and a Group x Reading Level $\mathrm{x}$ Word Type interaction, $\underline{F}(4,72)=3.22, \underline{p}<.05$. Both the Neutral 1, F $(1,36)=18.4, \underline{p}<.001$, and Neutral 3, $\underline{F}$ $(1,36)=45.4, \underline{p}<.001$, Stroop color-naming times were significant covariates. Table 10 presents the mean (adjusted for covariates) Stroop effect times by Group, Word Type and Reading Level. To explore the nature of the interaction and to determine how high and low readers differed by Word Type and Group, a separate ANCOVA was conducted for each Reading Level (there were 13 participants in the low reader group, and 32 participants in the high reader group).

Figures 3 and 4 depicts the mean (adjusted for covariates) Stroop effect times by Group and Word Type for low and high readers, respectively. For the low reading group, a 3 x 3 (Group x Word Type) repeated measures ANCOVA was conducted with Group as a between-subject variable, Word Type as a within-subject variable, Neutral 1 and 3 color-naming times as covariates, and the HuynhFeldt correction for repeated measures. This analysis revealed no main effects or interactions and no 
significant covariates. Thus, there were no effects for low readers on the Stroop task, as is visually evident in Figure 3.

For the high reading group, a 3 x 3 (Group x Word Type) repeated measures ANCOVA was conducted with Group as a between-subject variable, Word Type as a within-subject variable, Neutral 1 and 3 color naming times as covariates, and the Huynh-Feldt correction for repeated measures. This analysis revealed a main effect for Word Type, $\underline{\mathrm{F}}(1.84,49.56)=5.90, \underline{\mathrm{p}}<.01$, and a Group $\mathrm{x}$ Word Type interaction, $\underline{\mathrm{F}}(3.67,49.56)=2.87, \underline{\mathrm{p}}<.05$. Both the Neutral 1, $\underline{\mathrm{F}}(1,27)=26.5, \underline{\mathrm{p}}<.001$, and Neutral 3, $\underline{\mathrm{F}}(1,27)=104.2, \underline{\mathrm{p}}<.001$, Stroop color-naming times served as significant covariates. To explore the nature of the Participant Group x Word Type interaction, post hoc comparisons (LSD) were conducted. Results indicated that the MVA-D group differed significantly from the Non-MVA and MVA-ND groups on color-naming the MVA words, with the MVA-D group taking longer to color-name. There were no significant differences between the Non-MVA and MVA-ND groups on time to color-name MVA words. Additionally, the MVA-D group took significantly longer to colorname the MVA words than both the Neutral 2 and School words; and there were no differences between the color-naming times for these latter Word Types.

Color-naming times for the MVA-ND group were not different for the MVA and Neutral 2 words, but this group took significantly longer to name these latter Word Types than the School words. There were no differences in color-naming times between Word Types for the Non-MVA group.

It should be noted that the above analysis was completed with the factor Reading Level divided into Aow@and Anigh@eader levels because, for the purposes of the present study, the impact of Reading Level was most relevant in terms of whether the children were inexperienced or proficient 
readers (refer back to introduction for a review of the rationale for dividing Reading Level into low and high readers). However, it should be noted that an analysis was also completed using absolute reading grade-level as a covariate (instead of a factor). Unlike when the impact of Reading Level was explored in terms of high and low readers, this analysis did not result in significant differences between the groups, even when fatigue was also controlled.

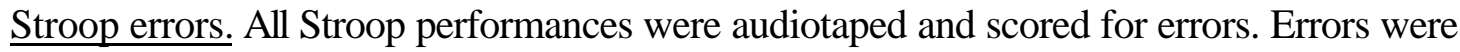
defined as: (a) saying a word instead of the color; (b) saying part of a word instead of the color (e.g., beginning to saying the word, but then correcting by naming the color); and (c) making any utterance other than the color (even when corrected, for example, Aumm...red@)

A total of 45 audiotapes were scored for errors. Twenty percent $(\underline{n}=9)$ of the tapes were scored by a second rater (either the present author, the principal investigator of the over-arching study, or a trained undergraduate assistant) for inter-rater agreement, with three tapes from each participant group randomly selected. Both Percent Total Agreement (for agreement in the scoring of all participant responses, correct or error) and Effective Percentage Agreement (recommended by Hartmann, 1977, for agreement in scoring errors only, when there is a low rate of occurrence) were obtained for each Word Type category. Table 11 presents the inter-rater agreement scores for these two types of interrater reliability measures. Mean Percentage Total Agreement scores were high, with $99.3 \%$ for NonMVA, $99.0 \%$ for MVA-ND, and 99.5\% for MVA-D groups. Effective Percentage Agreement was somewhat lower at 79.4\% for Non-MVA, 76.8\% for MVA-ND, and 89.8\% for MVA-D groups (overall agreement for the three groups was $82.1 \%$ ), but within acceptable bounds for this more conservative measure (Hartmann, 1977). 
Mean errors for each Group and each Word Type are presented in Table 12. A 3 x 2 x 5 (Group x Reading Level x Word Type) repeated measures ANOVA (with the Huynh-Feldt correction for repeated measures) was conducted with Group and Reading Level as between-subject variables, and Word Type as a within-subject. A significant main effect was found for Word Type, $\underline{\mathrm{F}}$ $(4,152)=3.92, \mathrm{p}<.01$. A significant interaction was also obtained for Word Type $\mathrm{x}$ Reading Level, $\underline{\mathrm{F}}(4,152)=2.75, \underline{\mathrm{p}}<.05$. Figure 5 depicts the mean error rates by Word Type for low and high readers. Upon visually inspecting the data, it became apparent that the source of the Word Type by Reading Level interaction may have been a practice effect in the low reading group. To explore the nature of the interaction, separate repeated measures ANOVA were conducted for High and Low reading levels. Low readers had an overall decrease in Stroop errors as evidenced by a main effect for Word Type, $\underline{\mathrm{F}}(4,36)=3.12, \underline{\mathrm{p}}<.05$. High readers were generally uniform in error rates across Word Type, with repeated measures ANOVA failing to reveal any main effects or interactions. This decrease in error rates for the low readers (from a mean of 3.5 errors on the first set of words to a mean of 2.0 errors on the last set of words) was interpreted as a practice effect that needed to be controlled to eliminate the possibility that a Group effect was obscured by the practice effect (as with the fatigue effect in the previous Stroop time analyses). To accomplish this, the above analysis was repeated using the number of errors on the first and last sets of Neutral words as covariates. A 3 x 2 x 3 (Group x Reading Level x Word Type) repeated measures ANCOVA was conducted using Group and Reading Level as between-subject variables, Word Type (School, Neutral 2, MVA) as a within-subject variable, number of errors on Neutral 1 and 3 words as covariates, and the Huynh-Feldt correction for repeated measures. This analysis revealed no main effects or interactions. Number of errors on the 
Neutral 1, $\underline{\mathrm{F}}(1,36)=20.8, \mathrm{p}<.001$, and Neutral 3, $\underline{\mathrm{F}}(1,36)=7.7, \mathrm{p}<.01$, Word Types served as significant covariates.

Association Between Stroop Effect and Psychometrics

Simple correlations were computed to test whether color-naming time on the MVA words (raw and corrected) was associated with report of psychopathology on the psychometric scales. Mean color-naming times were not significantly correlated with any of the psychometric scales, or with parent and child ACCIDENT total scores. See Table 13.

Correlations Among Psychometric Measures

Table 13 presents the Pearson correlation coefficients and significance levels. The CDI-Total and CBCL-Internalizing scales were not correlated with one another. Additionally, the ACCIDENTS$\mathrm{P}$ was not correlated with either the CDI or the RCMAS. All other measures were significantly correlated with one another.

Discussion

The clinical Stroop task has been shown to discriminate between distressed and non-distressed adult survivors of a range of traumatic events (e.g., Bryant \& Harvey, 1996; Cassiday et al., 1992; Kaspi et al., 1995). The present study investigated the ability of a clinical Stroop task to discriminate between distressed and non-distressed child survivors of MVAs, and children who have not experienced an MVA.

Summary of Major Hypotheses and Result

The Stroop effect hypotheses. The primary hypotheses of this study were: (a) MVA participants who were currently reporting symptoms of MVA-related distress would exhibit differential color-naming 
time for MVA-related words compared to other types of words, and (b) this effect would be more pronounced for these children than for comparison groups. Previous studies using a clinical Stroop task with trauma-survivors have exclusively studied adults. The present study aimed to investigate the effect and utility of the task with a child population.

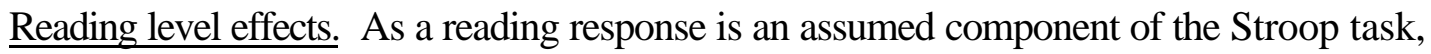
reading level needed to be taken into account during analyses of results. Studies with children using the original Stroop task suggest that children in the second and third grades exhibit longer response times than older children and adults. Presumably this occurs because the reading response has a history of being frequently reinforced (given its emphasis in school curriculum during these grades) but has not yet become Aver-learned,@o as to allow the children to effectively complete a simultaneous task. Thus, in the present clinical Stroop study, it was further hypothesized that the Alow readers@those reading at the second and third grade level) would generally take longer than Anigh readers@those reading at the fourth grade level or above) to color-name, irrespective of word type.

$\underline{\text { Results of primary analyses. Results of analyses did not initially support the above hypotheses. }}$ Main effects of Reading Level and Word Type were evident, as was an interaction between the two. Upon graphical analysis, it became evident that the main effect of Word Type may actually have been a fatigue effect. That is, there was a general increase in response time, regardless of participant group or reading level, as the task progressed. Thus, the initial analyses were repeated, with the first and last word groups (both neutral word types) used as covariates to control for fatigue.

Results of these analyses were consistent with the primary hypotheses: MVA participants who were distressed evidenced the Stroop effect for MVA-words, relative to comparison words and 
groups. These results did not seem to be related to group differences in accident severity, as there were no statistical differences in how parents in both MVA groups rated the accidents (however, while parent ratings--considered objective reports--of accident severity did not differ, subjective ratings did, with those children in the MVA-D group reporting having experienced more severe accidents). Interestingly, however, these results only occurred for the high readers. MVA-D participants who were low readers did not demonstrate significant differential responses to MVA-words, and did not differ from NonMVA participants on time taken to name MVA-words. Further, and consistent with hypotheses, low readers across all groups, evidenced nearly twice the color-naming times of high readers, regardless of word type.

Thus, the clinical Stroop task was found to discriminate between distressed and non-distressed MVA survivors who read at or above the fourth-grade level. These results replicate findings from similar studies with adult trauma populations, and support the use of this measure with a portion of the child trauma population, namely those reading at or above the fourth-grade level. These results, however, lend themselves to several questions: First, what may account for the differential response observed in the high reader, MVA-D group? Second, why was this effect not observed in the low readers? Because they were low readers? Third, why do the low readers take longer to color-name, overall? Fourth, how might the fatigue effect be addressed in future research? Each question will be now examined in turn.

\section{Conditioned Emotional Response Paradigm}

As discussed earlier, the clinical Stroop effect may be most parsimoniously understood as analogous to the phenomenon noted by Estes and Skinner (1941, as cited by Scotti, 1992) with their Conditioned Emotional Response paradigm. Recall that these researchers found that the random 
presentation of a tone that had previously been paired with shock was associated with a decreased rate of operant behavior in rats. It was assumed that the tone disrupted operant behavior because of its earlier pairing with shock. Scotti (1992) found similar behavioral disruptions in shadowing (upon the presentation of trauma-related stimuli) using a dichotic listening task with veterans. Generalizing these results to the present study, the Stroop color-naming task may be considered an operant behavior-children have histories of being reinforced for naming colors, as well as for following directions from adults. MVA-related words that have become associated, through stimulus equivalence, with a prior aversive, unconditioned stimulus (e.g., car accident) may become conditioned stimuli. Thus, the behavioral disruption noted by Estes and Skinner, and observed during the present and other clinical Stroop studies, may have occurred because conditioned stimuli (MVA words) resulted in conditioned responses (e.g., physiological responses), that in turn, disrupted the operant task of color-naming.

With this as a possible explanation, it is easy to understand why the Non-MVA participants did not evidence a Stroop effect, but it is less clear why the MVA-ND participants also did not evidence a Stroop effect. Perhaps for the MVA-ND children, MVA words never became conditioned stimuli, that is, never generalized to a class containing MVA-related stimuli, and thus were not followed by disruptive conditioned responses. Alternatively, conditioned responses may have initially occurred upon presentation of MVA-related stimuli, but already extinguished (e.g., with exposure by returning to carriding soon after the accident) by the time of assessment. One way that this might be assessed in future studies is by asking parents whether they Axposed@heir children to feared stimuli by encouraging them to ride in the car soon after the accident.

It should be noted that an alternative explanation for the differential Stroop effect found for the 
MVA words in the MVA-D high readers may be the phenomenon known as Apriming@e.g., Williams et al., 1996). Because the clinical Stroop task occurred after the psychophysiological assessment (during which the children were exposed to audiotaped vignettes describing MVAs), reductions in color-naming times might be the result of subject-content priming. However, this explanation seems unlikely as a body of research has suggested that the clinical Stroop effect may not occur when the task follows a related stressor (e.g., Amir et al., 1996; Mathews \& Sebastian, 1994).

\section{The Absence of Clinical Stroop Effect for Low Readers}

The next question becomes, AWhy was the Stroop effect not demonstrated in low readers?@ Any explanation for this finding must be considered with caution due to the relatively small number of participants in the low reader group. It may be, however, that for these participants the reading response is challenging enough to block a conditioned response to the presentation of MVA-words. That the task required considerable effort by these children was supported by the finding that all word groups were color-named in nearly twice the time that it took high readers to color-name. Several studies using the original Stroop paradigm obtained similar results, with low readers taking significantly longer than high readers to color-name (e.g., Horn \& Manis, 1987; Laberge \& Samuels, 1974). If this explanation is indeed the case, the clinical Stroop task may not be an appropriate measure of posttrauma response for children reading below the fourth-grade level. Further investigation is needed using a greater number of participants reading below the fourth-grade level to adequately explore these results.

The Problem of the Fatigue Effect

Another major finding was the apparent fatigue effect across all participant groups. The Stroop 
task, as it was administered in this study, may have been too long for children, despite the fact that it was already modified in length to be appropriate for children. Most studies using blocked presentation formats with adults present 100 words per block/screen. This study presented 50 words per block/screen. One solution may be to reduce the number of stimulus blocks/screens presented, perhaps by reducing the number of presentations of neutral control words. In the present study, though, each of the three neutral word groups served a particular function: (a) the first set of neutral words was used to reduce the potential of a practice effect (e.g., in case performance is facilitated by practice, it is prudent not to place stressor words at the beginning of the task, instead allowing practice to occur with the neutral words), and (b) the other sets of neutral words were presented after each stressor word type to reduce the potential confound of carryover. Thus, it may be more beneficial to reduce the number of word stimuli presented in each word block/screen. Alternatively, the order of Stroop stimuli may be randomized to control for fatigue, although quantifying fatigue (e.g., assigning numeric values to all possible presentation orders and using the numbers as covariates) with this methodology would require a larger sample size.

\section{Additional Hypotheses and Results}


be evidenced is differential errors made between Word Type and Groups. In the case of the present study, it was hypothesized that the MVA-D group would make more errors than the comparison groups and word types. The clinical Stroop literature has generally failed to find differential error effects with adults (e.g., Bryant \& Harvey, 1996; Cassiday et al., 1992; Dalgleish, 1995; Kaspi et al., 1995; Vrana et al., 1995). Additionally, in one of the few clinical Stroop studies with children, Kindt et al. (1997) 
also did not find error effects.

The results of the present study were similar to previous studies, in that the MVA participants did not make more errors while color-naming the MVA words than comparison words and groups. However, it appeared that the low readers, irrespective of Group, made less errors over time, while the high readers remained relatively constant in the amount of errors made over time. A purpose of the present study is to investigate the applicability of a clinical Stroop task with children. These results are therefore interesting because they suggest that low readers become better (in terms of errors) over time (i.e., with practice). Finally, the absence of group differences in errors suggests that the differences in color-naming times discussed above were not the result of differences in number of errors.

MVA-word color-naming times and psychometrics. Another question of the study was whether color-naming time for the MVA words would be correlated with psychometric measures of distress obtained via self-report. Results indicated that MVA-color-naming time was not correlated with any of the psychometric measures. This finding is not very surprising, as it has been documented that the three behavioral systems (verbal report, physiological response, and overt behavior) may be poorly correlated with each other (e.g., Bernstein, 1973; Hodgson \& Rachman, 1974). Thus, comprehensive assessment depends on the availability of additional objective types of measures (Cone, 1979), such as physiological and clinical Stroop assessment. The finding that color-naming time for the MVA words was not correlated with psychometric measures supports the recommendation discussed earlier (e.g., Drobes \& Lang, 1995) for utilizing multi-method assessment in research and clinical practice. $\underline{\text { Future Directions }}$

A primary purpose of the present study was to investigate the utility of the clinical Stroop task 
with children. The results of this study suggest that MVA-D participants who were low readers did not evidence a differential Stroop color-naming effect for word type, relative to comparison participants. This is an important issue, as it questions the appropriateness of the clinical Stroop task for a segment of children (and some adults, as well). It may be the case that clinical Stroop studies with adults and children should administer reading level screeners to ensure that participants reading below the fourthgrade level are not included. The study also suggests that these readers may become more accurate, in terms of errors, with practice. These results are limited, however, by the relatively small number of low reader participants included in the analyses. Future research should further investigate the impact of reading level with a greater number of participants.

A second area for future research, related to the utility of using a clinical Stroop task with children, pertains to the selection of words. In the present study, for reasons of availability, college undergraduates were used as raters of representativeness to category and emotional valence (i.e., distress). It appears that these words were satisfactory in both regards. However, an important next step in the use of this measure with children involves utilizing words that have been similarly rated by children. This would provide better validation of the words, and support for their use in future studies and clinical contexts, such as community mental health centers. Additionally, the experimental stressor words used in future studies of child MVA-survivors might be used as comparison (i.e., control) stressor words in Stroop studies with other child populations (e.g., other trauma or clinically diagnosed populations). Finally, it may be useful to investigate the utilization of words that are individualized to each child participant. For example, Segal, Truchon, Horowitz, Gemar, and Guirguis (1995) utilized Stroop words with depressed adults that had been selected by the participants as self-descriptive. Similarly, 
Stroop words relating to the child fown MVA might be obtained from interview or psychometric assessment. However, a special challenge for utilizing ideographic assessment with children would be ensuring that the words were appropriate (i.e., Areadable@for the child sreading level.

A third area for future research involves further investigation of the appropriate length of this task for children. The results of the present study suggest that fatigue occurred, as evidenced by the lack of a Stroop effect unless fatigue was statistically controlled. These results seem to indicate that the task was too long for the children. Fatigue has not been extensively examined in previous studies. Using a word type presentation order similar to the present study, other researchers have noted the possibility of fatigue effects in their outcomes (e.g., Kaspi et al., 1995; McNally et al., 1990), but many previous studies have used a counterbalanced presentation order to remove fatigue effects from their results (e.g., Bryant \& Harvey, 1995; Cassiday et al., 1992; McNeil et al., 1995), making direct examination of fatigue effects unnecessary. While using a counterbalanced presentation order may prevent fatigue from influencing interpretation of the Stroop effect, it does not prevent fatigue from occurring. Assessing the developmental appropriateness of the task with respect to length is difficult if fatigue is not directly assessed. Studies addressing the best method of capturing the Stroop effect while being developmentally appropriate for children are warranted. For example, it may be useful to investigate the outcome of random versus fixed Stroop presentation formats. The outcome of such research might also prove useful for clinical Stroop studies with adults.

A fourth area for further investigation involves looking more closely at the theory proposed for understanding the clinical Stroop effect. Recall that, in accordance with Estes and Skinner₹Conditioned Emotional Response (CER) paradigm, it has been proposed that MVA-words become conditioned 
stimuli through the process of stimulus equivalence, and that it is the disruptive conditioned response that might account for decrements in color-naming times found in the MVA-D group. An important step in obtaining support for this theory involves closer scrutiny of the possible conditioned responses. For example, it would be beneficial to take psychophysiological measures during completion of the clinical Stroop task (it should be noted that these measures were completed for the larger study of which the present investigation is a part of, but were not analyzed here). Scotti (1992) measured physiological reactivity during completion of a dichotic listening task with veterans. He found that the veterans with PTSD evidenced increased shadowing errors and skin conductance responses to combat-related words, relative to comparison words and groups. This supports the theory that these participants were experiencing conditioned responses to the combat-words that may have been interfering with the shadowing task. Similarly, differential physiological activity during Stroop color-naming the MVA words would also seem to support the theory.

An additional step for supporting the use of the CER paradigm as an explanation for the Stroop effect would be to further study the MVA-ND children. As noted earlier, one reason that these children did not evidence the Stroop effect may be that conditioned responses to MVA-related conditioned stimuli extinguished prior to participation in the present study. Future research might include interviews with parents to identify whether these children exhibited initial fear responses in the presence of MVArelated stimuli (e.g., cars), if the children were exposed to the stimuli with some degree of regularity, and whether the fear responses seemed to abate.

Finally, investigators studying a child population may need to carefully consider methods for participant recruitment. Obtaining appropriate numbers of participants for the present study proved to 
be a considerable challenge, taking approximately three years. It may be possible that parents are reluctant to expose their children to a situation that will recall an unpleasant event. Thus, the development of informative, non-threatening methods of participant recruitment may prove beneficial to future investigators working with children.

To conclude, the present study is one of the first to investigate the utility of a clinical Stroop task with children, and the first to extend the task to child MVA survivors. This investigation yielded results consistent with prior studies with adult trauma populations. It demonstrated that distressed, child survivors of MVAs who read at or above the fourth-grade level exhibit differential decrements in colornaming time for MVA-related words, relative to comparison words and participant groups. These results indicate that the measure may be useful for discriminating between distressed and non-distressed survivors. Interestingly, however, this effect was not observed for children reading below the fourthgrade level. Although research is needed to further understand the applicability of this measure with children, preliminary results support its use. 
References

Achenbach, T. M. (1991). Manual for the Child Behavior Checklist/4-18. Burlington, VT: University of Vermont, Department of Psychiatry.

American Optical Company. (1940). Pseudo-isochromatic plates for testing color perception (revised selection). New York: Beck Engraving Co.

American Psychiatric Association. (1980). Diagnostic and statistical manual of mental disorders (3rd ed.). Washington, DC: Author.

American Psychiatric Association. (1987). Diagnosis and statistical manual of mental disorders

(3rd ed., rev.). Washington, DC: Author.

American Psychiatric Association. (1994). Diagnostic and statistical manual of mental disorders (4th ed.). Washington, DC: Author.

Amir, N., McNally, R. J., Riemann, B. C., Burns, J., Lorenz, M., \& Mullen, J. T. (1996). Suppression of the emotional Stroop effect by increased anxiety in patients with social phobia. Behaviour Research and Therapy, 34, 945-948.

Barnes, D., \& Keenan, M. (1993). A transfer of functions through derived arbitrary and nonarbitrary stimulus relations. Journal of Experimental Analysis of Behavior, 59, 61-81.

Baum, A., Solomon, S. D., \& Ursano, R. J. (1993). Emergency/disaster studies. In J. P. Wilson \& B. Raphael (Eds.), International handbook of traumatic stress syndromes (pp. 125-133). New York: Plenum.

Bernstein, D. A. (1973). Situational factors in behavioral fear assessment: A progress report. Behavior Therapy, 4, 41-48. 
Blanchard, E. B., Hickling, E. J., Taylor, A. E., Loos, W. R., \& Gerardi, R. J. (1994a). Psychological morbidity associated with motor vehicle accidents. Behaviour Research and Therapy, 32, 283-289.

Blanchard, E. B., Hickling, E. J., Taylor, A. E., Loos, W. R., \& Gerardi, R. J. (1994b). The psychophysiology of motor vehicle accident related posttraumatic stress disorder. Behavior Therapy, 25, 453-467.

Blanchard, E. B., Hickling, E. J., Vollmer, \& A. E., Loos, W. R., Buckley, T. C., \& Jaccard, J. (1995). Short-term follow-up of posttraumatic stress symptoms in motor vehicle accident victims. Behaviour Research and Therapy, 33, 369-377.

Blanchard, E. B., Kolb, L. C., Gerardi, R. J., Ryan, T. P., \& Pallmeyer, T. P. (1986). Cardiac response to relevant stimuli as an adjunction tool for diagnosing posttraumatic stress disorder in Vietnam veterans. Behavior Therapy, 17, 592-606.

Blanchard, E. B., Steffek, B. D., Jaccard, J., \& Nicholson, N. L. (1991). Psychological changes accompanying non-pharmacological treatment of chronic headache: The effects of outcome. Headache, 31, 249-253.

Bryant, R. A., \& Harvey, A. G. (1995). Avoidant coping style and post-traumatic stress following motor vehicle accidents. Behaviour Research and Therapy, 33, 631-635.

Bryant, R. A., \& Harvey, A. G. (1996). Initial posttraumatic stress responses following motor vehicle accidents. Journal of Traumatic Stress, 9, 223-235.

Cassiday, K. L., McNally, R. J., \& Zeitlin, S. B. (1992). Cognitive processing of trauma cues in rape victims with post-traumatic stress disorder. Cognitive Therapy and Research, 16, 283-295. 
Catania, A. C., Horne, P., \& Lowe, C. F. (1989). Transfer of function across members of an equivalence class. Analysis of Verbal Behavior, 7, 99-110.

Cohen, J. D., Dunbar, K., \& McClelland, J. L. (1990). On the control of automatic processes: A parallel distributed processing account of the Stroop effect. Psychological Review, 97, 332361.

Cone, J. D. (1978). The Behavioral Assessment Grid (BAG): A conceptual framework and a taxonomy. Behavior Therapy, 9, 882-888.

Cone, J. D. (1979). Confounded comparisons in triple response mode assessment research. Behavioral Assessment, 1, 85-95.

Curry, J. F., \& Craighead, W. E. (1993). Depression. In T. H. Ollendick \& M. Hersen (Eds.), Handbook of child and adolescent assessment (pp. 251-268). Boston: Allyn \& Bacon.

Dalgleish, T. (1995). Performance on the emotional Stroop task in groups of anxious, expert, and control subjects: A comparison of computer and card presentation formats. $\underline{\text { Cognition and }}$ Emotion, 9, 341-362.

Donahoe, J. W., \& Palmer, D. C. (1994). Learning and complex behavior. Boston: Allyn \& Bacon. Drobes, D. J., \& Lang, P. J. (1995). Bioinformational theory and behavior therapy. In W. O. Donohue \& L. Krasner (Eds.), Theories of behavior therapy: Exploring behavior change (pp. 229-258). Washington DC: American Psychological Association. 
Dunbar, K., \& Macleod, C. (1984). A horse race of a different color: Stroop interference patterns with transformed words. Journal of Experimental Psychology: Human Perception and Performance, $\underline{10,} 622-639$.

Eth, S., \& Pynoos, R. S. (1985). Developmental perspectives on psychic trauma in children. In C. Figley (Ed.), Trauma and its wake: The study and treatment of post-traumatic stress disorder (pp.36-52). New York: Brunner/Mazel.

Evans, I. M. (1986). Response structure and the triple response mode concept in behavioral assessment. In R. O. Nelson \& S. C. Hayes (Eds.), Conceptual foundations of behavioral assessment (pp. 131-155). New York: Guildford.

Foa, E. B., Feske, U., Murdock, T. B., Kozak, M. J., \& McCarthy, P. R. (1991). Processing of threat-related information in rape-victims. Journal of Abnormal Psychology, 100, 156-162.

Foa, E. B., Ilai, D., McCarthy, P. R., Shoyer, B., \& Murdock, T. (1993). Information processing of threat-related information in rape-victims. Journal of Abnormal Psychology, 100, 156-162.

Foa, E. B., \& Kozak, M. J. (1986). Emotional processing of fear: Exposure to corrective information. Psychological Bulletin, 99, 20-35.

Foa, E. B., Steketee, G., \& Rothbaum, B. O. (1989). Behavioral/cognitive conceptualizations of posttraumatic stress disorder. Behavior Therapy, 20, 155-173.

Fraisse, P. (1969). Why is naming longer than reading? Acta Psychologica, 30, 96-103.

Francis, W. N., \& Kucera, H. (1982). Frequency analysis of English usage. Lexicon and grammar. Boston: Houghton \& Mifflin.

Glass, A. J. (1954). Psychotherapy in the combat zone. American Journal of Psychiatry, 110, 725-731. 
Goenjian, A. K., Pynoos, R. S., Steinberg, A. M., \& Najarian, L. M. (1995). Psychiatric comorbidity in children after the 1988 earthquake in Armenia. Journal of the American Academy of Child and Adolescent Psychiatry, 34, 1174-1184.

Green, M., \& McKenna, F. P. (1993). Developmental onset of eating related color-naming interference. International Journal of Eating Disorders, 13, 391-397.

Hardy, L. H., Rand, G., \& Rittler, M. C. (1946). A screening test for defective red-green vision. Journal of the Optical Society of America, 36, 610-614.

Harris, A. J., \& Jacobson, M. D. (1982). Basic reading vocabularies. New York: Macmillan.

Hartmann, D. P. (1977). Considerations in the choice of interobserver reliability estimates. Journal of Applied Behavior Analysis, 10, 103-116.

Helzer, J. E., Robins, L. N., \& McEvoy, L. (1987). Post-traumatic stress disorder in the general population: Findings of the Epidemiologic Catchment Area Survey. New England Journal of Medicine, 317, 1630-1634.

Himle, J. A., Crystal, D., Curtis, G. C., \& Fluent, T. E. (1991). Mode of onset of simple phobia subtypes: Further evidence of heterogeneity. Psychiatry Research, 36, 37-43.

Hodgson, R., \& Rachman, S. (1974). Desynchrony in measures of fear. Behaviour Research and Therapy, 12, 319-326.

Hopkins, O., \& King, N. (1994). Posttraumatic stress disorder in children and adolescents. Behavior Change, 11, 110-120. 
Horn, C. C., \& Manis, F. (1987). Development of automatic and speeded reading of printed words. Journal of Experimental Child Psychology, 44, 92-108.

Horowitz, M. J., Wilner, N., \& Alvarez, W. (1979). Impact of Event Scale: A measure of subjective distress. Psychosomatic Medicine, 41, 209-218.

Hubbard, J., Realmuto, M., Northwood, A., \& Masten, A. (1995). Comorbidity of psychiatric diagnoses with posttraumatic stress disorder in survivors of childhood trauma. Journal of the American Academy of Child and Adolescent Psychiatry, 34, 1167-1173.

Jastak, S., \& Wilkinson, G. S. (1984). Wide Range Achievement Test-Revised. Wilmington, DE: Jastak Associates.

Jones, R. W., \& Peterson, L. W. (1993). Posttraumatic stress disorder in a child following an automobile accident. Journal of Family Practice, 36, 223-225.

Kaspi, S. P., McNally, R. J., \& Amir, N. (1995). Cognitive processing of emotional information in posttraumatic stress disorder. Cognitive Therapy and Research, 19, 433-445.

Kazdin, A. E. (1987). Assessment of childhood depression: Current issues and strategies. Behavioral Assessment, 9, 291-312.

Kindt, M., Brosschot, J. F., \& Everaerd, W. (1997). Cognitive processing biases of children in a real life stress condition and a neutral situation. Journal of Experimental Child Psychology, 64, 7997.

Kinzie, J. D., Sack, W. H., Angell, R. H., Manson, R., \& Rath, B. (1986). The psychiatric effects of massive trauma on Cambodian children: I. The children. Journal of the American Academy of Child Psychiatry, 25, 370-376. 
Kovacs, M. (1985). The Children=s Depression Inventory (CDI). Psychopharmacological Bulletin, 21, 995-998.

Kozak, M., Foa, E., \& Steketee, G. (1988). Process and outcome of exposure treatment with obsessive-compulsives: Psychophysiological indicators of emotional processing. $\underline{\text { Behavior }}$ Therapy, 19, 157-169.

Laberge, D., \& Samuels, S. J. (1974). Toward a theory of automatic information processing in reading. Cognitive Psychology, 6, 293-323.

Lang, P. J. (1968). Fear reduction and fear behavior: Problems in treating a construct. In J. M. Shlien (Ed.), Research in psychotherapy (Vol. 3, pp. 90-103). Washington, DC: American Psychological Association.

Lang, P. J. (1977). Imagery in therapy: An information processing analysis. Behavior Therapy, 8, 862886.

Lang, P. J. (1979). A bioinformational theory of emotional imagery. Psychophysiology, 16, 495-512.

Lang, P. J., Levin, D. N., Miller, G. A., \& Kozak, M. J. (1983). Fear behavior, fear imagery, and the psychophysiology of emotion: The problem of affective response integration. Journal of Abnormal Psychology, 92, 296-306.

Litz, B. T., \& Keane, T. M. (1989). Information processing in anxiety disorders: Application to the understanding of posttraumatic stress disorder. Clinical Psychology Review, 9, 243-257.

Malloy, P. F., Fairbank, J. A., \& Keane, T. M. (1983). Validation of a multimethod assessment of posttraumatic stress disorders in Vietnam veterans. Journal of Consulting and Clinical Psychology, 51, 488-494. 
Malmquist, C. P. (1986). Children who witness parental murder: Posttraumatic aspects. Journal of the American Academy of Child and Adolescent Psychiatry, 25, 320-325.

Martin, M., \& Horder, P., \& Jones, G. V. (1992). Integral bias in naming of phobia related words. Cognition and Emotion, 6, 479-486.

Mathews, A., \& MacLeod, C. (1985). Selective processing of threat cues in anxiety states. Behaviour Research and Therapy, 23, 563-569.

Mathews, A., \& Sebastian, S. (1994). Supression of emotional Stroop effects by fear-arousal. Cognition and Emotion, 7, 517-530.

Mayou, R., Bryant, B., \& Duthie, R. (1993). Psychiatric consequences of road traffic accidents. British Medical Journal, 307, 647-651.

McNally, R. J., Kaspi, S. P., Riemann, B. C., \& Zeitlin, S. B. (1990). Selective processing of threat cues in posttraumatic stress disorder. Journal of Abnormal Psychology, 99, 398-402.

McNally, R. J., Luedke, D. L., Besyner, J. K., Peterson, R. A., Bohm, K., \& Lips, O. J. (1987). Sensitivity to stress-relevant stimuli in posttraumatic stress disorder. Journal of Anxiety Disorders, 1, 105-116.

McNeil, D. W., Ries, B. J., Taylor, L., Boone, M. L., Carter, L. E., Turk, C., \& Lewin, M. R. (1995). Comparison of social phobia subtypes using Stroop tests. Journal of Anxiety Disorders, 9, 4757.

Methany, A. P. (1988). Accidental injuries. In D. K. Routh (Ed.), Handbook of pediatric psychology (pp. 108-134). New York: Guilford. 
Mghir, R., Freed, W., Raskin, A., \& Katon, W. (1995). Depression and posttraumatic stress disorder among a community sample of adolescent and young adult Afghan refugees. Journal of Nervous and Mental Disease, 183, 24-30.

Milgram, N. A., Toubiana, Y. H., Klingman, A., Raviv, A., \& Goldstein, I. (1988). Situational exposure and personal loss in children's acute and chronic stress reactions to a school bus disaster. Journal of Traumatic Stress, 1, 339-352.

Norris, F. H. (1992). Epidemiology of trauma: Frequency and impact of different potentially traumatic events on different demographic groups. Journal of Clinical and Counseling Psychology, 60, 409-418.

Posner, M. I. (1978). Chronometric explorations of mind. Hillsdale, NJ: Erlbaum.

Psychological Corporation. (1992). The Wechsler Individual Achievement Test, Manual. San Antonio, TX: Author.

Reynolds, C. R. (1980). Concurrent validity of What I Think and Feel: The Revised Children's Manifest Anxiety Scale. Journal of Consulting and Clinical Psychology, 48, 774-775.

Reynolds, C. R., \& Richman, B. O. (1978). What I think and feel: A revised measure of children's manifest anxiety. Journal of Abnormal Child Psychology, 6, 271-280.

Rode, C. A. (1997). Psychological reactions of children following exposure to motor vehicle accidents. (Doctoral dissertation, West Virginia University, 1997). Dissertation Abstracts International, 58/05, 2697. (University Microfilms No. DA 9734403)

Schadler, M., \& Thissen, D. M. (1981). The development of automatic word recognition and reading skill. Memory and Cognition, 9, 132-141. 
Schwarz, E. D., \& Kowalski, J. M. (1991). Posttraumatic stress disorder after a school shooting: Effects of symptom threshold selection and diagnosis by DSM-III, DSM-III-R, or proposed DSM-IV. American Journal of Psychiatry, 148, 592-597.

Schwarzwald, J., Solomon, Z., Weisenberg, M., \& Mikulincer, M. (1987). Validation of the Impact of Event Scale for psychological sequelae of combat. Journal of Consulting and Clinical Psychology, 55, 251-256.

Scotti, J. R. (1992). An analysis of several parameters of conditioned fear in combat-related posttraumatic stress disorder: Serial cues, contexts, conditioning trials, and avoidance behaviors. (Doctoral dissertation, State University of New York at Binghamton, 1992). Dissertation

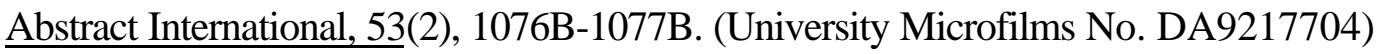

Scotti, J. R., Beach, B. K., Northrup, L. M. E., Rode, C. A., \& Forsyth, J. P. (1995). The psychological impact of accidental injury: A conceptual model for clinicians and researchers. In J. R. Freedy \& S. E. Hobfoll (Eds.), Traumatic stress: From theory to practice (pp. 181-212). New York: Plenum.

Scotti, J. R., Wilhelm, K. L., Northrup, L. M. E., Price, G., Vittemberga, G. L., Ridley, J., Cornell, K., Stukey, G. S., Beach, B. K., Mickey, G. H., \& Forsyth, J. P. (1992, November). An investigation of posttraumatic stress disorder in vehicular accident survivors. Paper presented at the $26^{\text {th }}$ annual meeting of the Association for Advancement of Behavior Therapy, Boston.

Segal, Z .V., Truchon, C., Horowitz, L. M., Gemar, M., \& Guirguis, M. (1995). A priming methodology for studying self-representation in major depressive disorder. Journal of Abnormal Psychology, 104, 205-213. 
Silverman, W. K., \& Nelles, W. B. (1988). The Anxiety Disorders Interview Schedule for Children. Journal of the American Academy of Child and Adolescent Psychiatry, 27, 772-778.

Spielberger, C. D., Gorsuch, R. C., \& Lushene, R. E. (1970). Manual for the State-Trait Anxiety Inventory. Palo Alto, CA: Consulting Psychologist Press.

Stanovich, K. E., Cunningham, A. E., \& West, R. F. (1981). A longitudinal study of the development of automatic recognition skills in first graders. Journal of Reading Behavior, 13, 57-74.

Stroop, J. R. (1935). Studies of interference in serial verbal reactions. Journal of Experimental Psychology, 18, 643-661.

Taylor, S., \& Koch, W. (1995). Anxiety disorders due to motor vehicle accidents: Nature and treatment. Clinical Psychology Review, 15, 721-738.

Teasdale, G., \& Jennett, B. (1974). Assessment of coma and impaired consciousness. Lancet, ii, $81-84$

Terr, L. C. (1983). Chowchilla revisited: The effects of psychic trauma four years after a school-bus kidnaping. American Journal of Psychiatry, 140, 1543-1550.

Treisman, A., \& Geffen, G. (1967). Selective attention: Perception or response? Quarterly Journal of Experimental Psychology, 19, 1-16.

Tuckman, A. J. (1973). Disasters and mental health intervention. Community Mental Health Journal, 9 , $151-157$.

Vogel, J. M., \& Vernberg, E. M. (1993). Part 1: Children's psychological responses to disaster. Journal of Clinical Child Psychology, 4, 464-484. 
Vrana, S. R., Roodman, A., \& Beckham, J. C. (1995). Selective processing of trauma-relevant words in posttraumatic stress disorder. Journal of Anxiety Disorders, 9, 515-530.

Wechsler, D. (1992). Wechsler Individual Achievement Test. San Antonio, TX: Psychological Corporation.

Williams, J. M. G., Mathews, A., \& MacLeod, C. (1996). The emotional Stroop task and psychopathology. Psychological Bulletin, 120, 3-24.

Woodcock, R. W., \& Johnson, M. B. (1989). Woodcock-Johnson Psycho-Educational Battery-Revised, Tests of Achievement. Allen, TX: DLM Teaching Resources.

Yule, W., \& Udwin, O. (1991). Screening child survivors for posttraumatic stress disorders: Experiences from the Jupiter sinking. British Journal of Clinical Psychology, 30, $131-138$

Yule, W., \& Williams, R. M. (1990). Post-traumatic stress reactions in children. Journal of Traumatic Stress, 3, 279-295. 


\section{Table 1}

\section{DSM-IV Diagnostic Criteria for Post-traumatic Stress Disorder}

A. experienced, witnessed, or was confronted with an event that involved actual or threatened death or serious injury, or a threat to the physical integrity of self or others. Response involved intense fear, helplessness, or horror. Note: In children, this may be expressed instead by disorganized or agitated behavior.

B. Event is persistently reexperienced in one or more of the following ways:

1. recurrent and intrusive distressing recollections. Note: In young children, repetitive play may occur in which themes or aspects of the trauma are expressed.

2. recurrent distressing dreams of the event. Note: In children, there may be frightening dreams without recognizable content.

3. acting or feeling as if the traumatic event were recurring. Note: In young children, traumaspecific reenactment may occur.

4. distress at exposure to internal or external cues that symbolize or resemble an aspect of the traumatic event.

5. physiological reactivity on exposure to internal or external cues that symbolize or resemble an aspect of the traumatic event.

(table continues) 
Table 1 (continued)

C. Avoidance of stimuli associated with the trauma and numbing of general responsiveness, as indicated by at least three of the following:

1. efforts to avoid thoughts, feelings, or conversations associated with the trauma.

2. efforts to avoid activities, places, or people that arouse recollections of the trauma.

3. inability to recall aspects of the trauma.

4. diminished interest or participation in significant activities.

5. feeling of detachment from others.

6. restricted range of affect.

7. sense of forshortened future.

D. Persistent symptoms of increased arousal:

1. difficulty falling or staying asleep.

2. irritability or outbursts of anger.

3. difficulty concentrating.

4. hypervigilance.

5. exaggerated startle response.

E. Duration of the disturbance is more than one month

F. Clinically significant distress or impairment in social, and/or occupational functioning

Note. Adapted from APA (1994). 
Table 2

Stroop Words by Word Type

\begin{tabular}{lllll}
\hline Neutral 1 & School & Neutral 2 & MVA & Neutral 3 \\
OVEN & QUESTION & FLOOR & ROAD & KITCHEN \\
EGG & BULLY & SHOE & CRASH & TELEPHONE \\
LADDER & SMARTER & BAG & ACCIDENT & BASEMENT \\
WINDOW & WRONG & NEWSPAPER & SEATBELT & BED \\
DOORBELL & TEST & POTATO & CAR & ROOF \\
& & & & \\
\hline
\end{tabular}


Table 3

Participant Characteristics by Group

Group

Characteristics

Non-MVA

MVA-ND

MVA-D

Gender

Girls

$73 \%(\underline{\mathrm{n}}=11)$

$40 \%(\underline{n}=6)$

$47 \%(\underline{n}=7)$

Race

Caucasian

$100 \%$

$93 \%(\underline{n}=44)$

$100 \%$

African American

0

$7 \%(\underline{\mathrm{n}}=1)$

0

Age

$10.9(2.1)$

$11.4(2.6)$

$9.6(2.8)$

Grade

$5.6(2.4)$

$6.0(2.6)$

$4.1(2.6)$

Reading level

$6.4(3.5)$

$6.7(3.1)$

$5.6(3.5)$

Reading below $4^{\text {th }}$ grade

$20 \%(\underline{\mathrm{n}}=3)$

$27 \%(\underline{\mathrm{n}}=4)$

$40 \%(\underline{n}=6)$

Yearly family income
Low (0 - \$29000)
$53 \%(\underline{\mathrm{n}}=8)$
$27 \%(\underline{n}=4)$
$33 \%(\underline{n}=5)$
Med (\$30000 - \$59000)
$40 \%(\underline{\mathrm{n}}=6)$
$40 \%(\underline{n}=6)$
$40 \%(\underline{n}=6)$
High (\$60000 and greater)
$7 \%(\underline{\mathrm{n}}=1)$
$33 \%(\underline{\mathrm{n}}=5)$
$27 \%(\underline{\mathrm{n}}=4)$

(table continues) 
Table 3 (continued)

\section{Group}

Characteristics

Non-MVA

MVA-ND

MVA-D

Parent participating in study

Mother

$80 \%(\underline{\mathrm{n}}=12)$

$80 \%(\underline{\mathrm{n}}=12)$

$80 \%(\underline{\mathrm{n}}=12)$

Father

$20 \%(\underline{n}=3)$

$20 \%(\mathrm{n}=3)$

$7 \%(\mathrm{n}=1)$

Grandparent

0

0

$13 \%(\underline{\mathrm{n}}=2)$

Parent education

Less than college degree

$53 \%(\underline{\mathrm{n}}=8)$

$68 \%(\underline{\mathrm{n}}=10)$

$68 \%(\underline{\mathrm{n}}=10)$

College degree or

Advanced degree

$47 \%(\underline{\mathrm{n}}=7)$

$33 \%(\underline{\mathrm{n}}=5)$

$33 \%(\underline{\mathrm{n}}=5)$

Parent employment

Employed

$80 \%(\underline{\mathrm{n}}=12)$

$67 \%(\underline{\mathrm{n}}=10)$

$100 \%(\underline{n}=15)$

Marital status

Single

$27 \%(\underline{\mathrm{n}}=4)$

$47 \%(\underline{\mathrm{n}}=9)$

$13 \%(\underline{n}=2)$

Married

$60 \%(\underline{\mathrm{n}}=9)$

$27 \%(\underline{\mathrm{n}}=4)$

$73 \%(\underline{\mathrm{n}}=11)$

Separated

$7 \%(\underline{\mathrm{n}}=2)$

$20 \%(\underline{\mathrm{n}}=2)$

$7 \%(\underline{\mathrm{n}}=2)$

Note. MVA-ND = MVA Non-Distressed, MVA-D = MVA-Distressed. Standard Deviations given in parentheses. Analyses failed to reveal any significant between group differences. 
Table 4

Mean Scores on Psychometric Measures by Group

\begin{tabular}{|c|c|c|c|}
\hline \multirow[b]{2}{*}{ Measure } & \multicolumn{3}{|c|}{ Group Means } \\
\hline & Non-MVA & MVA-ND & MVA-D \\
\hline CBCL total scale $\mathrm{b}^{\mathrm{b}, \mathrm{c}}$ & $42.3(10.6)$ & $46.2(9.4)$ & $56.3 \quad(9.9)$ \\
\hline CBCL externalizing scale $e^{b, c}$ & $42.5 \quad(9.0)$ & $45.6(7.9)$ & $53.3 \quad(8.9)$ \\
\hline CBCL internalizing scale $\mathrm{b}^{\mathrm{b}, \mathrm{c}}$ & 42.9 (9.9) & $50.3(10.7)$ & $59.3(10.2)$ \\
\hline CDI total ${ }^{\mathrm{a}, \mathrm{c}}$ & $6.5(5.1)$ & $2.3(2.5)$ & $9.0 \quad(6.8)$ \\
\hline IES total ${ }^{\mathrm{b}, \mathrm{c}}$ & 2.8 (4.9) & $2.6 \quad(2.2)$ & $29.4(12.9)$ \\
\hline IES avoidance scale ${ }^{b, c}$ & $3.3(4.4)$ & 1.7 (1.9) & $16.0(7.3)$ \\
\hline IES intrusion scale ${ }^{b, c}$ & $2.8(4.9)$ & $0.9 \quad(0.9)$ & 13.4 (7.6) \\
\hline RCMAS total $^{\mathrm{b}, \mathrm{c}}$ & $8.1(6.2)$ & $3.6 \quad(2.5)$ & $13.3(7.4)$ \\
\hline \multicolumn{4}{|c|}{ Note. MVA-ND = MVA Non-Distressed, MVA-D = MVA-Distressed. Standard Deviations given in } \\
\hline \multicolumn{4}{|c|}{ parentheses. Analysis of differences between groups: ${ }^{\text {a }}$ significant between Non-MVA and MVA-ND } \\
\hline \multicolumn{4}{|c|}{ groups; ${ }^{\mathrm{b}}$ significant between Non-MVA and MVA-D groups; ${ }^{\mathrm{c}}$ significant between MVA-ND and } \\
\hline
\end{tabular}


Table 5

$\underline{\text { Percentage of Children Exceeding Clinical Cut-off (T-score \$60) }}$

Group

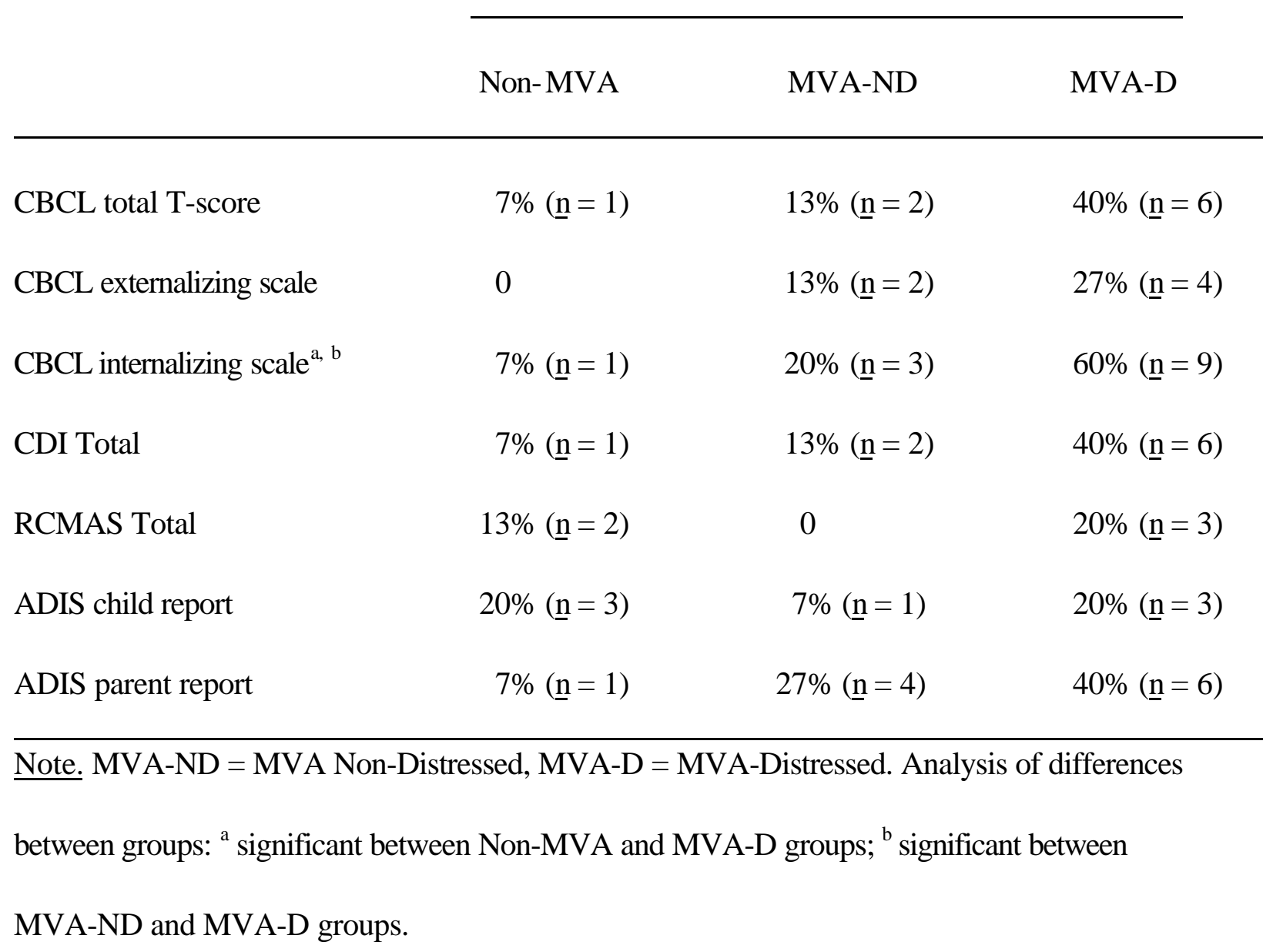


Table 6

ADIS Diagnoses and Number of Cases by Group

Diagnoses

ADHD

Social phobia

Simple phobia

Depression

PTSD

Obsessive compulsive disorder

Generalized anxiety disorder

Sleep terror
Non-MVA

1

2

0

0

0

0

1

0
MVA-ND

MVA-D

0

0

4

1

5

1

1

1

Note. Some participants received diagnoses of more than one disorder. Numbers reflect diagnoses received on both ADIS-P and ADIS-C. In the case of the MVA participants, these diagnoses may have been present prior to the MVA or be unrelated to the MVA. The exception is the PTSD diagnosis, which requires specification of the related traumatic event. None of the cases in the MVAND group were reported to be related to the MVA, while 3 of the 5 cases in the MVA-D group were reported to be MVA-related. 
Table 7

Mean Scores on ACCIDENTS and Accident Demographic Questions by Group

Group Means

\begin{tabular}{ll}
\hline Non-MVA & MVA-ND \\
\end{tabular}

ACCIDENTS total score
Child version $^{\mathrm{c}}$
$\mathrm{n} / \mathrm{a}$
$10.8(4.5)$
$14.7(5.2)$
Parent version ${ }^{\mathrm{a}, \mathrm{b}}$
$0.07(.3)$
$17.1(8.3)$
$20.5(7.3)$

Child fear of riding in car

(question 2 on ACCIDENTS*)
Child version $^{\mathrm{c}}$
$\mathrm{n} / \mathrm{a}$
$0.3(.6)$
$0.9(.8)$
Parent version ${ }^{\mathrm{b}, \mathrm{c}}$
$0.07(.3)$
$0.3(.5)$
$0.9(.8)$
Number of accidents ${ }^{\mathrm{d}}$
0
$1.5(.9)$
$1.7(.9)$

Time between accident ${ }^{\mathrm{d}}$

and assessment (months)

$\mathrm{n} / \mathrm{a}$

$7.9(10.1)$

$6.1(4.9)$

Note. MVA-ND = MVA Non-Distressed, MVA-D = MVA-Distressed. Standard Deviations given in parentheses. * Means for question 2 are based on the possible responses of $0=$ Anot at all,@ 1 = Al little,@Q = Ad lot,@and 3 = Arery. @analysis of differences between groups: ${ }^{\text {a }}$ significant between Non-MVA and MVA-ND groups; ${ }^{\mathrm{b}}$ significant between Non-MVA and MVA-D groups; ${ }^{\mathrm{c}}$ significant between MVA-ND and MVA-D groups. 
Table 8

Mean Raw Color-Naming Times in Seconds by Group and Word Type

Group

Word Type

Non-MVA

MVA-ND

MVA-D

\begin{tabular}{llll}
\hline XXXX₹ & $42.0(11.8)$ & $42.3(12.8)$ & $48.6(13.3)$ \\
Neutral 1 & $55.0(15.0)$ & $56.7(19.5)$ & $67.6(22.1)$ \\
School & $58.4(21.9)$ & $59.1(26.4)$ & $69.1(23.4)$ \\
Neutral 2 & $56.4(16.4)$ & $61.2(23.2)$ & $67.4(21.5)$ \\
MVA & $61.2(22.4)$ & $64.1(24.5)$ & $73.8(16.4)$ \\
Neutral 3 & $59.9(18.7)$ & $66.1(24.7)$ & $71.2(22.1)$ \\
\hline
\end{tabular}

Note. MVA-ND = MVA Non-Distressed, MVA-D = MVA-Distressed. Standard deviations given in parentheses. 
Table 9

$\underline{\text { Mean Color-Naming Times in Seconds Corrected for Individual Speed Differences by Group and }}$

Word Type

\begin{tabular}{|c|c|c|c|}
\hline \multirow[b]{2}{*}{ Word Type } & \multicolumn{3}{|c|}{ Group } \\
\hline & Non-MVA & MVA-ND & MVA-D \\
\hline Neutral1 & $15.0(3.6)$ & $17.0(2.8)$ & $19.1(2.5$ \\
\hline School & $23.4(5.5)$ & $21.7(4.2)$ & $21.5(3.8$ \\
\hline Neutral 2 & $13.9(4.3)$ & $23.1(3.3)$ & $19.7(3.0$ \\
\hline MVA & $27.6(4.4)$ & $26.3(3.3)$ & $25.7(3.0$ \\
\hline Neutral 3 & $22.0(4.6)$ & $29.2(3.5)$ & 23.6 \\
\hline
\end{tabular}


Table 10

Mean Corrected Color-Naming Times in Seconds Adjusted for Covariates by Group, Word Type, $\underline{\text { and Reading Level }}$

Group

Word Type

Non-MVA

MVA-ND

MVA-D

School

Low readers ${ }^{c}$

$27.8(6.4)$

$15.4(5.1)$

$19.5(3.8)$

High readers $^{c}$

$18.9(2.7)$

$15.9(2.8)$

$17.0(3.1)$

Neutral 2

Low readers ${ }^{c}$

8.6 (4.4)

$17.9(3.5)$

$18.1(2.6)$

High readers $^{\mathrm{a}}$

$19.2(1.8)$

$18.2(1.9)$

$15.6(2.1)$

MVA

Low readers ${ }^{c}$

$35.6(5.8)$

$24.1(4.6)$

22.8 (3.4)

High readers ${ }^{\mathrm{a}, \mathrm{b}}$

$19.7(2.4)$

$20.2(2.5)$

$23.5(2.8)$

Note. Corrected scores $=$ word time - XXXX $\mp$ time. MVA-ND = MVA Non-Distressed, MVA-D = MVA-Distressed. Standard deviations given in parentheses. Analysis of differences between groups: ${ }^{a}$ significant between Non-MVA and MVA-ND groups; ${ }^{\mathrm{b}}$ significant between Non-MVA and MVA-D groups; ${ }^{c}$ significant between MVA-ND and MVA-D groups. 
Table 11

$\underline{\text { Inter-rater Agreement Scores for Errors Using Percent Total Agreement and Effective Percentage }}$

$\underline{\text { Agreement }}$

Group Mean $\quad$ Range

Percentage total agreement

$\begin{array}{lll}\text { Non-MVA } & 99.3 \% & 99.0 \%-99.7 \% \\ \text { MVA-ND } & 99.0 \% & 98.3 \%-100.0 \% \\ \text { MVA-D } & 99.5 \% & 99.3 \%-100.0 \%\end{array}$

Effective percentage agreement (occurrence for errors)

$\begin{array}{lll}\text { Non-MVA } & 79.4 \% & 75.0 \%-84.6 \% \\ \text { MVA-ND } & 76.8 \% & 63.6 \%-100.0 \% \\ \text { MVA-D } & 89.8 \% & 80.0 \%-100.0 \%\end{array}$

Note. Inter-rater agreement calculated on 3 tapes per group (20\% of 45 tapes).

MVA-ND = MVA Non-Distressed, MVA-D = MVA-Distressed. 
Table 12

Mean Number of Errors by Group and Word Type

\begin{tabular}{|c|c|c|c|}
\hline \multirow[b]{2}{*}{ Word Type } & \multicolumn{3}{|c|}{ Group } \\
\hline & Non-MVA & MVA-ND & MVA-D \\
\hline Neutral 1 & $1.9(2.5)$ & $2.7(1.5)$ & $2.0(2.6)$ \\
\hline School & $2.5(3.6)$ & $2.1(2.6)$ & $1.7(1.6)$ \\
\hline Neutral 2 & $1.3(1.2)$ & $1.5(1.5)$ & $1.7(1.4)$ \\
\hline MVA & $2.4(3.5)$ & $2.1(1.4)$ & $2.4(2.4)$ \\
\hline Neutral 3 & $2.9(3.2)$ & $1.5(1.1)$ & $1.5(1.5)$ \\
\hline
\end{tabular}


Table 13

Correlations Among Psychometric Measures

\begin{tabular}{lccccccccccr} 
Measure & 1 & 2 & 3 & 4 & 5 & 6 & 7 & 8 & 9 & 10 & 11 \\
\hline & & & & & & & & & & & \\
1. XXXMVA & -- & .17 & .19 & .19 & -.14 & .01 & -.05 & .04 & .01 & -.07 & .13
\end{tabular}

2. IES-Intrusion

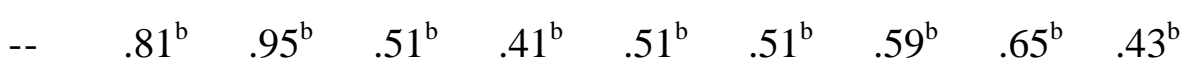

3. IES-Avoidance

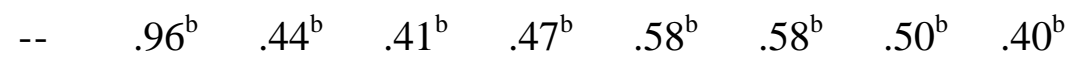

4. IES-Total



5. CBCL-Externalizing $\begin{array}{lllllll}-- & .65^{\mathrm{b}} & .88^{\mathrm{b}} & .33^{\mathrm{a}} & .40^{\mathrm{b}} & .39^{\mathrm{a}} & .39^{\mathrm{b}}\end{array}$

6. CBCL-Internalizing $\begin{array}{llllll}-- & .86^{\mathrm{b}} & .28 & .39^{\mathrm{b}} & .45^{\mathrm{a}} & .57^{\mathrm{b}}\end{array}$

7. CBCL-Total



8. CDI-Total $--\quad .75^{\mathrm{b}} \quad .64^{\mathrm{b}} \quad .17$

9. RCMAS-Total B $\quad .73^{\mathrm{b}} \quad .21$

10. ACCIDENTS-C-Total* B $\quad .72^{\mathrm{b}}$

11. ACCIDENTS-P-Total B

Note. XXXMVA refers to correlations using corrected MVA word times. ${ }^{a} \mathrm{p}<.05,{ }^{b} \mathrm{p}<.01 .{ }^{*}$ Measures were administered to all participants $(\underline{n}=45)$ except the ACCIDENTS-C, which was given to MVA participants only $(\underline{\mathrm{n}}=30)$. 
Figure 1. Mean color-naming times by Group and Word Type for low readers.

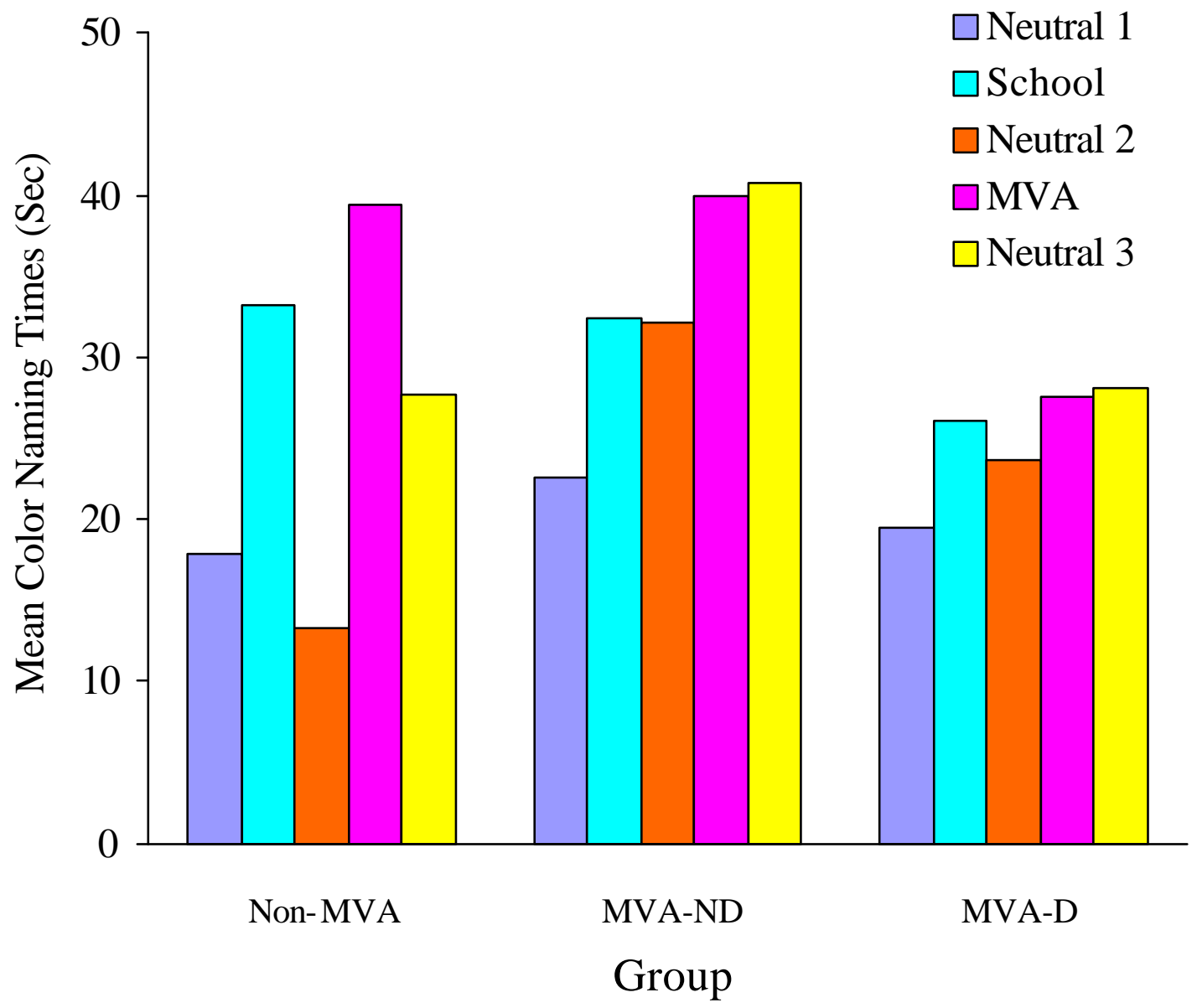


Figure 2. Mean color-naming times by Group and Word Type for high readers.

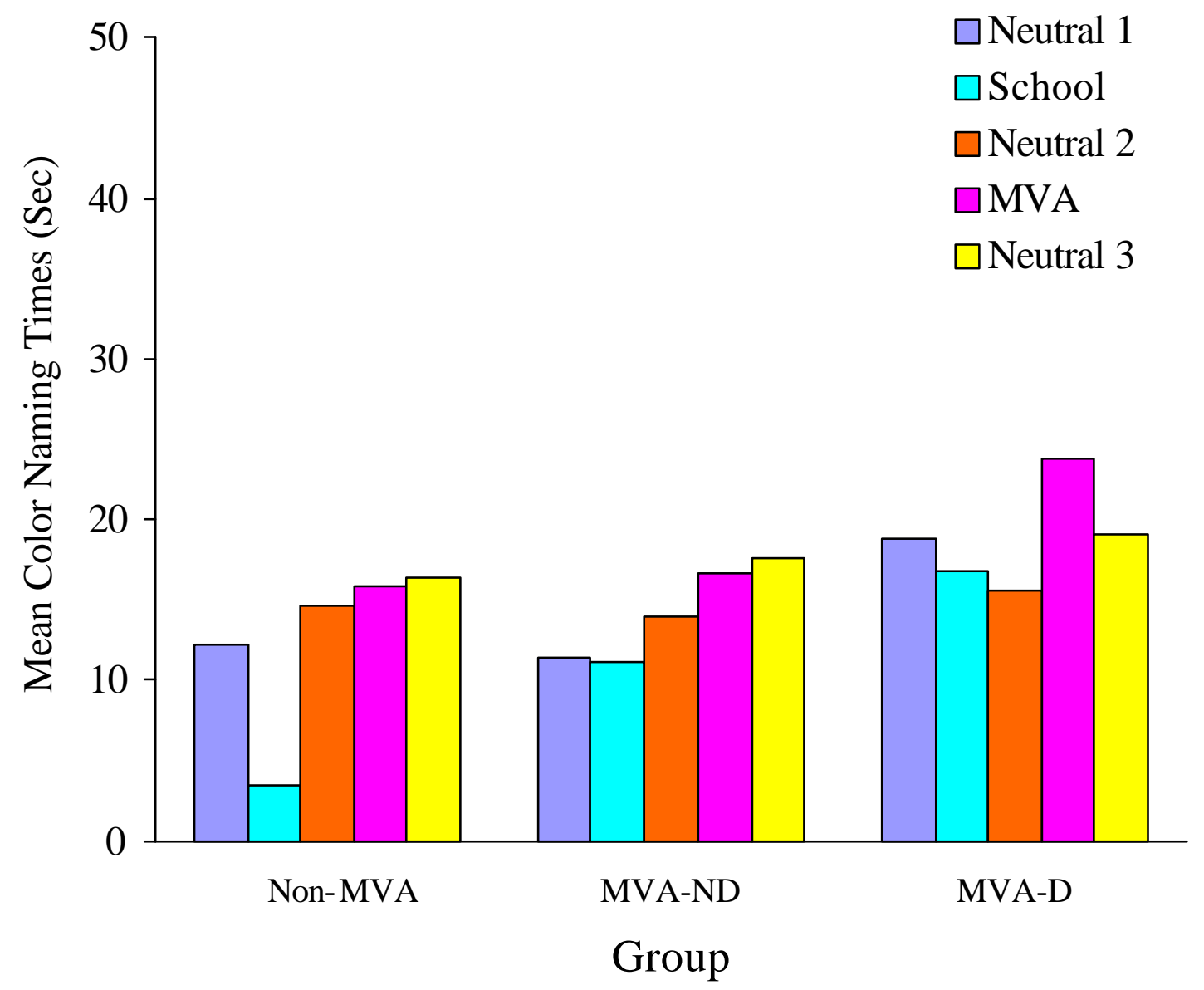


Figure 3. Mean color-naming times (adjusted for covariates) by Group and Word Type for low readers.

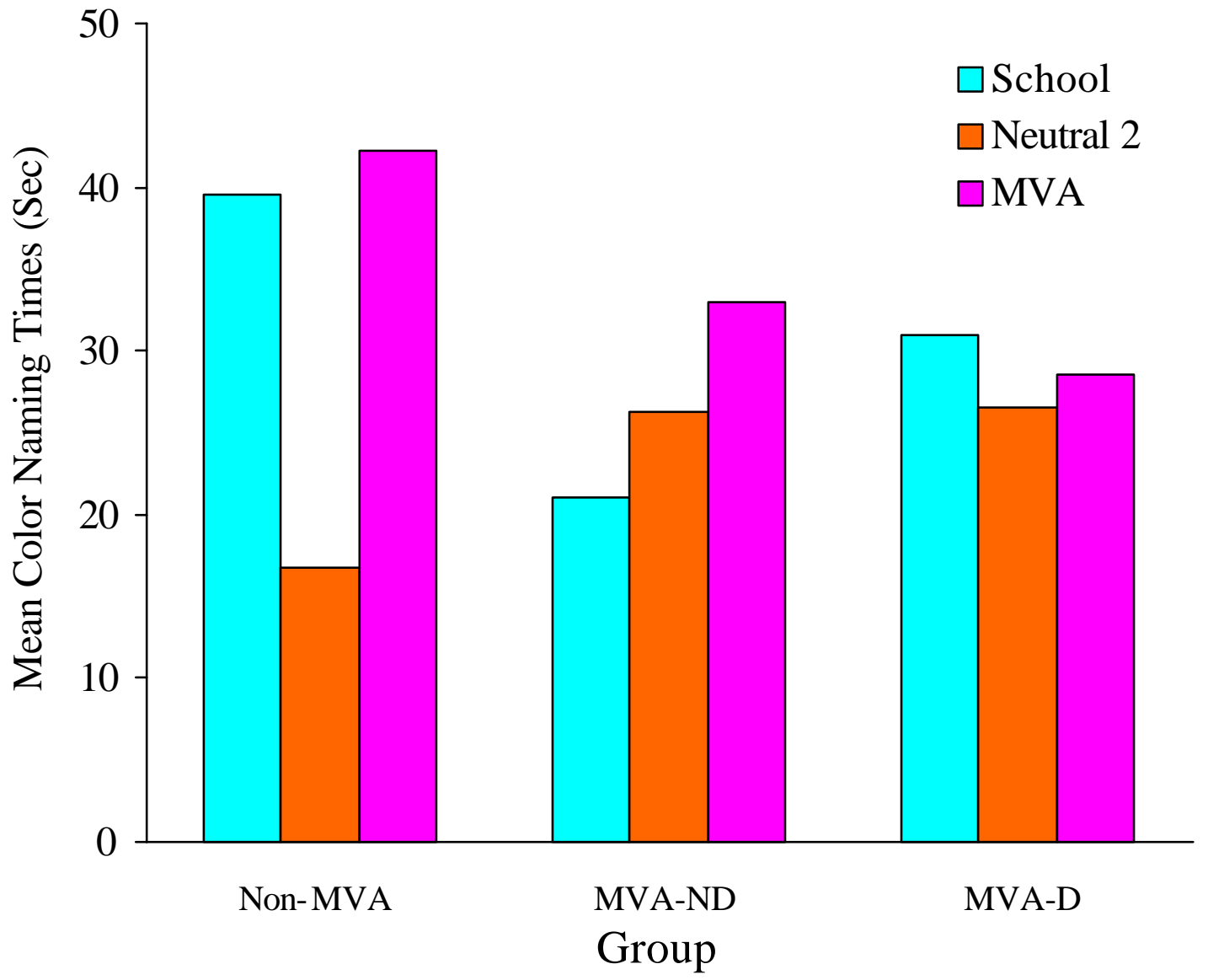


Figure 4. Mean color-naming times (adjusted for covariates) by Group and Word Type for high readers.

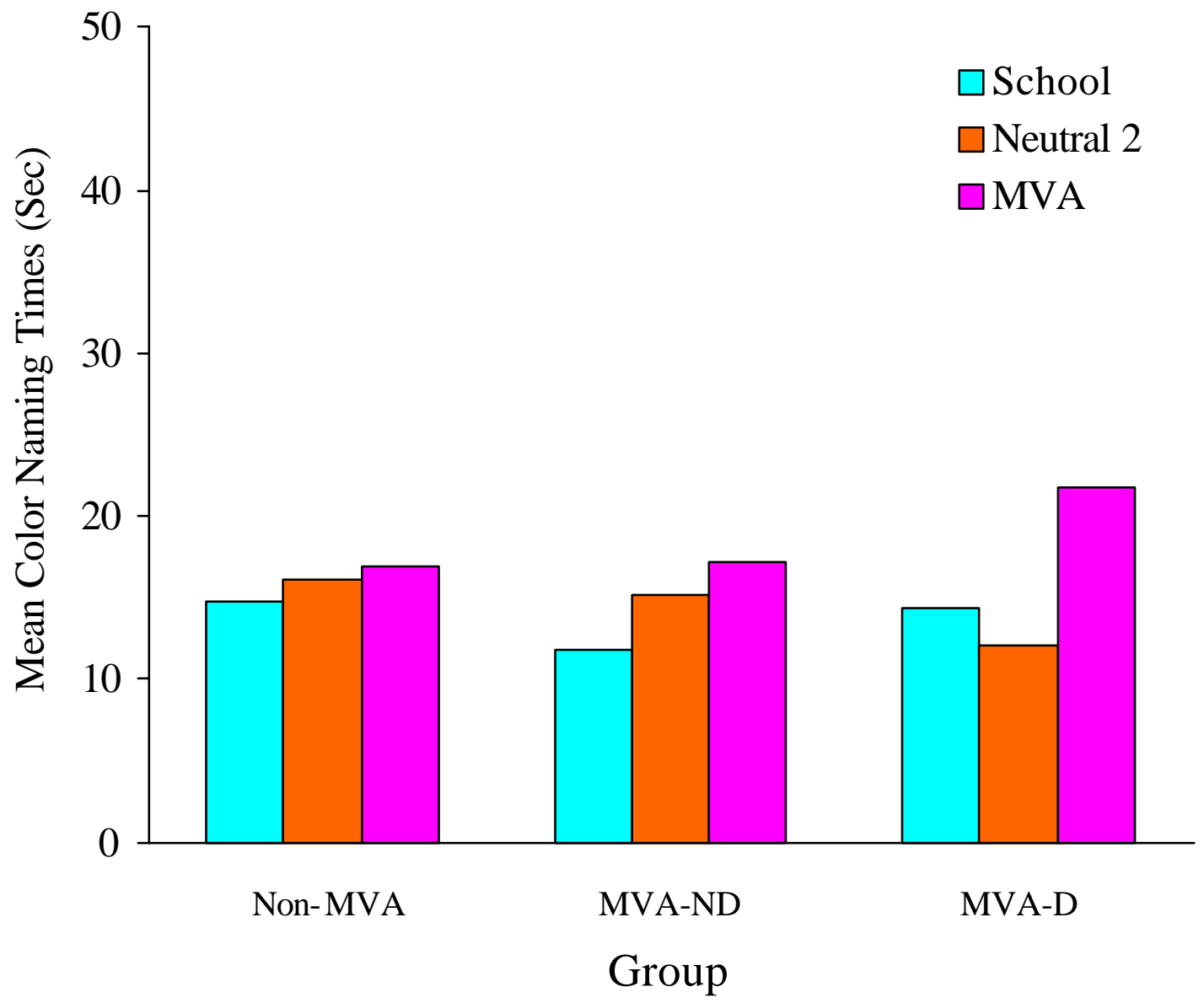


Figure 5. Mean number of errors by Reading Level and Word Type.

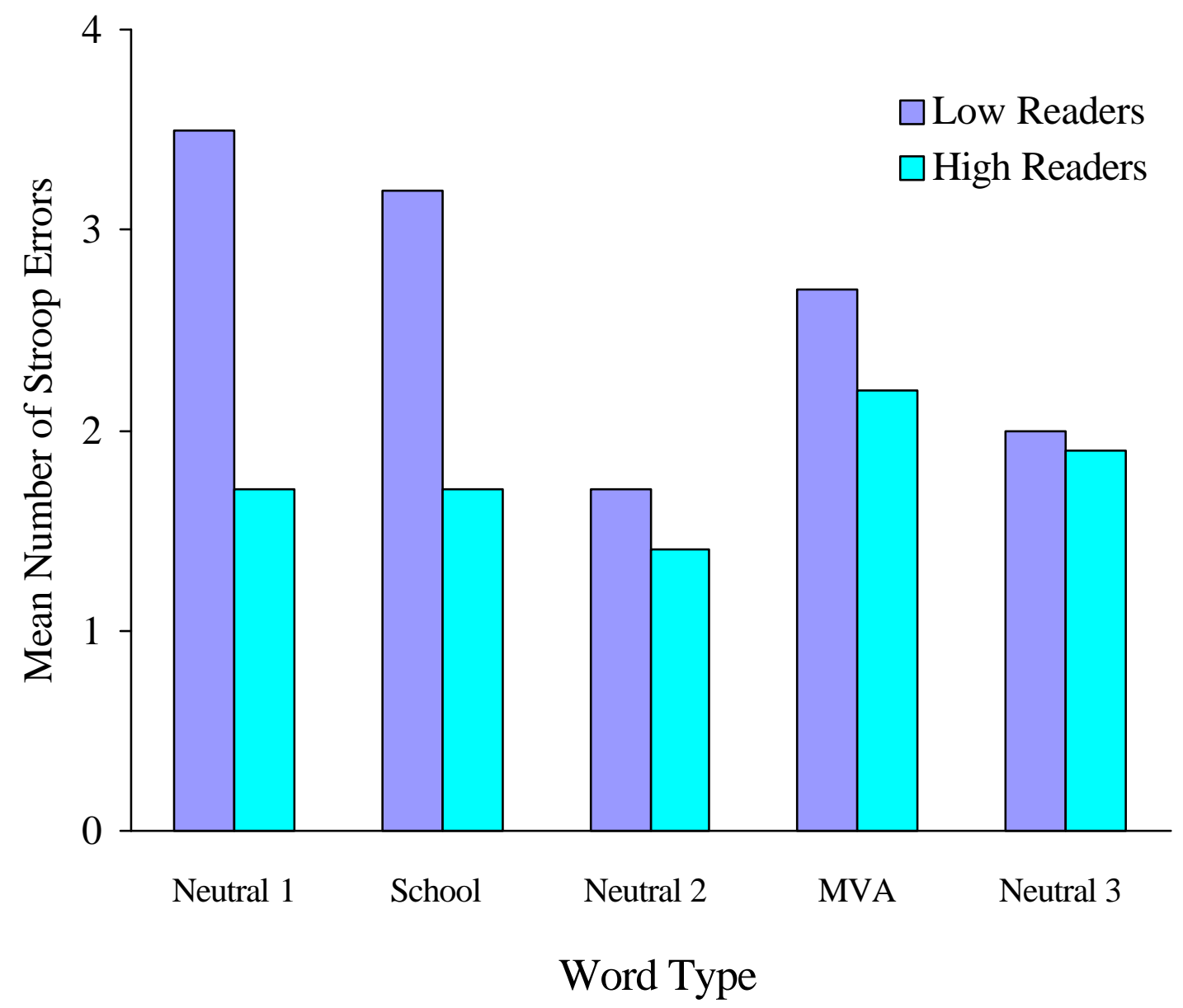




\title{
Appendix A
}

\section{Consent Form}

\section{PARENTAL or GUARDIAN CONSENT FORM}

\author{
Title of the Project: $\quad$ Children Exposed to MVAs: Assessment of Effects
}

Introduction. I, , have been asked to participate in a research study with my

child This study has been explained to me by Joseph R. Scotti, Ph.D., (the

Principal Investigator), or by (a research assistant).

Purposes of the Study. The purpose of this research is to learn about the behavioral reactions of children who have experienced a recent motor vehicle accident, and for the partial completion of the doctoral dissertation for Kimberly B. Mullen, MA. To understand how accidents affect children, it is important to compare the responses of children who have experienced a motor vehicle accident with the responses of children who have not had such an experience. A second purpose of the study is to understand why some children have more distress than others following the experience of a motor vehicle accident.

Description of Procedures. If I decide to participate, the research will consist of two sessions lasting approximately two hours each. Additionally, I may be mailed a packet of follow-up questionnaires, three months after I complete the second session, to be returned to the experimentors by mail, postage pre-paid. In the first session, my child and I (the parent/guardian) will be asked to complete several questionnaires with the aid of the researchers, and will participate in clinical interviews conducted by the principal investigator or a trained research assistant. These questionnaires and interviews ask about general behavioral and emotional functioning, and ask some specific questions about motor vehicle accident experiences. The interviews and questionnaires will be completed at either the Quin Curtis Center of the Department of Psychology at West Virginia University, or in my family home, which ever is most convenient for me. I understand that my child and I have the right to not to answer any question that we are not comfortable answering, and do not have to complete the questionnaires and interview. The second session, conducted at the Department of Psychology, will include a physiological assessment, and a Stroop task that will performed at a computer terminal. I have been given the opportunity to examine the questionnaires and interview materials. Additionally, I have the right to be present during all parts of my child's physiological assessment and Stroop task. Approximately 90 children will be participating in this research study.

Risks and Discomforts. For children who have experienced a motor vehicle accident, some of the questions that address this experience may be temporarily distressing. For all children and parents/guardians participating, there are no known psychological or physical risks involved due to completing questions, physiological assessment, and/or completion of the Stroop task. There is the possibility of mild discomfort associated with the application of electrodes for the physiological assessment. It has been explained to me that if any child or adult experiences emotional distress concerning the motor vehicle accident or other traumatic experience as a result of this research, the principal investigator will answer any questions or refer the participant to someone who can assist in relieving any distress. Additionally, if it is determined from the clinical interview that a child is experiencing any emotional distress that is interfering with his or her daily functioning, then the principal investigator will provide the family with a referral to a qualified agency, such as the Quin Curtis Center (293-2001-671, ask for Dr. Kouzes), or an appropriate center that can assist in relieving my child's distress.

Benefits. I understand that the investigators do not guarantee that the participants will personally receive any benefit from participating in this research. However, it has been explained to me that knowledge gained from this research may eventually benefit children who experience emotional distress from motor vehicle accidents. I 
understand participants will receive a total of $\$ 60, \$ 20$ for the first session, and $\$ 40$ for the second.

Contact Person. For more information about this research, I can contact Joseph R. Scotti, Ph.D. at 293-2001, extension 667; or Kimberly B. Mullen, MA, at 293-2001, extension 888. For information regarding my child's rights as a research subject, I may contact the Executive Secretary of the Institutional Review Board at 293-7073.

Confidentiality. I understand that any information obtained as a result of the participation of my child in this research will be kept as confidential as legally possible. I understand that although it is highly unlikely, these research records, just like hospital records, may be subpoenaed by court order or may be inspected by federal regulatory authorities. In any publications that may result from this research, neither my name nor that of my child nor any information from which we might be identified will be published. All completed questionnaires, interview materials, and collected data will be stored in a locked facility and will be identified by code numbers only to ensure confidentiality.

Voluntary Participation. Participation in this research is voluntary. I understand that I may withdraw my child from this research at any time. Refusal to participate or withdrawal from the research will not involve any penalty or loss of benefits for my child or myself. I have been given the opportunity to ask questions about the research, and I have received answers concerning areas I did not understand. Upon signing this form, I will receive a copy.

My signature below indicates that I have read and understand the above information and I willingly consent for my child and myself to participate in this research.

Signature of Parent or Guardian Date

Signature of Investigator Date

or Investigator's Representative

My signature below indicates my consent to be AUDIO taped for the purpose of this research. I understand that these recordings will only be used by the research investigators and the tapes will be securely stored during the study and erased upon completion of the research.

$\begin{array}{lll}\text { Signature of Parent or Guardian } & \text { Date } & \begin{array}{l}\text { Signature of Investigator } \\ \text { or Investigator's Representative }\end{array}\end{array}$

My signature below indicates my consent to be VIDEO taped for the purpose of this research. I understand that these recordings will only be used by the research investigators and the tapes will be securely stored during the study and erased upon completion of the research.

Signature of Parent or Guardian Date

Signature of Investigator
or Investigator's Representative




\title{
Appendix B
}

\author{
Child Assent Form
}

\section{ASSENT FORM}

Title of the Project: $\quad$ Children Exposed to MVAs: Assessment of Effects

Introduction. I, explained to me by Joseph R. Scotti, Ph.D., or have been asked to participate in this research which has been (a research assistant).

Purposes of the Research. The purpose of this research is to learn about the behavioral and emotional reactions of children who have experienced a recent motor vehicle accident.

Description of Procedures. During the first session, I will be asked to complete some questions and talk with the researcher about car accidents. It will take about two hours to answer the questions. I do not have to answer all of the questions. During the second session, I will wear electrodes and also perform a task on a computer. This session will also last approximately two hours.

Discomforts. Some of the questions might be difficult and I might not enjoy answering them. If I feel sad or uncomfortable answering the questions, I can tell the researcher or ask my parents to talk with the researcher, and the researcher will try to help me feel better. I may also experience mild discomfort from wearing the electrodes.

Benefits. I understand that this study probably will not help me directly, but what the researcher learns might be helpful for other children.

Confidentiality. I have been promised that anything the researchers learn about me or my family in this study will be kept as secret as possible. It has been explained to me what information cannot be kept secret.

Voluntary Participation. I have been told that it is my choice to participate in this study. It is alright for me to decide that I do not want to participate or that I want to quit at any time during the study. I have been allowed to ask questions about the study, and all of my questions were answered. I can ask other questions at any time if I need to. I will be given a copy of the form after I sign it.

Signing my name below means that I am willing to be in this study.

Signature of Participating Child Date

Signature of Investigator or Representative Date 


\section{Appendix C}

\section{Standardized Instructions for Modified Stroop Task}

AYou are to name out loud the color of each word on the screen. Start at the top of the left-most column and move downward, naming the color of each word in the order that you see (experimenter will point to the first word of the left-most column, and gesture downwards). When you get to the last word in a column, move to the first word in the column to its right (experimenter will point to the first word of the next column). Name only the color of each word, working as fast as you can. You will see colored Xs that are set-up like the words. You are still to name the color that you see for each group of Xs. If you make any mistakes while doing this task, do not correct them, but just continue to name the colors. You will get to practice this on the first screen you see.@ 
Appendix D

Example of MVA Screen

\begin{tabular}{|c|c|c|c|c|}
\hline SEATBELT & CRASH & ACCIDENT & ROAD & SEATBELT \\
\hline CAR & ROAD & CRASH & SEATBELT & CRASH \\
\hline ACCIDENT & SEATBELT & ROAD & ACCIDENT & CAR \\
\hline CRASH & CAR & SEATBELT & CAR & ACCIDENT \\
\hline ROAD & ACCIDENT & CAR & CRASH & ROAD \\
\hline SEATBELT & CAR & ROAD & CAR & ACCIDENT \\
\hline CRASH & ROAD & CRASH & SEATBELT & ROAD \\
\hline ROAD & SEATBELT & ACCIDENT & CRASH & SEATBELT \\
\hline CAR & ACCIDENT & CRASH & ACCIDENT & CRASH \\
\hline ACCIDENT & CRASH & SEATBELT & ROAD & CAR \\
\hline
\end{tabular}


Appendix E

Example of a Neutral Screen

$\begin{array}{lllll} & & & \\ \text { LADDER } & \text { DOORBELL } & \text { OVEN } & \text { EGG } & \text { OVEN } \\ \text { DOORBELL } & \text { OVEN } & \text { WINDOW } & \text { DOORBELL } & \text { EGG } \\ \text { OVEN } & \text { LADDER } & \text { DOORBELL } & \text { WINDOW } & \text { LADDER } \\ \text { WINDOW } & \text { EGG } & \text { LADDER } & \text { OVEN } & \text { DOORBELL } \\ \text { EGG } & \text { WINDOW } & \text { EGG } & \text { LADDER } & \text { WINDOW } \\ \text { DOORBELL } & \text { OVEN } & \text { DOORBELL } & \text { EGG } & \text { LADDER } \\ \text { WINDOW } & \text { LADDER } & \text { OVEN } & \text { DOORBELL } & \text { EGG } \\ \text { LADDER } & \text { EGG } & \text { LADDER } & \text { WINDOW } & \text { OVEN } \\ \text { OVEN } & \text { WINDOW } & \text { EGG } & \text { OVEN } & \text { DOORBELL } \\ \text { EGG } & \text { LADDER } & \text { WINDOW } & \text { LADDER } & \text { WINDOW } \\ & & & & \end{array}$


November, 1999

\author{
CURRICULUM VITAE \\ KIMBERLY MULLEN JAMES
Developmental Disabilities Institute
75 Landing Meadow Road
Smithtown, NY 11787
516-208-9004 (wk)
kmjames@peconic.net

Date of Birth: December 14, 1968

\title{
EDUCATIONAL HISTORY
}

Ph.D. $\quad$ West Virginia University (December, 1999)

Major: Child Clinical Psychology

Advisor: Joseph R. Scotti, Ph.D.

Dissertation: The use of a modified clinical Stroop task to assess overt behavioral disruption in children who have experienced a motor vehicle accident (in progress). Committee: Joseph R. Scotti, Ph.D. (Chair), Jody M. Kashden, Ph.D., Kevin T. Larkin, Ph.D., Daniel W. McNeil, Ph.D., and JoNell Strough, Ph.D.

Qualifying

Exam Paper: The educative approach to behavior problems: Toward an application to child behavior intervention packages. Committee: Joseph R. Scotti, Ph.D. (Chair), Cheryl Bodiford McNeil, Ph.D. Passed January, 1996

M.A. University of California at Santa Barbara (January, 1995)

Major: Educational Psychology

Area of Emphasis: Human Development and Disability

Thesis: $\quad$ The use of a parent-professional consultation model to teach parents functional assessment. Committee: Robert L. Koegel, Ph.D. (Chair), Lynn Kern Koegel, Ph.D., and Gale Morrison, Ph.D.

B.A. University of California at Santa Barbara (December, 1991)

Major: Psychology 


\section{CLINICAL EXPERIENCE}

Dates:

Position:

Duties:

Supervisor:

Dates:

Position:

Duties:

Supervisor(s):

Dates:

Position:

Place:

Duties:

Supervisor(s):
September 13, 1999-Present

Psychologist

Developmental Disabilities Institute, 75 Landing Meadow Rd, Smithtown, NY, 11787

Include: (a) positive behavior support and person-centered planning for adults with autism and other developmental disabilities; (b) research in the area of positive behavior support; (c) participating as faculty for psychology internship; and (d) supervision of applied behavior specialists.

Darlene Magito-MacGlouglin, Ph.D., Director of Clinical Services, Adult Community Division.

August 15, 1998-August 13, 1999

Psychology Resident

Department of Psychiatry and Human Behavior, University of Mississippi

Medical Center, Jackson MS 39216

Include: (a) community-based consultation for service providers working with children exhibiting challenging behavior; (b) pediatric consultation at UMC Children's Hospital; (c) bi-weekly participation in multi-disciplinary diabetes management team; and (d) teaching courses in positive behavior management strategies to court, and self-referred parents.

Ronald Drabman, Ph.D., Licensed Psychologist, Director of Residency Program in Clinical Psychology

July, 1997-June, 1998

Graduate Student Coordinator

Quin Curtis Center for Psychological Research and Services, Department of Psychology, West Virginia University, Morgantown, WV 26506

Clinical and administrative management of department psychological center. Position involved: (a) providing direct clinical service; (b) developing clinic programs (e.g., eating disorders support groups); (c) coordinating weekly caseconference series; (d) providing supervision (group and individual) to undergraduate clinic assistants; (e) maintaining and enhancing public relations; (f) maintaining client records and billing; (g) participating in department committees that involve the Center (e.g., QCC steering committee), and (h) coordinating clinic sponsored National Depression, Eating Disorders, and Anxiety Awareness Days and Screenings.

Daniel W. McNeil, Ph.D., Director of Clinical Training Jan Kouzes, Ed.D., Director, Quin Curtis Center 
Dates:

Position:

Place:

Duties:

Supervisor(s):

Dates:

Position:

Place:

Duties:

Supervisor(s):
January, 1997-November, 1997

Graduate Student Therapist

HealthSouth MountainView Regional Rehabilitation Hospital

1160 Van Voorhis Road, Morgantown, WV 26505

Participation as interdisciplinary team member at rehabilitation hospital for inpatient psychological treatment and discharge planning. Provision of assessment, intervention, and consultation for children, adolescents, and adults presenting with behavioral and psychological problems associated with: (a) chronic illness, (b) developmental disabilities, (c) stroke, (d) traumatic brain injury, (e) chronic pain, (f) food refusal, and (g) medical routine/compliance. Participation at weekly pediatric interdisciplinary team meetings as representative of hospital Department of Psychology. Psychological interventions consisted of strategies such as behavioral parent training; staff and patient/family education; function-matched interventions; environmental antecedent modification, negotiation/contracting; skills training; progressive muscle, abdominal breathing, and guided imagery relaxation training; and individual supportive counseling.

Jody Kashden, Ph.D., Director of Psychological Services

August, 1995-June, 1998

Graduate Student Therapist

Quin Curtis Center for Psychological Research and Services

Department of Psychology, West Virginia University, Morgantown, WV 26506

The provision of behavioral assessment and intervention to adults and children as a member of three "Vertical Teams" (wherein faculty direct specialty clinics in their area of interest and a team of students from all levels of training, allowing students to take on increasing clinical case responsibility as they advance through the doctoral program). Teams participated in were: Posttraumatic Stress Disorder Team (2 years), Anxiety Disorders Team (1 year), and General Child Team (1 year). Psychological interventions include: (a) exposure therapy; (b) response prevention; (c) individual and group cognitive-behavioral therapy for persons with social phobia/anxiety (using Social Effectiveness Therapy); and (d) behavioral parent training.

Joseph R. Scotti, Ph.D. (PTSD Team; provision of "bug in the ear" coaching); Daniel W. McNeil, Ph.D. (Anxiety Disorders Team);

Tracy L. Morris, Ph.D. (General Child Team). 
Dates:

Position:

Place:

Duties:

Supervisor(s):

Dates:

Position:

Place:

Duties:

Supervisor(s):

Dates:

Position:

Place:

Duties:
August, 1995-June, 1996

Graduate Student Therapist

Valley Comprehensive Community Mental Health Center

501 North Pike Street, Grafton, WV 26354

The provision of assessment and intervention for typically developing children with the following types of presenting problems: (a) attention-deficit hyperactivity disorder, (b) depression, (c) post-traumatic stress disorder, (d) school refusal, (e) medication refusal, (f) oppositional defiant disorder, (g) conduct disorder, and (h) sleep problems. Assessment methods included naturalistic and clinic-based observation, functional assessment, standardized behavioral checklists, structured interviews, and intellectual/achievement testing. Intervention strategies included behavioral parent training, skills training, school consultation, relaxation training, exposure therapy, and antecedent interventions. On-site: Joseph Kuzniar, Ed.D., Licensed Psychologist; Sharon McMillon, M.A., Licensed Psychologist

WVU Department of Psychology Consultant: Kevin T. Larkin, Ph.D., Licensed Psychologist

August, 1994-August, 1995

Graduate Student Coordinator

The School Consultation Project

Department of Psychology

West Virginia University, Morgantown, WV 26506

Graduate student coordinator and research assistant for state funded, community-based service and research clinic addressing challenging behaviors associated with developmental disabilities. Duties included overseeing and participating in state-wide clinical service and research related to the provision of: (a) functional assessment, and antecedent/communication-based interventions; (b) brief and long-term consultation with schools, group homes, and families; (c) supervision to undergraduate field-placement and graduate level students in the above activities; and (d) co-teaching a course for special and regular educators on functional assessment and antecedent/communicationbased interventions.

Joseph R. Scotti, Ph.D.

January, 1993-June, 1994

Behavior Specialist

The Intensive Behavior Intervention Program

3775 Constellation Rd, \#2, Lompoc, CA 93436

The provision of functional assessments and positive behavior support for persons with developmental disabilities exhibiting challenging behavior. Other duties included consultation and education to care providers (family and staff), and participating in interdisciplinary team meetings (e.g., individualized education 
program).

Supervisor(s): $\quad$ Robert Holdsambeck, Ed.D., Licensed Psychologist, Program Director

Karen Chandler, MFCC, Program Supervisor

Dates:

Position:

Place:

Duties:

Supervisor(s):

Dates:

Position:

Place:

Duties:

Supervisor(s):

Dates:

Position:

Duties:

Consultant:
January, 1993-June, 1994

Behavioral Consultant

La Paloma Group Home, F Street, Lompoc, CA 93436

Assisting with the planning and review of behavior intervention plans for residents, educating staff on how to conduct descriptive functional assessment, providing in-service training to staff on behavior assessment and management strategies, participating in monthly multidisciplinary team meetings, and assisting staff in promoting generalization of programs and gains to school, day programs, and other community environments.

Robert Holdsambeck, Ed.D., Licensed Psychologist

January, 1992-June, 1992

Behavioral Consultant

Elementary Special Education Program

Santa Barbara City School District

Santa Barbara, CA, 93101

Weekly consultation with a regular education teacher and school principal to facilitate the full inclusion of a student with autism into a regular education sixth grade class. Assisted the teacher in learning to conduct a descriptive functional assessment of disruptive behavior, and design an intervention based on the assessment. Attended Individualized Education Program meetings as the student's behavioral consultant and advocate.

Gerry Murphy, Ph.D., Director of Special Education

Consultant: Lynn Kern Koegel, Ph.D., Clinical Supervisor, the UCSB Autism

Research and Training Center, University of California at Santa Barbara, Santa Barbara, CA 93106

January, 1992-January, 1993

$\underline{\text { Behavior Specialist }}$

(hired privately by family with a four-year-old boy with autism) Implementing functional assessments and interventions to address: decreasing noncompliance and stereotypic behavior, increasing use of language and social skills, teaching neighborhood safety and kindergarten preparation skills, and assisting in the full inclusion into regular neighborhood kindergarten class.

Lynn Kern Koegel, Ph.D., Clinical Supervisor, UCSB Autism Research and Training Center 
Dates:

Position:

Duties:

Supervisor(s):

January, 1992-June, 1992

\section{Behavior Specialist}

(hired privately by family with a 21-year old son with autism) Assisting with community and occupational integration, teaching social skills and functional reading skills.

Lynn Kern Koegel, Ph.D., Clinical Supervisor, UCSB Autism Research and Training Center

\section{RESEARCH EXPERIENCE}

\section{Dates: \\ Position: \\ Place: \\ Duties:}

Supervisor(s):

Dates:

Position:

Place:

Duties:

Supervisor(s):

Dates:

Position:

Place:

Duties:
August, 1996-August, 1998

$\underline{\text { Research Investigator }}$

(NIMH grant-funded position; 20 hrs/ week August 1996 - March, 1997)

Department of Psychology, West Virginia University, Morgantown WV 26506 Included: (a) subject recruitment for an NIMH grant-funded study investigating the psychological effects of motor vehicle accidents on children; (b) administering psychometric, psychophysiological, and behavioral assessment to research participants; (c) supervising undergraduate and graduate students assisting with the study; (d) locating and initiating community assistance with the project; (e) conducting data analysis; and (f) participating in manuscript preparation.

Joseph R. Scotti, Ph.D., Associate Professor (Principal Investigator)

May, 1996-July, 1996

Research Assistant

Survey Associates

313 Simpson Street, Morgantown, WV 26505

(Private practice survey research firm)

Included assisting with the implementation of community-wide surveys regarding the psychological and behavioral effects of traumatic events, such as technological accidents, disasters, and personal injury. Involved the administration of: (a) self-report psychological measures, (b) structured interview, and (c) data-entry.

Joseph R. Scotti, Ph.D., Tracy L. Morris, Ph.D.

September, 1992-June, 1994

$\underline{\text { Research Assistant }}$

UCSB Autism Research and Training Center, School of Education, University of California at Santa Barbara

Participated in research and manuscript preparation related to providing nonaversive, family-focused intervention for challenging behavior, including teaching parents how to implement descriptive functional assessments and communication-based intervention for challenging behavior. Participated in the 
Supervisor(s):

Dates:

Position:

Place:

Duties:

Supervisor(s):

development of techniques for integrating persons with severe disabilities into regular school and community settings.

Robert L. Koegel, Ph.D., Director, UCSB Autism Research and Training Center Lynn Kern Koegel, Ph.D., Clinic Supervisor, UCSB Autism Research and Training Center

September, 1990-September, 1992

Data Collector

The UCSB Autism Research and Training Center

Collecting reliability data for on-going research projects.

Robert L. Koegel, Ph.D., Director, UCSB Autism Research and Training Center; Lynn Kern Koegel, Ph.D., Clinic Supervisor, UCSB Autism Research and Training Center

\section{TEACHING EXPERIENCE}

Dates:

Position:

Place:

Duties:

Supervisor(s):

Dates:

Position:

Place:

Duties:

Supervisor(s):

Dates:

Position:

Place:

Duties:

Supervisor(s):
August, 1998-August, 1999

Instructor

The Parenting Place: Exchange Club Parent Child Center

2906 North State Street, Jackson MS 39216

Teaching 12-week courses on Positive Parenting Strategies and anger/stress management to DHHS, court and self-referred parents.

Ronald Drabman, Ph.D., Licensed Psychologist, Director of UMC

Residency Program in Clinical Psychology

January, 1998-May, 1998

Teaching Assistant

Department of Psychology, West Virginia University

Participating in: The design of course, lecturing, and grading for graduate-

level course Adult Behavior Therapy.

Daniel W. McNeil, Ph.D., Associate Professor

January, 1997-May, 1997

Co-Instructor

Department of Psychology, West Virginia University

Co-designed and taught (with two other graduate-level instructors) an undergraduate elective course called Special Topics in Psychology: Parental Influences on Child Behavior. Duties included, design of course, lectures, design of tests and other evaluative methods, grading, and provision of office hours.

Christina Adams, Ph.D., Assistant Professor 


\begin{tabular}{|c|c|}
\hline Dates: & January, 1996-April, 1996 \\
\hline Position: & $\underline{\text { Teaching Assistant }}$ \\
\hline Place: & Department of Psychology, West Virginia University \\
\hline Duties: & $\begin{array}{l}\text { Teaching assistant for graduate-level course Behavior Assessment II. Observed } \\
\text { on-site administration of intellectual testing to provide oral and written feedback } \\
\text { to graduate students learning to administer intelligence and scholastic } \\
\text { achievement tests. }\end{array}$ \\
\hline Supervisor(s): & Tracy L. Morris, Ph.D., Assistant Professor \\
\hline Dates: & January, 1996-April, 1996 \\
\hline Position: & Teaching Assistant \\
\hline Place: & Department of Psychology, West Virginia University \\
\hline Duties: & $\begin{array}{l}\text { Teaching assistant for undergraduate-level course Laboratory in Behavior } \\
\text { Modification. Provided community-based consultation to undergraduate } \\
\text { psychology majors doing field placements, and participated in didactic } \\
\text { consultation in weekly meetings. }\end{array}$ \\
\hline Supervisor(s): & Robert Hawkins, Ph.D., Professor \\
\hline Dates: & January, 1995-April, 1995 \\
\hline Position: & $\underline{\text { Co-instructor }}$ \\
\hline Place: & Potomac Center, Romney, WV \\
\hline Duties: & $\begin{array}{l}\text { Co-instructor (design, lecturing, grading) for invited course Functional } \\
\text { Assessment and Nonaversive Interventions With the Excess Behaviors of } \\
\text { Students With Severe Disabilities. Course provided to public regular and } \\
\text { special education teachers, and direct-care staff, for WVU extension credit. }\end{array}$ \\
\hline Supervisor(s): & Joseph R. Scotti, Ph.D., Associate Professor \\
\hline
\end{tabular}

\section{PUBLICATIONS}

Mullen, K. B., \& Scotti, J. R. (in press). The educative approach to intervention with child excess behavior: Toward an integration with parent training packages. Child and Family Behavior Therapy.

Zvolensky, M., Mullen, K., Lejuez, C., \& McNeil, D. (in press). The benefits for clinical training programs of university-based support groups. the Behavior Therapist.

Masia, C., \& Mullen, K. B., \& Scotti, J. (1998). Severe peanut allergy: The psychologist's role. Education and Treatment of Children, 21, 514-531.

Anderson, C. M., Freeman, K., Mullen, K. B., \& Scotti, J. R. (1999). Assessment and intervention with excess behaviors: A series of cases from the school consultation project (319-337). In J. R. Scotti \& L. H. Meyer (Eds.) Behavioral intervention: Principles, models, and practices. Baltimore: Paul H. Brookes. 
Scotti, J. R., Mullen, K. B., \& Hawkins, R. P. (1998). From theory to practice in the treatment of excess behavior in child conduct and developmental disabilities (pp. 172-202). In J. J. Plaud \& G. H. Eifert (Eds.), From behavior theory to behavior therapy. New York: Allyn \& Bacon.

Koegel, R. L., Kern-Koegel, L., Kellegrew, D., \& Mullen, K. B. (1996). Parent education for prevention and reduction of severe problem behaviors (3-30). In L. K. Koegel, R. L. Koegel, \& G. Dunlap (Eds.), Positive behavioral support. Baltimore: Paul H. Brookes.

Mullen, K. B., \& Frea, W. D. (1995). A parent-professional consultation model for functional analysis (pp.175-188). In R. L. Koegel \& L. Kern-Koegel (Eds.), Teaching children with autism: Strategies for initiating positive interactions and improving learning opportunities. Baltimore: Paul H. Brookes.

Scotti, J. R., Anderson, C. A., \& Mullen, K. B. (1995). [Review of book, Severe learning disabilities and challenging behaviors: Designing quality service]. Journal of the Association for Persons with Severe Handicaps, 20, 164-169.

\section{WORKS IN PROGRESS}

Scotti, J. R., Mullen, K. B., Freeman, K., \& Anderson, C. M. Assessment of a course on functional assessment and nonaversive interventions on educator's behavior intervention plans. Data being analyzed.

Scotti, J. R., Morris, T. L., Annan, S., \& Mullen, K. B. Cumulative effects of traumatic events on post-traumatic stress disorder. Data collection completed.

Mullen, K. B., \& Scotti, J. R. Using a clinical Stroop task to assess the effects of motor vehicle accidents on children. Manuscript being completed.

Scotti, J. R., \& Mullen, K. B. Psychophysiological assessment of children who have been in a motor vehicle accident. Data being collected.

\section{PRESENTATIONS AND CONFERENCE PROCEEDINGS}

Mullen, K. B., Annan, S., Myers, M., \& Scotti, J. R. (1997, November). Using a clinical Stroop task to assess the effects of motor vehicle accidents on children. Poster presented at the $31^{\text {st }}$ annual convention of the Association for Advancement of Behavior Therapy, Miami, FL.

Annan, S., Mullen, K. B., Scotti, J. R., \& Morris, T. L. (1997, November). Cumulative effects of traumatic events on post-traumatic stress disorder. Poster presented at $31^{\text {st }}$ annual convention of the Association for Advancement of Behavior Therapy, Miami, FL. 
Mullen, K. B., Rode, C. M., \& Scotti, J. R. (1997, March). Multimodal assessment of children who have been in a motor vehicle accident. In C. Masia \& T. L. Morris (Chairs), Assessment of anxiety disorders in children and adolescents: Innovative techniques for comprehensive assessments of anxiety symptomatology. Symposium conducted at the $17^{\text {th }}$ national conference for the Anxiety Disorders Association of America, New Orleans.

Anderson, C. M., Mullen, K. B., \& Hawkins, R. P. (1996, May). Assessment of treatment outcomes in a community mental health center. Poster presented at the $22^{\text {nd }}$ annual convention of the Association for Behavior Analysis, Washington, D.C.

Anderson, C. M., Mullen, K., Freeman, K. A., Lewis, J., Weigle, K., Kirk, K., \& Scotti, J. R. (1995, May). Assessment of a course designed to increase educator's understanding of behavioral principles and functional assessment methodologies. Poster presented at the $21^{\mathrm{st}}$ annual convention of the Association for Behavior Analysis, Washington, D.C.

Scotti, J. R., \& Mullen, K. B. (1995, August). Focus on the function, not the consequences. In C. M. Franks (Chair), Time out for time-out? Its place in today's behavior therapy. Audiotaped Symposium conducted at the $103^{\text {rd }}$ annual convention of the American Psychological Association, New York.

Dunlap, G., Horner, R., Koegel, R. L., Koegel, L. K., \& Mullen, K. B. (1995, November). Behavioral support strategies for school and home ecologies: Recent research and emerging strategies. In R. Horner \& J. Halle (Chairs), Positive approaches in behavioral support. Symposium presented at the annual convention for the Association for Persons with Severe Handicaps, San Francisco.

Freeman, K. A., Anderson, C. A., Mullen, K. B., Boccio, K., \& Scotti, J. R. (May 1995). $\underline{A}$ comparison of three forms of graphical representation of functional assessment data on ability to identify maintaining variables. Poster presented at the 21 st annual convention for the Association for Behavior Analysis, Washington, D.C.

Mullen, K. B., Koegel, L. K., \& Koegel, R. (1995, May). Using a professional consultation model to teach parents functional assessment. Poster presented at the 21st Annual Convention for the Association of Behavior Analysis, Washington, D.C.

Scotti, J. R., Mullen, K. B., Anderson, C. A., Freeman, K. A., Weigle, K., Robertson, M., Boccio, K., Tanner, C., \& Long, E. (1995, May). Functional analysis of excess and positive replacement skills: A series of cases from the School Consultation Project. Poster presented at the 21st annual convention for the Association for Behavior Analysis, Washington, D.C. 


\section{WORKSHOPS and PRESENTATIONS}

Mullen, K. B. (1999, April). A case of functional vomiting and leg-pain. Presentation at the Clinical Psychology Residency Program Clinical Case Conference Series, University of Mississippi Medical Center (April 14, 1999; 1 hour).

Undesser, C., \& Mullen, K. B. (1999, July). Somatization disorders: An overview and case-study. Invited presentation at the Department of Pediatrics Grand Rounds Series, University of Mississippi Medical Center (July 23, 1999; 1 hour).

Mullen, K. B., \& Masia, C. (1996, November). The peanut kid: Behavioral treatment of the psychological effects of severe peanut allergy. Case conference at the Department of Psychology Colloquium Series, West Virginia University, WV (November 3, 1996; 1 hour).

Scotti, J. R., Mullen, K. B., \& Anderson, C. M. (1995, March). Overview of functional assessment and nonaversive intervention with the excess behaviors of students with severe disabilities. Invited workshop at the T. A. Lowery Elementary School, Shenandoah Junction, WV (March 23, 1995; 3 hours).

Scotti, J. R., Mullen, K. B., Anderson, C. A., \& Freeman, K (1995, April). Overview of functional assessment and nonaversive intervention with the excess behaviors of students with severe disabilities. Invited workshop at the Wiley Ford Elementary School, Wiley Ford, WV (April 23, 1995; 3 hours).

\section{PROFESSIONAL ACTIVITIES}

September, 1998-March, 1999

August, 1997-May, 1998
Committee Member for Hinds County Multiagency Action Planning (MAP) Team. Committee comprised of Mississippi state-funded human service agencies for the purpose of collaboratively supporting children of Hinds County Mississippi who are at risk of being placed in more restrictive living settings. Committee meets twice/month during which nominated consenting families are discussed, and plans for support are generated.

Coordinator of "Noon Clinical Case Conference Series." Quin Curtis Center for Psychological Research and Services Department of Psychology, West Virginia University Duties include: locating and arranging for clinical case presenters, providing clinical students and faculty with schedule of presentations, providing weekly reminders, and organizing and arranging for presentation facilities and equipment. 
August, 1997-June, 1998

August, 1997-April, 1998

May, 1997- May, 1999

August, 1996-October, 1997

August, 1996-January, 1997

August, 1995-May, 1996

June, 1995

August, 1994-August, 1995
Served on the Department of Psychology Quin Curtis Center Steering Committee. Graduate Assistant Representative. Duties included participating as graduate student representative on Steering Committee for Department Psychological Research and Services Clinic.

Coordinator of Site Screening for National Depression, Anxiety, and Eating Disorders Awareness Days. Quin Curtis Center for Psychological Research and Services, Department of Psychology, West Virginia University

Duties included: preparing and executing outreach and public service announcements, recruiting and training clinician assistance, and participating in screening.

Served on the West Virginia Early Childhood Autism Work Group. Committee comprised of parents of children with autism and state professionals working in the area of research and/or provision of service to children with autism, formed to create a state-wide position paper delineating best service practices for young children diagnosed with autism.

Undergraduate Thesis Committee Member. Thesis entitled: "Cumulative Effects of Traumatic Events on PTSD," Sandra L. Annan.

Served on the Valley Comprehensive Community Mental Health Center Human Rights Committee. Voting member on committee to ensure and maintain the integrity of interventions for Center clients with disabilities.

Served on the Department of Psychology Full Faculty Committee. Child Clinical Program Student Representative at biweekly full faculty meetings.

Grant-Writing Assistant. Assisted with project design and grant writing for "Children exposed to MVAs: Assessment of effects." National Institute of Mental Health, Behavioral Science Tract Award for Rapid Transition (B/START), Joseph R. Scotti, Ph.D., Principal Investigator (\$35,000).

$\underline{\text { Served on the Behavior Management Committee for Valley }}$ Comprehensive Community Mental Health Center. Voting 
September, 1994

September, 1992-June, 1994 member on committee for the promotion and maintenance of non-aversive behavior management strategies for Center clients with disabilities.

Served on the West Virginia State Task Force on Best Practices, West Virginia Department of Health and Human Resources, Office of Behavioral Health Services. Duties included assisting in the creation of a position paper delineating best practices in providing support to persons with developmental disabilities.

Assistant at annual national conference for the NIDRR Research and Training Center on Community Referenced Technologies for Nonaversive Behavior Management (San Diego, Santa Barbara, \& Nashville). Duties included assisting in the planning and execution of three conferences on positive behavioral support for persons with developmental disabilities.

\section{AWARDS}

September, 1993

Achievement-based graduate fellowship (\$500.00)

School of Education, University of California at Santa Barbara

April, 1994

Achievement-based graduate fellowship ( $\$ 500.00$ )

School of Education, University of California at Santa Barbara

\section{EDITORIAL EXPERIENCE}

\section{$\underline{\text { Ad-Hoc Reviewer }}$}

Behavior Therapy (1998)

\section{$\underline{\text { Ad-Hoc Assistant Reviewer }}$}

Cognitive and Behavioral Practice (1 with J. R. Scotti, Ph.D.)

Journal for the Association for Persons with Severe Handicaps (3 with J. R. Scotti, Ph.D.)

Journal of Psychopathology and Behavioral Assessment (1 with D.W. McNeil, Ph.D.) 